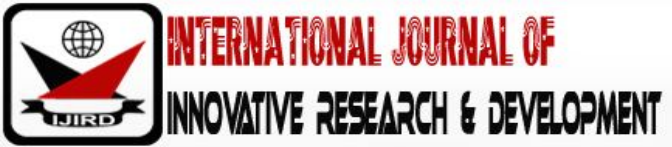

ISSN 2278 - 0211 (Online)

\section{Associated Stranded Natural Gas Monetized in Real-Time Via Conversion to Petrochemical and Other Useful End Products}

\author{
Dr. Azunna I.B. Ekejiuba \\ Senior Lecturer, Petroleum Engineering Department, Federal University of Technology Owerri, Nigeria
}

\begin{abstract}
:
The chemical industry which is solely responsible for converting various chemical substances to useful products started as early as $7,000 \mathrm{BC}$ by combining alkali and limestone to make glass. During the industrial revolution (1736 to 1918), the raw materials for the chemical industry came from coal, molasses, fats, oils, water and the atmosphere. Production of chemicals from petroleum started in the United States in 1918 with the manufacture of alcohol (isopropyl alcohol) from surplus refinery gas, and up until the 1950 's the only type of polyethylene was low density granules (pellets or resins). Presently, more than 95\% of the total world production of organic chemicals comes from petroleum (crude oil, shale oil, natural asphalts, condensate gas and natural gas) with endless variety of chemical compounds formed by either replacing the hydrogen atoms of the benzene with other functional groups or replacing the hydrogen atoms in any of the basic structure/ non-benzene rings with other functional groups et cetera. This study on associated stranded natural gas monetized in real-time via conversion to petrochemical and other useful end products, is focused on the comprehensive analysis of the various process techniques for converting natural gas to diversity of valuable products options, and highlight their multiple utility in details. The flare stream is completely separated into its hydrocarbon and non-hydrocarbon pure liquid components (through successive cooling and fractionation steps) and subsequently the different liquid components are converted to petrochemicals of all descriptions, either used directly as end products or indirectly as raw material for other products. The paper contains the overview of the various processes for obtaining petrochemicals from the separate components via conversion to either olefins, acetylenes, aromatics, synthetic gas (syngas), carbon black, organometallic, functional group hydrocarbons such as oxidation derivatives- alcohols, ethers, aldehydes, ketones, carbohydrates, esters, fats and oils; nitrogen derivatives-amines, amides, amino acids, nitriles; sulfur derivatives-thiols, disulfides; and polymerization. It also provided examples of the numerous petrochemicals and other end products obtained from the chemical reactions(on the separate hydrocarbon and non-hydrocarbon components), and stated their various everyday uses, in the households- foods, flavors, fragrances, toiletries, detergents, cosmetics, medicines, cloths, furniture; as feedstock to both petrochemical and chemical industries such as foam, textile, paint, plastic, fiber, printing, building, electrical and electronics, laboratory, industrial, agricultural, pharmaceutical, biological, etc., for manufacturing various intermediate chemicals and finished products like ammonia (synthetic nitrogen fertilizer), methanol, chloromethane, ox alcohols, polythene, synthetic drugs, toys, solvents, adhesives, glues, varnishes, fuels, lubricants, car tires, explosives, soles of shoes et cetera. The modular design involves 5 categories of petrochemical plants based on their end products: mini gas processing, olefins/ acetylene/ aromatics, polymer, chemicals and manufacturing. The customized skid mounted mini gas processing module convert all the components of the flare stream into their separate liquid quantities in real-time (i.e. water, carbon dioxide, nitrogen and hydrocarbons) whereas the 4 other varieties of specialty modules are used for the subsequent production of various petrochemicals from the separate hydrocarbon liquid components. The modular approach allows flexibility for upgrading/ downgrading as well as encourages more entrepreneurs, to engage in both small and medium scale petrochemicals related ventures, depending on their available resources. Two or more enterprises can share the flare stream from one flare line, each targeting different products. Nigeria spends over $\$ 10$ billion (about N3 trillion at the current CBN exchange rate of N300 to a dollar) annually to import, about $80 \%$ petrochemicals of all descriptions used by various chemical processing industries. Converting the $40 \%$ to $50 \%$, associated natural gas that is still being flared to petrochemicals, would satisfy all the domestic requirement for petrochemicals at reduced retail prices, create numerous job opportunities, increase foreign earning from export, bring gas flaring to extinction and stimulate infrastructural development to various petroleum producing areas in Nigeria.
\end{abstract}

Keywords: Entrepreneurs, hydrocarbon components, monetized, natural gas processing, petrochemicals, real-time

\section{Introduction}

Petroleum exists in three physical states of nature/matter (gas, liquid and solid/semisolid), thus the term Petroleum encompasses Shale Oil, Crude Oil, Natural Asphalts, Condensate Gas and Natural Gas. Petroleum in all its form, is composed primarily of hydrocarbons (compounds containing only carbon and hydrogen) ranging from Methane ( $\mathrm{CH}_{4}$ ) to Asphaltene $\left(\mathrm{C}_{80} \mathrm{H}_{162}\right)$ (Katz et al., 1959) and other minor inorganic elements such as oxygen $\left(\mathrm{O}_{2}\right)$, nitrogen $\left(\mathrm{N}_{2}\right)$, carbon dioxide $\left(\mathrm{CO}_{2}\right)$, sulfur $(\mathrm{S})$, hydrogen sulfide $\left(\mathrm{H}_{2} \mathrm{~S}\right)$, carbonyl sulfides $(\mathrm{COS})$, carbon disulfide $\left(\mathrm{CS}_{2}\right)$, mercaptans $(\mathrm{RSH})$, mercury $(\mathrm{Hg})$, water vapor $\left(\mathrm{H}_{2} \mathrm{O}\right)$ and trace metals such as tin $(\mathrm{Sn})$, lead $(\mathrm{Pb})$, helium $\left(\mathrm{H}_{\mathrm{e}}\right)$, sodium $(\mathrm{Na})$, magnesium $(\mathrm{Mg})$, calcium (Ca), copper $(\mathrm{Cu})$, silver $(\mathrm{Ag})$, gold $(\mathrm{Au})$, boron $(\mathrm{B})$, uranium $(\mathrm{U})$, nickel $(\mathrm{Ni})$, platinum (Pt), iron $(\mathrm{Fe})$, cobalt $(\mathrm{Co})$, chromium $(\mathrm{Cr})$, silicon $(\mathrm{Si})$, arsenic(As), antimony ( $\mathrm{Sb})$, molybdenum (Mo) and vanadium (V). Also, it may contain some

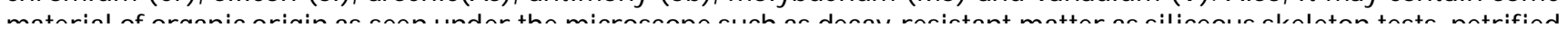


wood fragments, spores, spines, cuticles, resins coal and lignite fragments, algae, unicellular organisms spore coats insect scales, and barbules (Levrosen, 1967). Although they may appear to be the same, no two-petroleum occurring in different reservoirs are exactly alike, for each consists of mixtures of countless different hydrocarbons.

\subsection{Chemistry of Petroleum}

Chemistry is the branch of science concerned with describing and explaining the different forms of matter and the chemical reactions (and accompanying energy changes) of matter (Ebbing et al., 1995). Matter refers to material things which could be a single chemical substance or a complex mixture of substances. Anything that we can smell, see, touch including the air, water, ground, plants and animals are composed of chemical substances. The study of chemistry is divided into branches, such as Inorganic, Organic, Physical, Analytical, Nuclear, Pure and Applied, Biochemistry etc. The chemistry of petroleum is a part of organic chemistry, defined as the study of carbon compounds (organic compounds) which includes:

- Compounds containing only carbon and hydrogen (hydrocarbons) such as paraffins/isoparaffins (or alkanes), olefins (or alkenes), acetylenes (or alkynes), cycloparaffins (or naphthenes) and aromatics (or benzenes) (Hess, 1980).

- Compounds containing carbon, hydrogen plus any of the following atoms/ elements: oxygen, nitrogen, sulfur and phosphorous (Myers et al., 2007) or the functional groups/ class: alcohol $(-\mathrm{OH})$, aldehydes $(\mathrm{C}=\mathrm{O})$, amides $\left(\mathrm{CONH}_{2}\right)$, amines (- $\left.\mathrm{NH}_{2}\right)$, alkyl halides, acyl halides, carboxylic acids $(\mathrm{COOH})$, esters $(\mathrm{COO})$, ethers(-O-), ketones $(\mathrm{C}=0)$ and nitriles, including those derived by inter conversion of functional groups (Bamkole and Ogunkoya, 1978) and

- Compounds containing carbon-metal bonds (organometallic compounds) eg organomagnesium, organolithium, organomercury, oganocopper, organopalladium etc. (Brown et al., 2005).

The entire organic compounds are divided into two groups (saturated / stable and unsaturated/ unstable) with differing chemical properties and relationships. The saturated hydrocarbons include paraffins/isoparaffins (or alkanes), naphthenes (cycloparaffins), and asphaltics (multi-ring paraffins) figure 1, while the unsaturated hydrocarbons include olefins (or alkenes), acetylenes (or alkynes), aromatics (or benzene) and all their derivatives. The saturated hydrocarbons are chemically very stable compounds, which can exist in any of the three states of matter (gas, liquid and solid); many of them occur naturally (their chief source being petroleum). The unsaturated hydrocarbons are chemically very unstable because they are hydrogen deficient. They do not occur naturally, rather they are mainly created in the refinery (by the breakdown of larger hydrocarbon molecules) and in the natural gas processing/reforming plants (figure 2) or formed in small quantities by natural reactions of the saturated hydrocarbons in the reservoirs. Because of the hydrogen deficiency of the unsaturated hydrocarbons, the carbon atoms are always seeking to attach their 'empty' bonds, thus they are very reactive and are easily used to make new petrochemicals compounds. The key element in organic chemistry and all organic chemicals is carbon, which has a valence of 4 (i.e. 4 electrons in its outer most shell), which are used in forming covalent bonds with atoms of hydrogen, oxygen, the halogens (iodine, bromine, chlorine and fluorine), nitrogen, sulfur and other carbon atoms (Hess, 1980) to give a vast array of molecules.

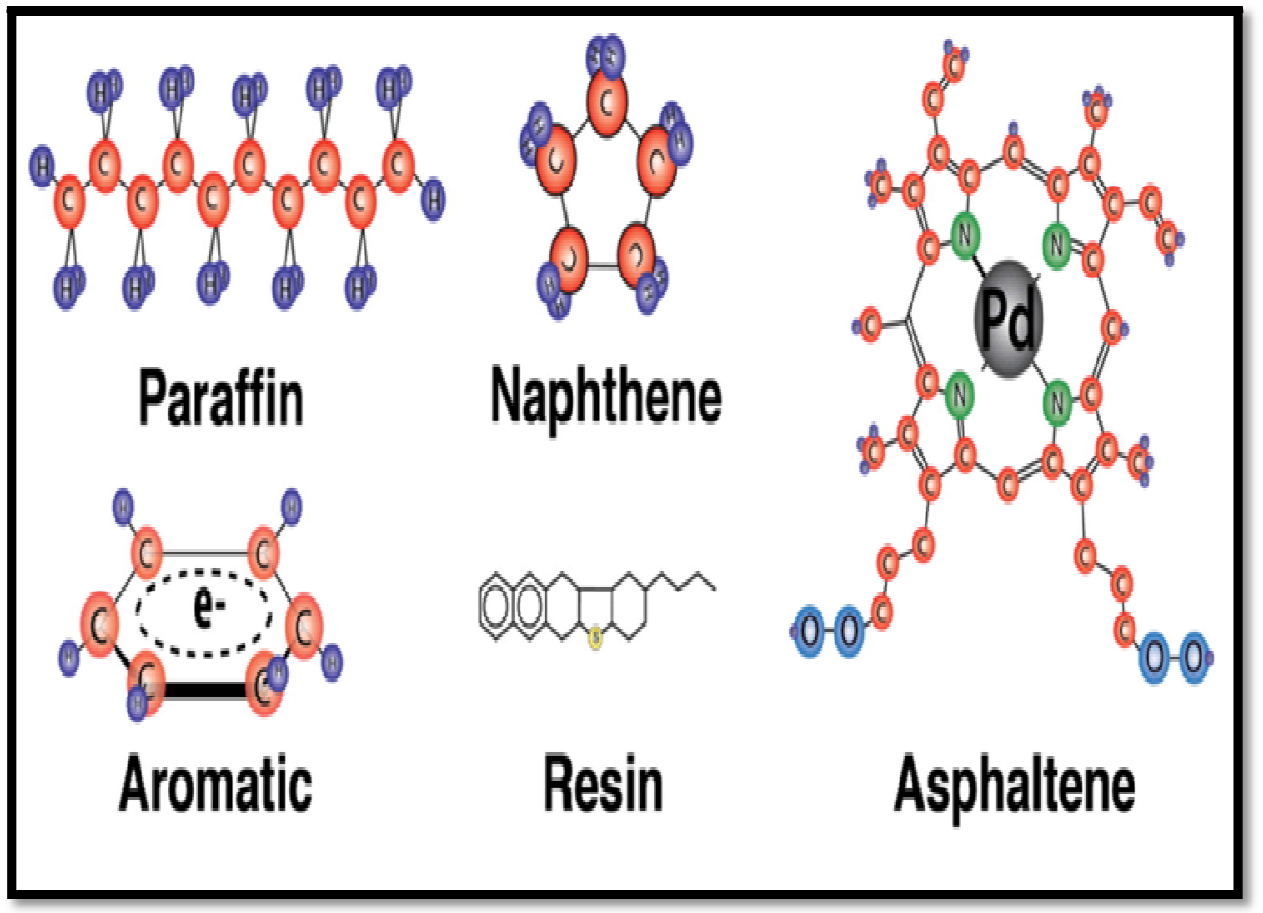

Figure 1: Types of Hydrocarbons

Source: Adapted from Images of Types of Hydrocarbons 


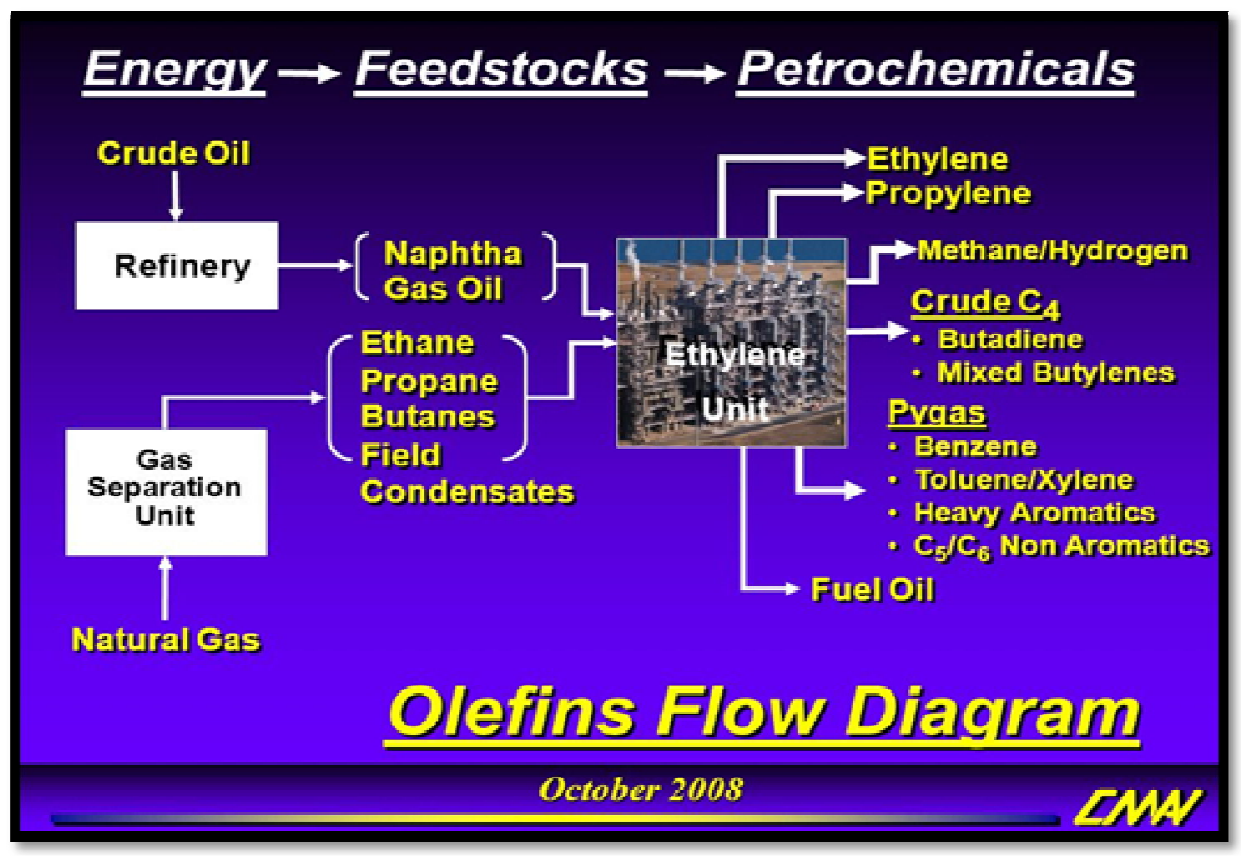

Figure 2: Petrochemicals from Crude Oil and Natural Gas

Source: Adapted from Images of Olefin Flow Diagram for Production of Petrochemicals

\subsection{Composition of Natural Gas}

Each natural gas stream, have a unique mixture that is mostly composed of the lower-molecular weight hydrocarbons of the paraffin series, ranging from minute quantities dissolved in the solid or liquid petroleum (crude oil, shale oil, natural asphalts) up to $100 \%$ of the gaseous petroleum (condensate Gas and natural gas). Methane constitute the greater part of natural gas, while variable small amounts of other paraffin hydrocarbons (alkanes), such as ethane, propane, butanes, pentanes, hexanes, heptanes octane, nonane, decane are often present with water vapor and other gaseous impurities, consisting of oxygen, nitrogen, carbon dioxide, sulfur, hydrogen sulfide, carbonyl sulfides, helium, mercaptans, mercury in varying amounts. The volume or mole percentages of the individual hydrocarbon components present in a natural gas stream are reported through heptanes-plus (i.e. heptanes and all heavier hydrocarbons fractions).

\subsection{Chemicals and Petrochemicals}

A chemical substance (also known as pure substance) is a form of matter that has constant chemical composition and characteristic properties, such as chemical elements, molecules, chemical compounds, ions or alloys etc. (Wikipediachemical substances). They can exist as solids, liquids, gases or plasma and can change from one phase to the other with changes in pressure or temperature. The chemical industries are responsible for converting raw materials- oil, natural gas, air, water, metals and minerals into desired useful products (Wikipedia-chemical industry). The history of the chemicals industry can be traced back to ancient times (as early as 7,000 BC), when alkali and limestone were combined to make glass (Technofunc, n.d.). Chemicals industry as an independent branch started during the industrial revolution (17361918). Then, the chemical industry relied on coal, molasses, fats, oils, salts, ores, water and the atmosphere as sources of raw materials for its manufacturing processes (Bamkole and Ogunkoya, 1978). The first chemical plant (sulfuric acid plant) was built in Great Britain in 1740(Richmond).

Petrochemicals are chemical compounds obtained or derived from petroleum (crude oil, shale oil, natural asphalts, condensate Gas and natural gas) hydrocarbons and utilized in chemical market. There are basically, three types of petrochemicals: (a) aliphatic petrochemicals, (b) aromatic petrochemicals and (c) inorganic petrochemicals. This includes all paraffinic, naphthenic, aromatic and asphaltic organic chemicals and inorganic materials such as sulfur and ammonia, as well as those produced from polymerization of olefins or aromatic hydrocarbons. Aromatic compounds are the petrochemical organic compounds with molecular structure consisting of one or more benzene rings. Aliphatic compounds are the petrochemical organic compounds with basic structure involving chains of carbon in either straight (normal paraffins), branched, puckered or coiled (isoparaffins) as well as those in rings which are different from the benzene rings (referred to as alicyclic compounds or cycloparaffins or naphthenes). Asphaltics are made up of cyclic hydrocarbons with substantial amount of sulfur, nitrogen and oxygen content, figure 1 . The petroleum chemicals industry (i.e. production of chemicals from petroleum) started in the United States in 1918 with the manufacture of alcohol (isopropyl alcohol) from surplus refinery gas (Shell International, 1975), and up until the 1950's the only type of polyethylene was low density granules (pellets or resins). Now, endless variety of both the aromatic compounds and the aliphatic compounds are formed by either replacing the hydrogen atoms of the benzene with other functional groups or replacing the hydrogen atoms in any of the basic structure/non-benzene rings with other functional groups, and some of the compounds form polymers. Presently, more than $95 \%$ of the total world production of organic chemicals is from - n...-1 n.... 


\subsection{Existing Petrochemical Structures in Nigeria}

From 1985 to 1990, Nigeria built three petrochemical complexes, located at Warri, Kaduna and Eleme. At present, only the privatized Eleme petrochemical (now Indorama Eleme petrochemical company limited 'IEPL') is in operation and it is a Poly-Olefins producer, designed to produce more than 42 customized grades of Polyethylene (PE) and Polypropylene (PP) products, suiting to the specific requirements of the customers. Two other private petrochemical plants are under construction, the Dangote group in Lekki Lagos with 750,000 metric tonnes per year (Polyethylene and Polypropylene) unit and the Quantum Petrochemical Company Limited, in Akwa Ibom, with 3,000MT of methanol per day at full capacity (About IEPL; OilGasNg.com; Fairtrade Nigeria).

\subsection{Study Significance}

Nigeria spends over $\$ 10$ billion yearly, to import about $80 \%$ petrochemicals of all descriptions used by various chemical processing industries (Ogunade, 2016). The central bank of Nigeria (CBN) exchange rate now is N305 to a dollar, thus $\$ 10$ billion is equivalent to about N3 trillion. The products target from the existing petrochemical structures are mainly polyethylene and polypropylene, which implies that the country will continue to rely on importation for the other numerous petrochemicals. The price summary for the seven key petrochemicals: Benzene, Ethylene, LDPE, Toluene, Paraxylene, Propylene and Polypropylene(S \& P global petrochemical index, 2018), ranges between $\$ 700$ to $\$ 1400$ per metric ton, figures 3 and 4 . Flaring of produced associated stranded natural gas in Nigeria (figure 5), remains at between $40 \%$ to $50 \%$, which on conversion could satisfy all the domestic requirement for petrochemicals and chemicals at reduced retail prices, as well as create numerous job opportunities, increase foreign earning from export, bring gas flaring to extinction and stimulate infrastructural development to various petroleum producing areas in Nigeria.

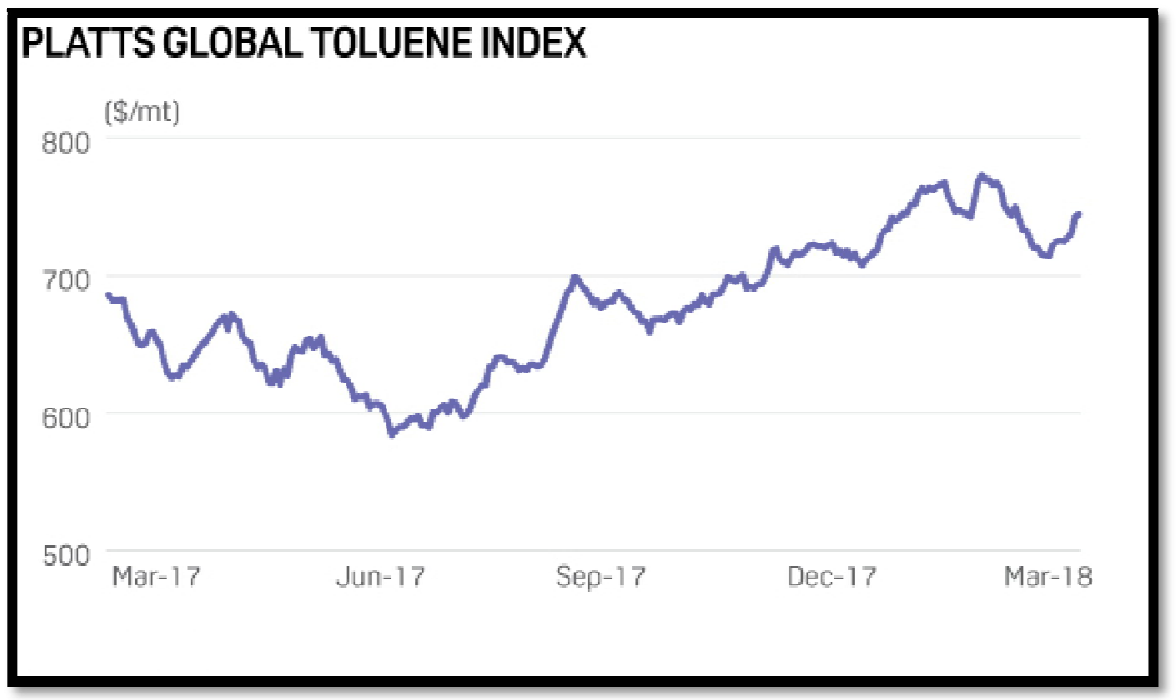

Figures 3: Price of Toluene between March 2017 to March 2018

Source: Adapted From S\& P Global Platt Petrochemical Index (PGPI)-March 2018

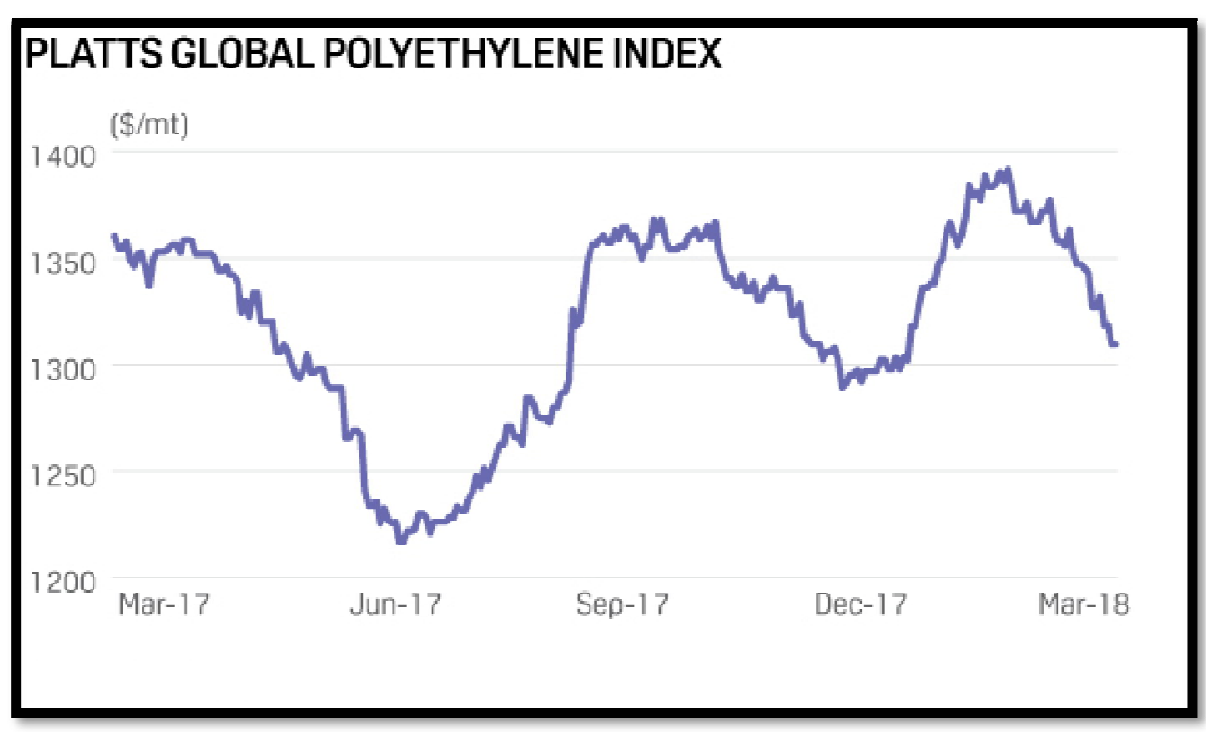

Figures 4: Price of Polyethylene between March 2017 to March 2018

Source: Adapted From S \& P Global Platt Petrochemical Index (PGPI)-March 2018 


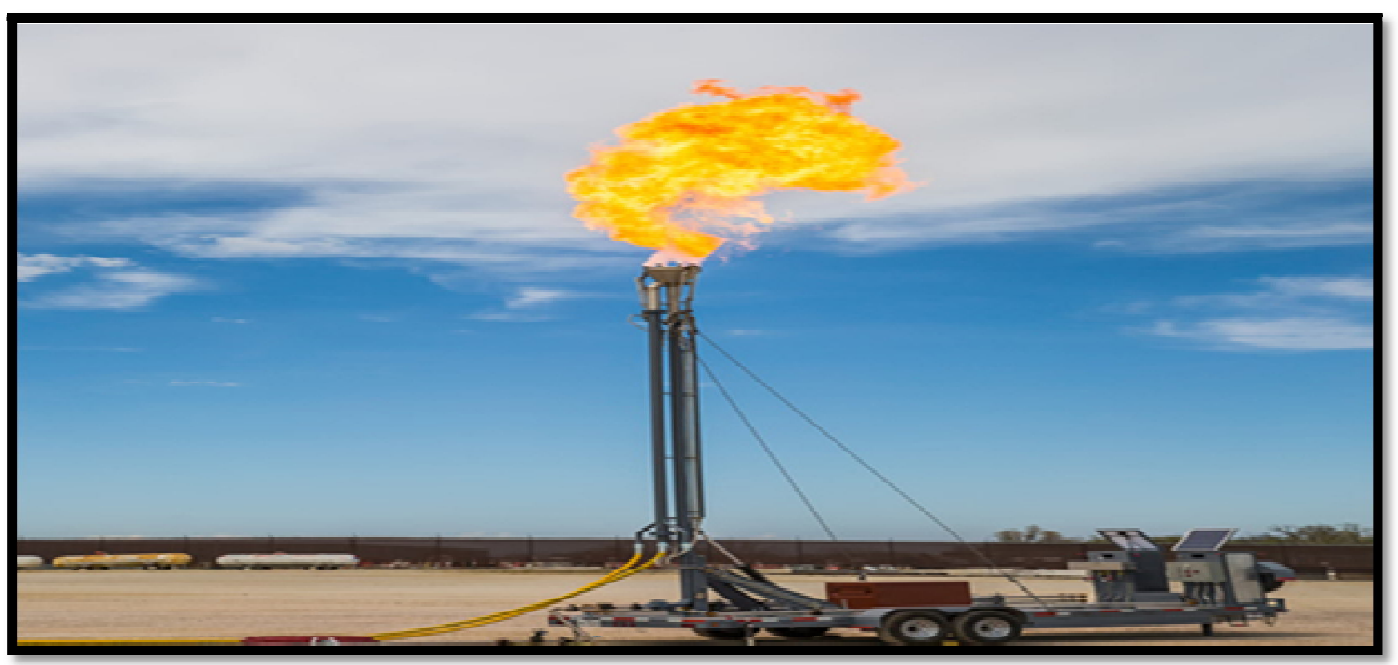

Figure 5: Typical Associated Natural Gas Flare Stream Layout.

Source: Adapted From Images of the Complete Flare Line from the Wellhead to the Flare Stack

This investigation is aimed at using different customized skid mounted mini gas processing plants in real-time to convert the entire Flared Associated Stranded Natural Gas Stream, for any particular flare line, to various desired petrochemicals. The study stated the mechanisms for the production of the various petrochemicals from the different components of the flare gas stream as well as outlined their respective uses by different industries, such as food, medical, pharmaceutical, agricultural, chemical, manufacturing etc.

\section{Background}

At high pressures, raw natural gas containing nitrogen and carbon dioxide can be used as source of power in petroleum- field operations via boilers, where their expansive force acts like that of steam (Levrosen, 1967), even when they are noninflammable as a result of high nitrogen and carbon dioxide content. Gas processing plants remove/ recover impurities such as water vapor, elemental sulfur, carbon dioxide, nitrogen etc. as well as remove and separate the mixture of hydrocarbon liquids (NGL's) into individual products, based on their different boiling points (International Energy Agency, 2010, Ikoku, 1980, Natgas, 2013). Although, gas treatment is aimed at purifying methane, technically all the components of natural gas are produced in their purified state, such as pure nitrogen, pure carbon dioxide, pure water and the pure versions of all the hydrocarbon compounds (pure methane, ethane, propane, pentanes plus (natural gasoline). The gas is first cleared of its impurities and dewatered. Successive cooling and fractionation steps, isolates the heavier hydrocarbons, and finally, methane undergoes several heat exchanges with refrigeration cycles to bring it down to its liquefaction temperature $\left(-160^{\circ} \mathrm{C}\right)$.

\section{Theoretical Model}

All petrochemicals and other useful end products obtainable from the flared associated natural gas, are derived from five sources:(a) Olefins/ acetylene obtained from methane and the pyrolysis of ethane, propane, butane and other hydrocarbon distillates; (b) Aromatics obtained from catalytic reforming of methane, ethane, propane, butane and other hydrocarbon distillates; (c) Different chemicals obtained from the various chemical reactions between the different chemical functional groups and the natural gas components methane, ethane, propane, butane and other hydrocarbon distillates; (d) Synthesis gas (syngas): carbon monoxide / Hydrogen $\left(\mathrm{CO} / \mathrm{H}_{2}\right.$ ) obtained from reforming natural gas components methane, ethane, propane, butane and other hydrocarbon distillates; and (e) Carbon black obtained through various high temperature processing( Furnace Black, Channel, and Acetylene Black ) of natural gas components methane, ethane, propane, butane and other hydrocarbon distillates.

\subsection{Route A: Chemical Conversion of the Entire Hydrocarbon (Methane, $\mathrm{C}_{1}$ to Octane $\mathrm{C}_{10}$ ) Content of the Flare Stream to Either Olefins (Alkenes) or Acetylene (Alkynes)}

(i) Electrochemical Oxidative Coupling of methane yields ethene:
$2 \mathrm{CH}_{4}+\mathrm{O}_{2}$
$\longrightarrow \mathrm{C}_{2} \mathrm{H}_{4}+2 \mathrm{H}_{2} \mathrm{O}$
(1)

(ii) At temperatures of over $800{ }^{\circ} \mathrm{C}-900{ }^{\circ} \mathrm{C}$ alkanes $\left(\mathrm{C}_{2}+\right)$ cracks to alkenes $\left(\mathrm{C}_{2}+\right)$, for instance ethane cracks to ethene (ethylene) and hydrogen, (Brown et al., 2005):

$\mathrm{CH}_{3} \mathrm{CH}_{3} \longrightarrow \mathrm{CH}_{2}=\mathrm{CH}_{2}+\mathrm{H}_{2}$

Pyrolysis of propane $\left(\mathrm{C}_{3} \mathrm{H}_{8}\right)$ yields propene $\left(\mathrm{C}_{3} \mathrm{H}_{6}\right)$ while pyrolysis of butane $\left(\mathrm{C}_{4} \mathrm{H}_{10}\right)$ yields butene $\left(\mathrm{C}_{4} \mathrm{H}_{8}\right)$.

Similarly catalytic cracking of pentane, hexane, heptane, octane, and nonane will respectively yield pentene; hexene; heptene; octene; nonene; decene; etc. The most desired alkenes are ethene, propene, and butenes.

Further cracking of alkenes $\left(\mathrm{C}_{2}+\right.$ ) yields alkynes( acetylene), ethyne, propyne, butyne, pentyne; hexyne; heptyne; octyne,

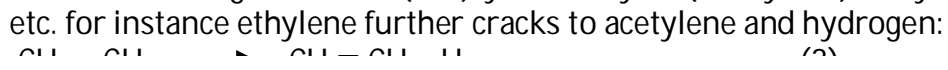


3.2. Route B: Catalytic Reformation of the Entire Hydrocarbon Content of the Flare Stream to Aromatics

(i) Cracking of methane at temperature of over $1200^{\circ}$ Cyields acetylene (Bamkole and Ogunkoya, 1978) $2 \mathrm{CH}_{4} \longleftrightarrow \mathrm{C}_{2} \mathrm{H}_{2}+3 \mathrm{H}_{2}$

(ii) Polymerization acetylene, equation 3 , yields benzene (aromatic):

$\mathrm{CH} \equiv \mathrm{CH}+\mathrm{CH} \equiv \mathrm{CH}+\mathrm{CH} \equiv \mathrm{CH} \longrightarrow \mathrm{C}_{6} \mathrm{H}_{6}$

3.3. Route C: Hydrocarbons Derivatives via the Various Hydrocarbons Functional Groups Chemical Reactions Such As: Alkyl, Hydroxyl, Halogeno, Amino, Carboxyl, Organometallics, Etc.; Cyclo-Hydrocarbons, Heterocyclic Compounds and Interconversion of Functional Groups.

A functional group is a reactive portion of a molecule that undergoes predictable reactions (Ebbing et al., 1995). Functional groups are specific groups of atoms within molecules that impact specific unique characteristic properties on the molecule regardless of the other atoms present in a molecule. Compounds with the same functional group undergo similar chemical reactions (Timberlake, 2006). For molecules with two or more functional group, the properties of the compound will be the sum of the properties of the different functional group if the distance between them in the compound is enough to allow each operate fully with no interference or noticeable modification by the other(s) adjoining functional group(s). Figure 6 and Figure 7 shows some main functional groups of organic compounds.

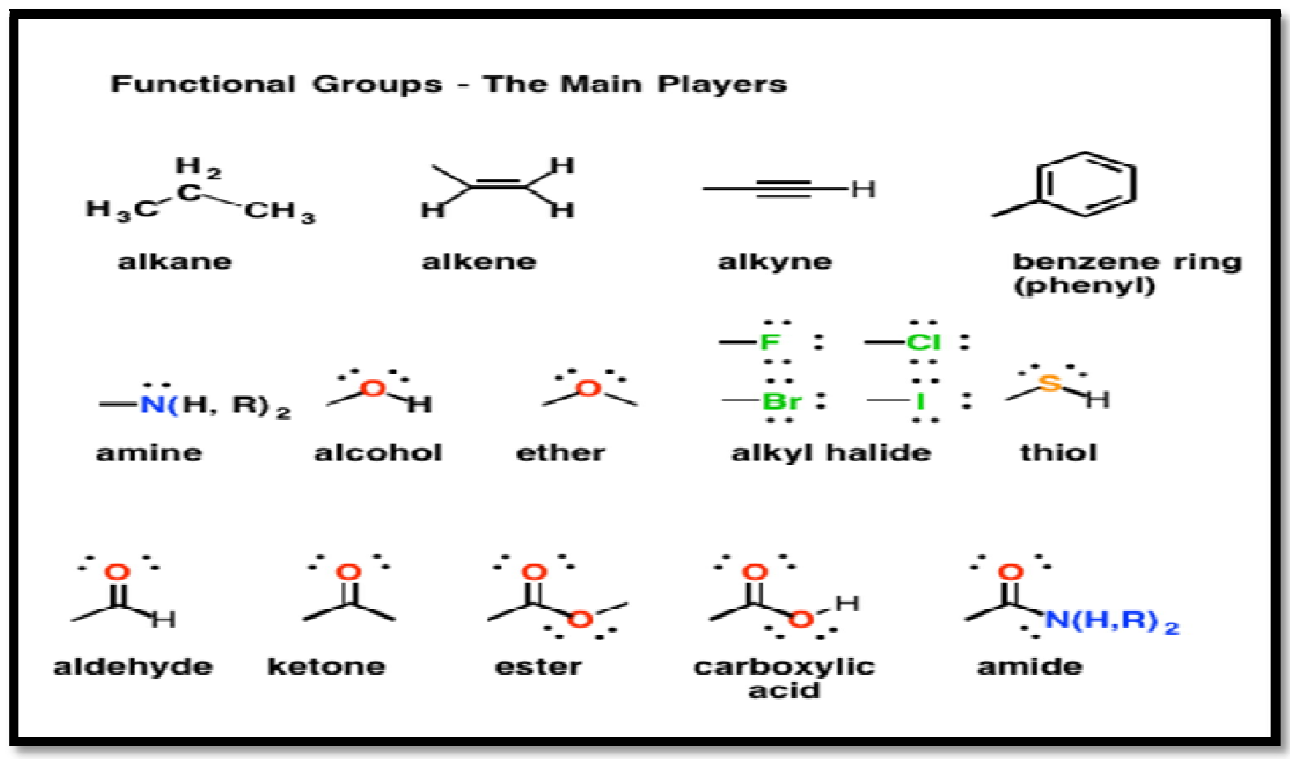

Figure 6: Major Functional Groups

Source: Adapted from Images of the List of All the Functional Groups in Organic Chemistry

Functional Groups - Supporting Actors

$$
-\mathrm{C} \equiv \mathrm{N}:
$$<smiles>CC1[C@@H]2C[C@H]1CO2</smiles>

nitrile<smiles>CC(=O)OC(C)=O</smiles>

anhydride

epoxide<smiles>C[Si]1(C)[Si]=[Si]=[Si]1</smiles>

disulfide<smiles>C/C=N\C</smiles>

imine<smiles>CC(=O)C(C)=[Te]</smiles>

acid chloride<smiles></smiles>

nitro

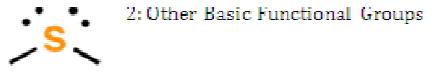

sulfide (thioether)

Figure 7: Other Basic Functional Groups

Source: Adapted From Images of the List of All the Functional Groups in Organic Chemistry 
3.4. Route D: Reforming The Entire Hydrocarbon Content of the Flare Stream to Synthesis Gas (Syngas): Carbon Monoxide/ Hydrogen $\left\{\mathrm{CO} / \mathrm{H}_{2}\right\}$.

Six principal technologies for syngas production from saturated hydrocarbons have been commercialized or are at an advanced stage of development: They include:-(i)Steam Reforming (SR), (ii) Partial Oxidation (POX) or non- catalytic reforming, (iii) Auto thermal reforming (ATR), (iv) Catalytic reforming (CPOX), (v) Heat exchanger reforming (HER), (vi) Compact reforming (CPR).The first three listed reformers are the basic types, and all industrial plants use either variants or combinations of these.

Equation 6 is the general formula for steam reforming of saturated hydrocarbon (Wikipedia- steam reforming, n.d) components, and equations 7 to 16 are the respective results for $\mathrm{C}_{1}$ to $\mathrm{C}_{10}$ :
$\left.\mathrm{C}_{\mathrm{n}} \mathrm{H}_{\mathrm{m}}+\mathrm{nH}_{2} \mathrm{O} \longleftrightarrow \quad \mathrm{n}+(\mathrm{m} / 2)\right\} \mathrm{H}_{2}+\mathrm{nCO}$
Methane:
$\mathrm{CH}_{4}+\mathrm{H}_{2} \mathrm{O} \longleftrightarrow 3 \mathrm{H}_{2}+\mathrm{CO}$ (endothermic $+206 \mathrm{KJ} /$ mole)
Ethane:
$\mathrm{C}_{2} \mathrm{H}_{6}+2 \mathrm{H}_{2} \mathrm{O}$
$\longleftrightarrow \quad 5 \mathrm{H}_{2}+2 \mathrm{CO}$
Propane:
$\mathrm{C}_{3} \mathrm{H}_{8}+3 \mathrm{H}_{2} \mathrm{O}$
$\longleftrightarrow \quad 7 \mathrm{H}_{2}+3 \mathrm{CO}$
Butane:
$\mathrm{C}_{4} \mathrm{H}_{10}+4 \mathrm{H}_{2} \mathrm{O}$
Pentane:
$\mathrm{C}_{5} \mathrm{H}_{12}+5 \mathrm{H}_{2} \mathrm{O}$
Hexane:
$\mathrm{C}_{6} \mathrm{H}_{14}+6 \mathrm{H}_{2} \mathrm{O}$
Heptane:
$\mathrm{C}_{7} \mathrm{H}_{16}+7 \mathrm{H}_{2} \mathrm{O}$
Heptane:
$\mathrm{C}_{8} \mathrm{H}_{18}+8 \mathrm{H}_{2} \mathrm{O}$
Heptane:
$\mathrm{C}_{9} \mathrm{H}_{20}+9 \mathrm{H}_{2} \mathrm{O}$
Heptane:
$\mathrm{C}_{10} \mathrm{H}_{22}+10 \mathrm{H}_{2} \mathrm{O}$

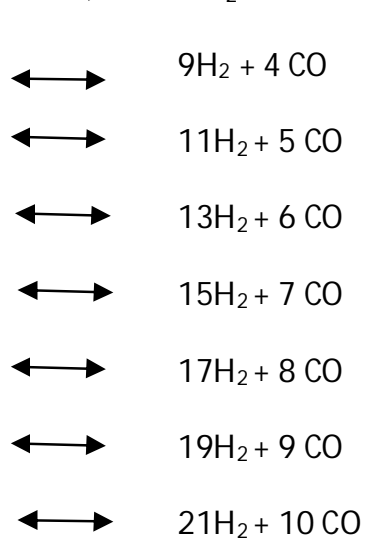

\subsection{Route E: Conversion to Carbon Black}

Carbon black is produced by the incomplete combustion of heavy petroleum products such as FCC tar, coal tar, ethylene cracking tar, with natural gas in high temperature reactors through a tightly controlled flame-synthesis process. Various features of carbon black are controlled in production by partially combusting of the feedstock. It is classified by manufacturing process (Mitsubishi Chemical Corporation) such as : Furnace Black Process, Channel Process, Acetylene Black Process etc.

\subsection{Route F: Polymerization of the Olefins, Acetylene, Aromatics and the Derivatives from Functional Groups Reactions}

Although, petrochemicals as derived from the five sources above, is used directly by many industries, many more giant industries, rely on polymerization reactions of various petrochemicals, to produce their useful end products.

Polymerization is the process of linking together many similar simple units (or bricks) to form larger, more complex molecules. It takes place only in molecules containing double or triple bonds and is usually dependent upon temperature, pressure and the presence of a suitable catalyst. The two types of polymerization reactions are addition reactions and condensation reactions. Addition reaction occur when smaller molecules/ compounds (monomers) join together to make larger ones (polymers)e.g. production of polyethene from ethylene (equation 17), while condensation reaction (Myers et al., 2007) occur when two molecules combine to form a larger molecule (water can be generated during this reaction) e.g. production of polyethylene terephthalate (PET) and water from the reaction of alcohol and organic acid.

$$
\mathrm{CH}_{2}=\mathrm{CH}_{2}+\mathrm{CH}_{2}=\mathrm{CH}_{2}+\mathrm{CH}_{2}=\mathrm{CH}_{2} \longrightarrow \mathrm{CH}_{2}-\mathrm{CH}_{2}-\mathrm{CH}_{2}-\mathrm{CH}_{2}-\mathrm{CH}_{2}-\mathrm{CH}_{2}-
$$

That is,

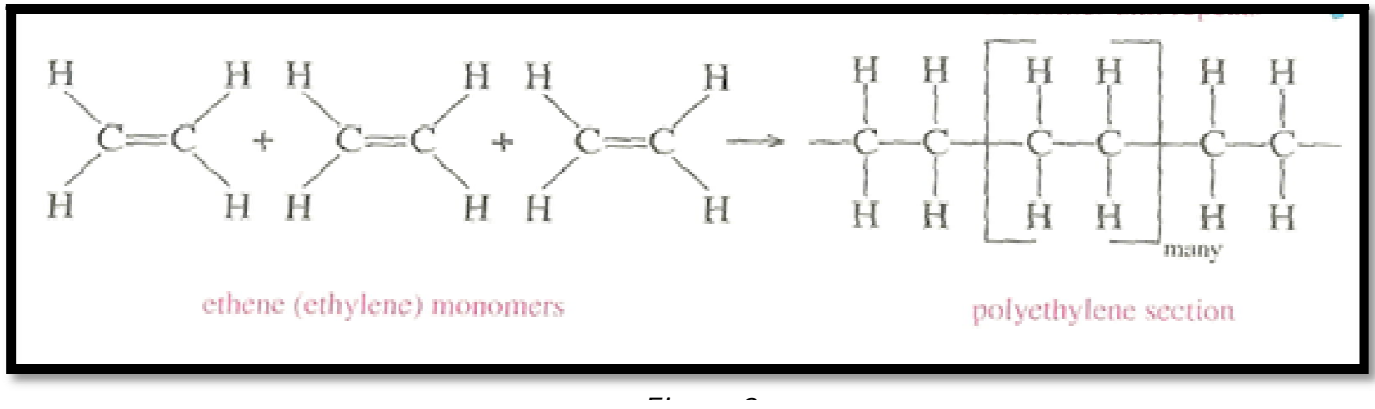


Through polymerization compounds with certain desired chemical and mechanical properties such as deformability, mouldability, high resistance to acids, alkalis and other chemicals, etc. can be produced (Bamkole and Ogunkoya, 1978). Any simple change (s) in the chemical structure of a given polymer, changes its mechanical properties to yield an entirely different product (s). For instance, by using various substitutes of any polymer, products with differing physical properties are produced.

When ethylene gas is subjected to high pressures and temperatures and is brought into contact with the right sort of catalyst, a very involatile, tough material (polyethylene) is produced which contains carbon and hydrogen only and has a very high molecular weight figure 9. Using various substituted ethylene, yields much larger range of polyalkeneplastics.

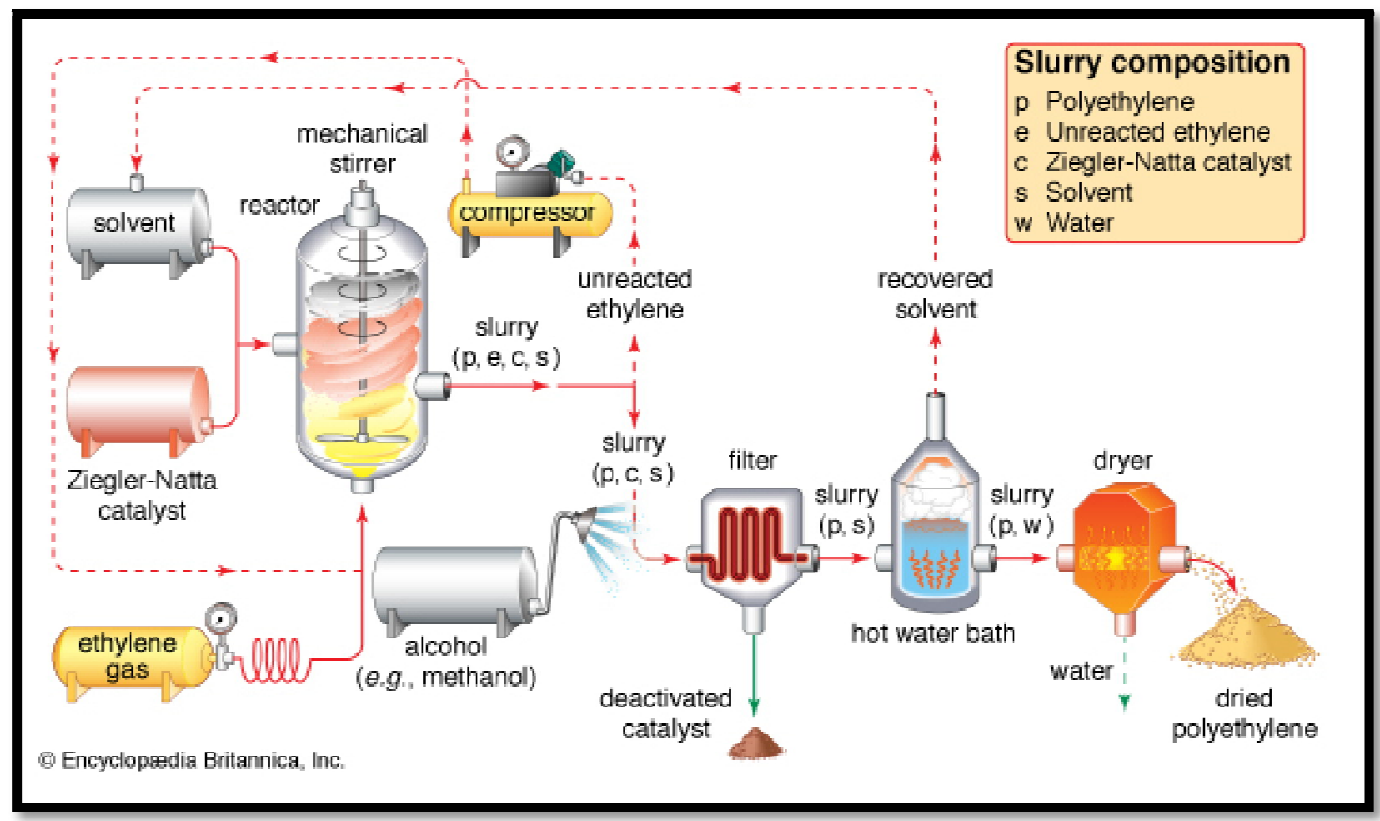

Figure 9: Ethylene Gas to Polyethylene Production Process. Source: Adapted from Images Ethylene

Polymerization acetylene (also called ethyne): Ethyne is used to obtain vinyl chloride, vinyl acetate, chloroprene and acrylonitrile all of which are used for the manufacture of various types of plastics. Acrylonitrile is also used in the textile industry for the manufacture of acrylic fibres such as orlon and acrilon. For example, hydrochlorination of ethyne, at $100-180^{\circ}$ at atmospheric pressure in the presence of mercury (II) chloride on charcoal as catalyst, gives vinyl chloride which is then polymerized to polyvinyl chloride (PVC), used in the manufacture of sheeting, flooring material etc. Polymerization of aliphatic and aromatic compounds (polycyclic ring systems) occurs when two or more rings are fused together in the same molecule. Two rings can meet at a single carbon atom, to form a spiro compound or bridged at two or more carbon atoms, to form compounds referred to as bicyclic (two rings), tricyclic (three rings) and in general, polycyclic compounds (for three or more rings), table 1

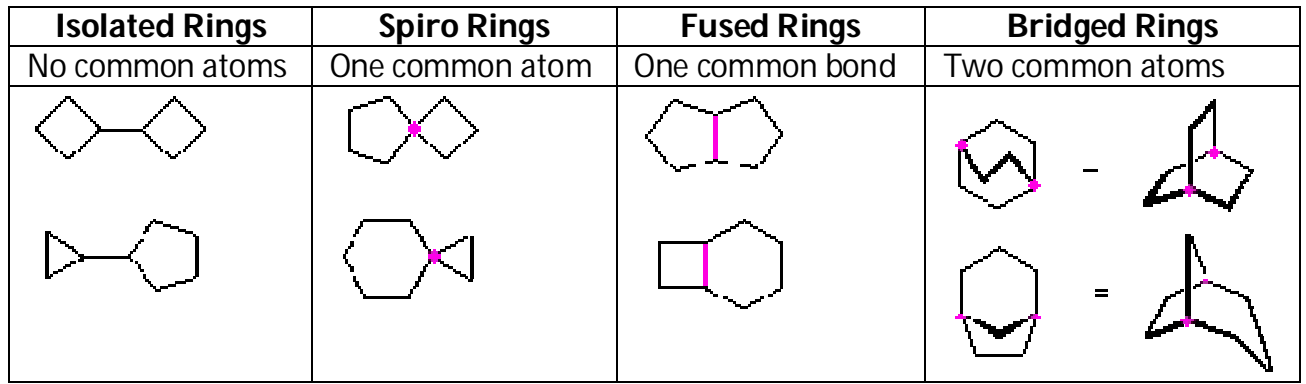

Table 1: Examples of Isomeric $\mathrm{C}_{8} \mathrm{H}_{14}$ Bicycloalkanes (Aliphatics) Source: Adapted from Images of Cycloalkanes

Polycyclic aromatic hydrocarbons (PAHs) are formed by fusing together two or more benzene ring edge -to- edge, such that neighboring benzene rings share two carbon atoms. Naphthalene $\left(\mathrm{C}_{10} \mathrm{H}_{8}\right)$ is a white crystalline solid with two benzene rings joined side-by-side and is used as moth balls/repellant, figure 10 . Anthracene $\left(\mathrm{C}_{14} \mathrm{H}_{10}\right)$ is crystalline fluorescent solid with three benzene rings joined side -by-side, used to prepare dyes. 


\section{Polycyclic Aromatic Hydrocarbons}<smiles>c1ccc2ccccc2c1</smiles><smiles>c1ccc2c(c1)ccc1ccccc12</smiles>

Napthalaene

$\mathrm{C}_{10} \mathrm{H}_{8}$

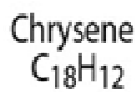

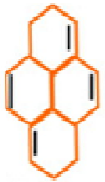

Pyrene

$\mathrm{C}_{16} \mathrm{H}_{10}$

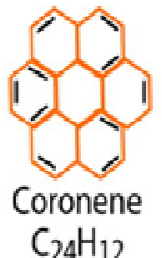

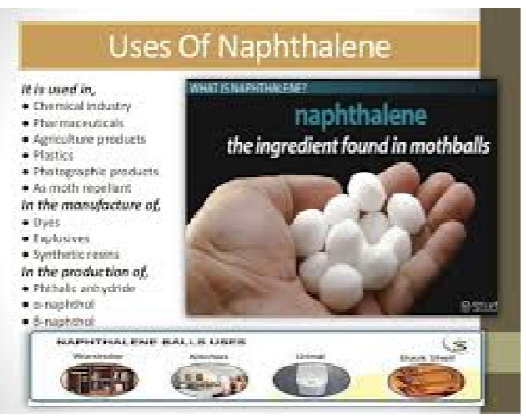

Figure 10: Some Examples of Polycyclic Aromatic Hydrocarbons Source: Adapted from Images of Hydrocarbons

\section{Material}

Table 2 shows the typical representative composition of the flared associated stranded natural gas stream in Nigeria, obtained from statistical analysis of 36 flare streams, selected from 150 flare line data samples. And table 3 contains the average operational parameters of the Nigeria flare gas stream. NB: Production from different wells will have different Compositional Analyses.

\begin{tabular}{|c|c|}
\hline Component & Mole \% \\
\hline Methane & 78.5375 \\
\hline Ethane & 7.7880 \\
\hline Propane & 5.9625 \\
\hline i-butane & 1.4842 \\
\hline n-butane & 1.8882 \\
\hline i-pentane & 0.6964 \\
\hline n-pentane & 0.4982 \\
\hline Hexane plus & 0.7550 \\
\hline Nitrogen & 0.1729 \\
\hline Carbon dioxide & 2.0105 \\
\hline Other undesirables & 0.2066 \\
\hline & 100.0000 \\
\hline
\end{tabular}

Table 2: A Typical Representative Composition of Flare Associated Stranded Natural Gas in Nigeria Source: Adapted from Ekejiuba, 2017

\begin{tabular}{|c|c|c|}
\hline Parameter & Range & Value for the Study \\
\hline Gas Gravity (air) & 0.607 to 0.996 & 0.755 \\
\hline Flow rate MMscfd & 5 to 63 & 20 \\
\hline Pressure Psig & 7 to 75 & 10 \\
\hline Pressure & 21.7 to 89.7 & 25 \\
\hline Temperature OF & 60 to 115 & 80 \\
\hline Base Temperature During Analysis & - & 60 F \\
\hline Base Pressure During Analysis & - & $14.7 \mathrm{psia}$ \\
\hline
\end{tabular}

Table 3: Flare Conditions of the Associated Stranded Natural Gas in Nigeria 


\section{Data Analysis}

Table 4, shows the real-time daily production of the various components for a flare stream with typical composition $\mathrm{Cl}(78.5 \%), \mathrm{C}_{2}+(21.5 \%)$ and flow rate of $20 \mathrm{MM}$ scfd, tables 4 and 5.

\begin{tabular}{|c|c|c|c|}
\hline Component & Mole \% & $\begin{array}{c}\text { Fractional } \\
\text { Composition }\end{array}$ & $\begin{array}{c}\text { Daily Production, Scf, (for } \\
\text { 20MM scfd stream) }\end{array}$ \\
\hline Methane & 78.5375 & 0.7854 & $15,708,000$ \\
\hline Ethane & 7.7880 & 0.0779 & $1,558,000$ \\
\hline Propane & 5.9625 & 0.0596 & $1,192,000$ \\
\hline i-butane & 1.4842 & 0.0148 & 296,000 \\
\hline n-butane & 1.8882 & 0.0189 & 378,000 \\
\hline i - Pentane & 0.6964 & 0.0070 & 140,000 \\
\hline n - Pentane & 0.4982 & 0.0050 & 100,000 \\
\hline Hexane and heavier & 0.7550 & 0.0075 & 150,000 \\
\hline Nitrogen & 0.1729 & 0.0017 & 34,000 \\
\hline Carbon Oxide & 2.0105 & 0.0201 & 402,000 \\
\hline Hydrogen Sulfide & 0.00 & 0.00 & 0.00 \\
\hline Water vapor & 0.2066 & 0.0021 & 42,000 \\
\hline Total & 100.00 & 1.0000 & $20,000,000$ \\
\hline
\end{tabular}

Table 4: Typical Nigerian Flare Gas Stream Daily Real-Time Component by Component Production

\begin{tabular}{|c|c|c|c|c|}
\hline Component & $\begin{array}{l}\text { Daily Production, } \\
\text { Scf, (for 20MM } \\
\text { scfd stream) }\end{array}$ & $\begin{array}{l}\text { Daily Liquid } \\
\text { Equivalent: } \\
\text { Barrels }\end{array}$ & $\begin{array}{c}\text { Daily Liquid } \\
\text { Equivalent: US } \\
\text { Gallons }\end{array}$ & $\begin{array}{c}\text { Daily Liquid } \\
\text { Equivalent: Litres }\end{array}$ \\
\hline Methane & $15,708,000$ & 1570.80 & $65,973.6$ & 251,328 \\
\hline Ethane & $1,558,000$ & 155.80 & $6,543.6$ & 24,928 \\
\hline Propane & $1,192,000$ & 119.20 & $5,006.4$ & 19,072 \\
\hline i-butane & 296,000 & 29.60 & $1,243.2$ & 4,736 \\
\hline n-butane & 378,000 & 37.80 & $1,587.6$ & 6,048 \\
\hline i - Pentane & 140,000 & 14.00 & 588 & 2,240 \\
\hline $\mathrm{n}$ - Pentane & 100,000 & 10.00 & 420 & 1,600 \\
\hline Hexane and heavier & 150,000 & 15.00 & 630 & 2,400 \\
\hline Nitrogen & 34,000 & 3.40 & 142.8 & 544 \\
\hline Carbon Oxide & 402,000 & 40.20 & $1,688.4$ & 6,432 \\
\hline Hydrogen Sulfide & 0.00 & 0.00 & 0.00 & 0.00 \\
\hline Water vapor & 42,000 & 4.20 & 176.4 & 672 \\
\hline Total & $20,000,000$ & & & \\
\hline
\end{tabular}

Table 5: Estimated Real-Time Component by Component Quantity of Ngls Equivalent

Note: To Convert It to Barrels, Gallons, Cubic Meters or Liters We Require the Appropriate Conversion Factor

Table7 shows the estimated real-time component by component quantity of natural gas liquids (barrels, gallons and litres) production based on table 5 and the general rule for gas to liquid (GTL) conversion, that is, GTL converts every 10,000-cu ft to approximately 1 barrel ( $1 \mathrm{bbl}=5.615 \mathrm{cu}$. ft. or 42 US gallons or 160 liters). For instance, Ethane's 1,558,000 scfd will yield 155.80 barrels (6,543.6 gallons or 24,928 litres).

Most often the liquefied paraffin (primary petrochemical) produced from the gas processing plant are purchased in units of mass (tons or $\mathrm{kg}$ ), for use as raw material in chemical plants and olefin petrochemical plants, which converts it to ethylene, propylene, butene, pentene, hexene, heptene etc. The conversion factor, from standard cubic feet (scf) to moles is ( $1 \mathrm{scf}=1.19804$ moles). For instance at the flow rate of $20 \mathrm{MM} \mathrm{scfd}$, the daily production of methane will be 15,708,000 scfd, which is equal to $18,818,812.32$ moles (i.e. $15,708,000 \times 1.19804$ ). Because the molecular weight of methane is $16.043 \mathrm{~g} / \mathrm{mole}$, the mass of methane produced daily is $301,910,206.04976$ grams $(301,910.206 \mathrm{~kg})$. Using the natural gas conversion guide expression (i.e. 1 metric ton $=1,000$ metric $\mathrm{kg}$. or $1 \mathrm{~kg} .=0.001$ metric ton), the equivalent metric ton of methane produced daily is 301.910 tons. Table 6 shows the comprehensive real-time mass equivalent of the component by component daily production from the flared associated stranded gas in Nigeria. 


\begin{tabular}{|c|c|c|c|c|}
\hline Component & $\begin{array}{c}\text { Molecular Weight } \\
\text { (Mi) G/ Mole }\end{array}$ & $\begin{array}{c}\text { Daily Production (P), Scf, } \\
\text { (For 20MM Scfd Stream) }\end{array}$ & $\begin{array}{c}\text { Equivalent Mass, Kg } \\
\text { (MiX P X 1.19804) }\end{array}$ & $\begin{array}{c}\text { Equivalent Mass, } \\
\text { Metric Ton }\end{array}$ \\
\hline Methane & 16.043 & $15,708,000$ & $301,910.206$ & 301.910 \\
\hline Ethane & 30.070 & $1,558,000$ & $56,127.048$ & 56.127 \\
\hline Propane & 44.097 & $1,192,000$ & $62,973.324$ & 62.973 \\
\hline i-butane & 58.124 & 296,000 & $20,611.923$ & 20.612 \\
\hline n-butane & 58.124 & 378,000 & $26,321.923$ & 26.322 \\
\hline i - Pentane & 72.151 & 140,000 & $12,101.570$ & 12.101 \\
\hline n - Pentane & 72.151 & 100,000 & $8,643.978$ & 15.644 \\
\hline Hexane and heavier & 86.178 & 150,000 & $15,486.704$ & 1.487 \\
\hline Nitrogen & 28.013 & 34,000 & $1,141.064$ & 21.196 \\
\hline Carbon Oxide & 44.010 & 402,000 & $21,195.748$ & 0.000 \\
\hline Hydrogen Sulfide & 0.000 & 0.00 & 0.000 & \\
\hline Water vapor & 18.015 & 42,000 & 906.473 & \\
\hline Total & & $20,000,000$ & & 0.906 \\
\hline
\end{tabular}

Table 6: Real-Time Mass Equivalent of the Component by Component Daily

Production from the Flared Associated Stranded Gas in Nigeria

\section{Model Application}

To process the flared associated stranded gas in Nigeria for the production of petrochemicals and other useful end products, entails an initial systematic uncoupling of the entire components of the gas stream into their individual pure components based on their different boiling points. Pure octane $\left(\mathrm{C}_{8}\right)$ and heavier hydrocarbons, $126{ }^{\circ} \mathrm{C}$; purified water, $100{ }^{\circ} \mathrm{C}$; pentane $\left(\mathrm{C}_{5}\right) 36^{\circ} \mathrm{C}$; hexane $\left(\mathrm{C}_{6}\right) 6{ }^{\circ} \mathrm{C}$; heptanes $\left(\mathrm{C}_{7}\right) 98{ }^{\circ} \mathrm{C}$; pure normal butane, $-0.5^{\circ} \mathrm{C} /-1{ }^{\circ} \mathrm{C}$; pure iso butane, -11.7 ${ }^{\circ} \mathrm{C}$; pure propane, $-42{ }^{\circ} \mathrm{C}$; pure carbon dioxide, $-78.5{ }^{\circ} \mathrm{C}$; pure ethane, $-89{ }^{\circ} \mathrm{C}$; pure methane, $-162{ }^{\circ} \mathrm{C}$; pure nitrogen, -195.8 $\left.{ }^{\circ} \mathrm{C}\right)$.

At standard temperature and pressure $\left\{60{ }^{\circ} \mathrm{F}\left(15.55^{\circ} \mathrm{C}\right)\right.$ and 14.7 psia or $68{ }^{\circ} \mathrm{F}\left(20^{\circ} \mathrm{C}\right)$ and 14.7 psia $\}$, pentane, hexane, heptane, water and octane and heavier hydrocarbons, are in liquid state and they are recovered in scrub column. Cooling the remaining stream to $-90{ }^{\circ} \mathrm{C}$ will liquefy normal butane, iso butane, propane, carbon dioxide and ethane respectively. Further cooling to $-162{ }^{\circ} \mathrm{C}$ will liquefy methane while nitrogen still remains gaseous. Methane is knocked off and the stream is cooled to $-196{ }^{\circ} \mathrm{C}$ to liquefy nitrogen. By fractional distillation (or fractionation), the overall extracted natural gas liquids (NGLs) are separated into individual components. Figure 11, is the proposed design process layout for the overall liquefaction of the associated flared natural gas and the detailed NGLs component by component products.

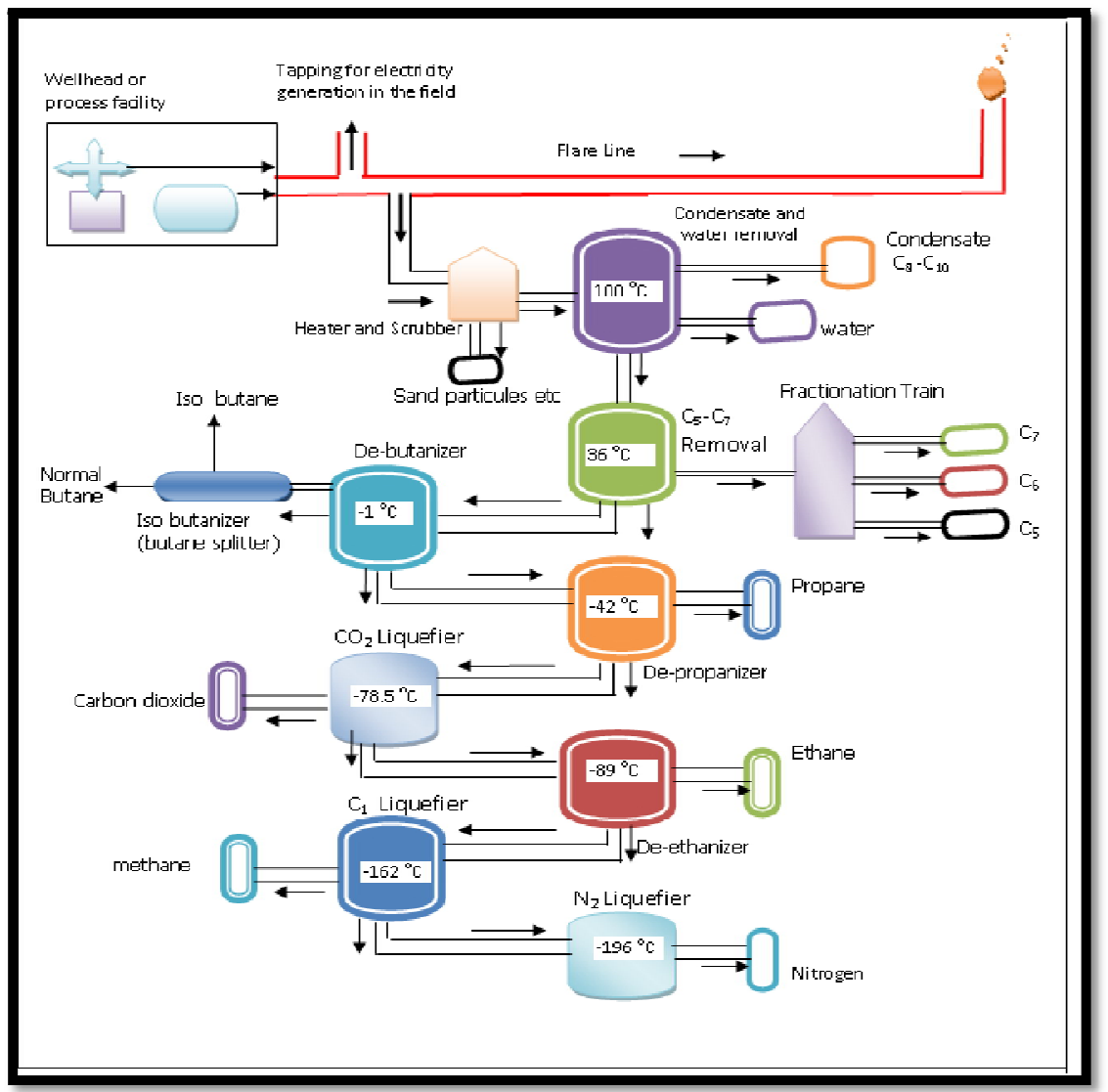

Figure 11: Process Layout for Flare Stream Liquid Components Production 


\section{Process Techniques for Making Valuable Petrochemicals and Other Useful Products}

The valuable petrochemicals and useful products from the flared associated stranded gas in Nigeria, are derived through, processing the organic compounds, obtained from the various fractional components: olefins/acetylenes, aromatics, functional groups derivatives (alkyl, hydroxyl, halogeno, amino, carboxyl, organometallics, etc.; cyclohydrocarbons, heterocyclic compounds), synthesis gas (syngas), carbon black, and by polymerization.

\subsection{Olefins/ Acetylene Process Techniques and Products / Uses}

- Processing ethene (ethylene), lead to the manufacture of epoxyethane (i.e. ethylene oxide), chloroethane, ethanol, polythene and derivatives (substituted ethenes) such as styrene, figure 12.

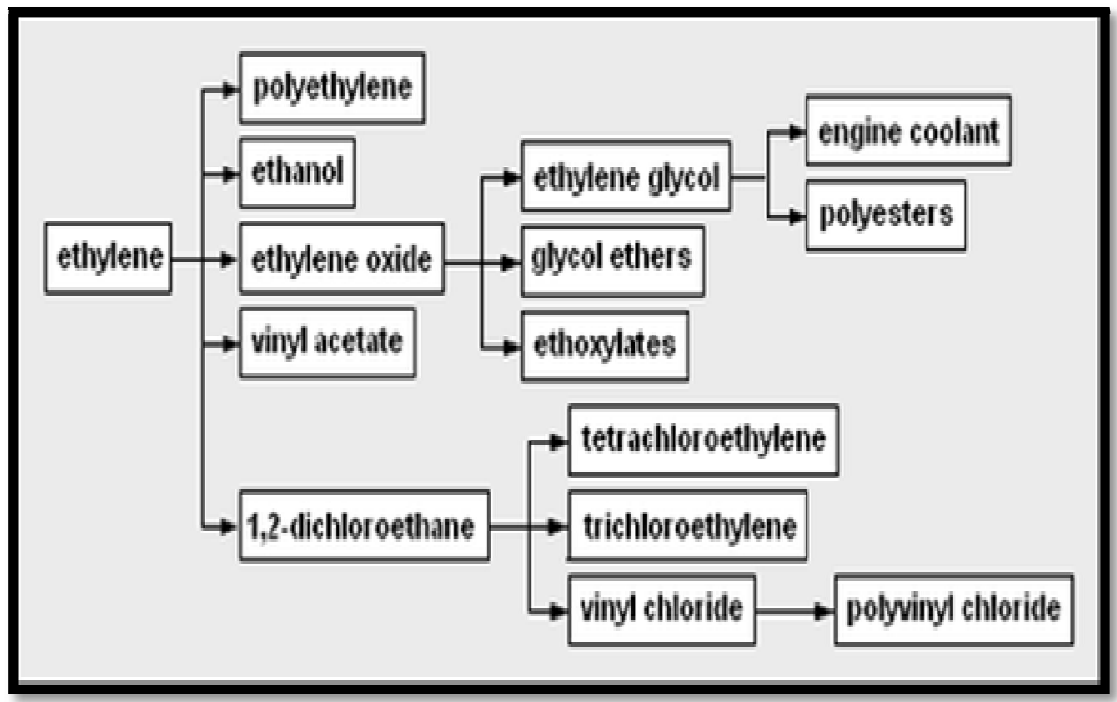

Figure 12: Some of the Basic Chemical Products from Ethylene Source: Adapted from Images Ethylene

- Ethene to ethylene oxide to ethylene glycol ---Used as antifreeze for car radiators

- Ethene to chloroethane $\mathrm{CH}_{2}=\mathrm{CH}_{2}+\mathrm{HCL} \longrightarrow \mathrm{CH}_{3} \mathrm{CH}_{2} \mathrm{CL}$

- Ethene to ethanol to ethanal, then to ethanoic acid and ethanoic anhydride

$>$ Ethanoic acid - Used to produce ethyl and butyl ethanoates solvents for industries and laboratories.

$>$ Ethanoic anhydride - used to produce cellulose acetate for manufacture artificial fibres called acetate rayon in textile industry.

Dthane to polythene: Polythene- Is used to produce unbreakable goods and items of all descriptions: toys, pails, bowls, soap cases, packaging bags, etc. figure 13.

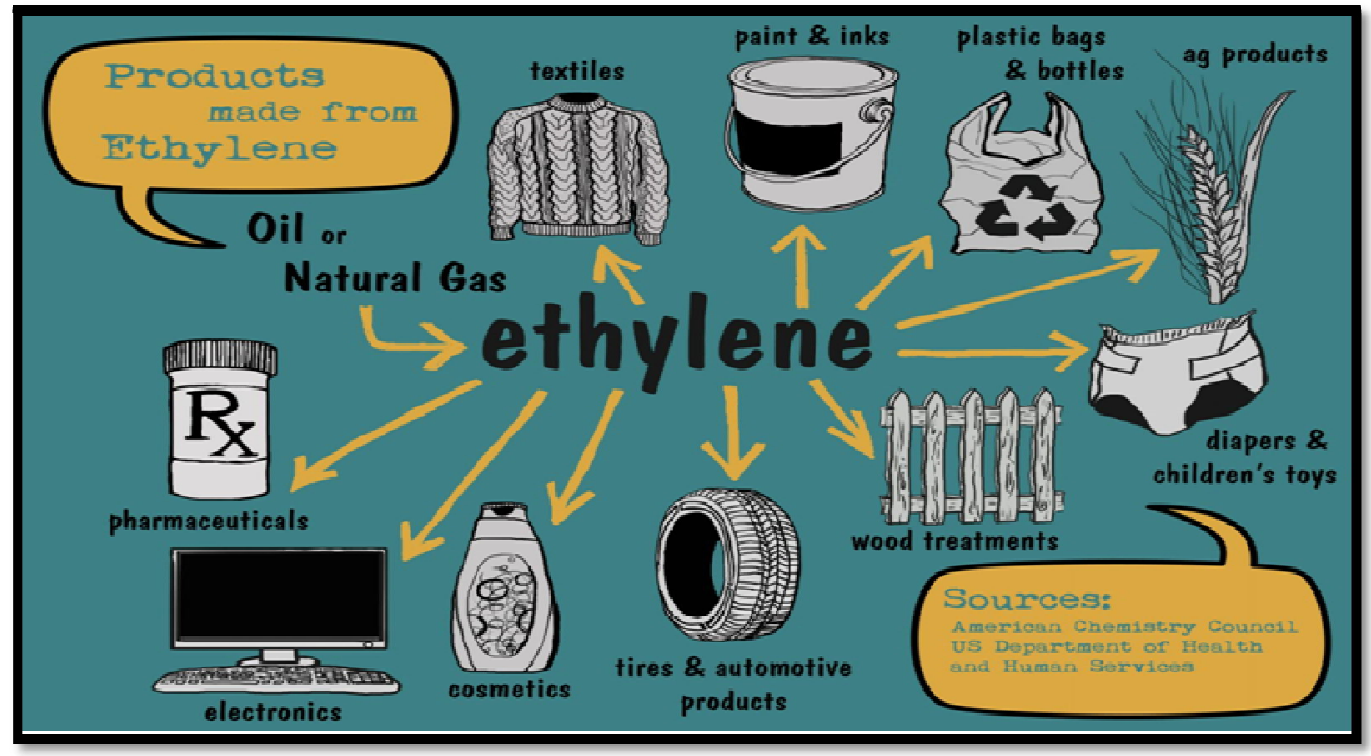

Figure 13: Some of the Basic End Use Product from Propylene Source: Adapted from Images Ethylene 
- Processing propene(propylene), lead to the manufacture of propan-2-ol, used for manufacturing propanone and polypropylene, figure 14. Combination of propylene with ammonia is used to produce acrylonitrile, which in turn is converted to produce acrylic fibers.

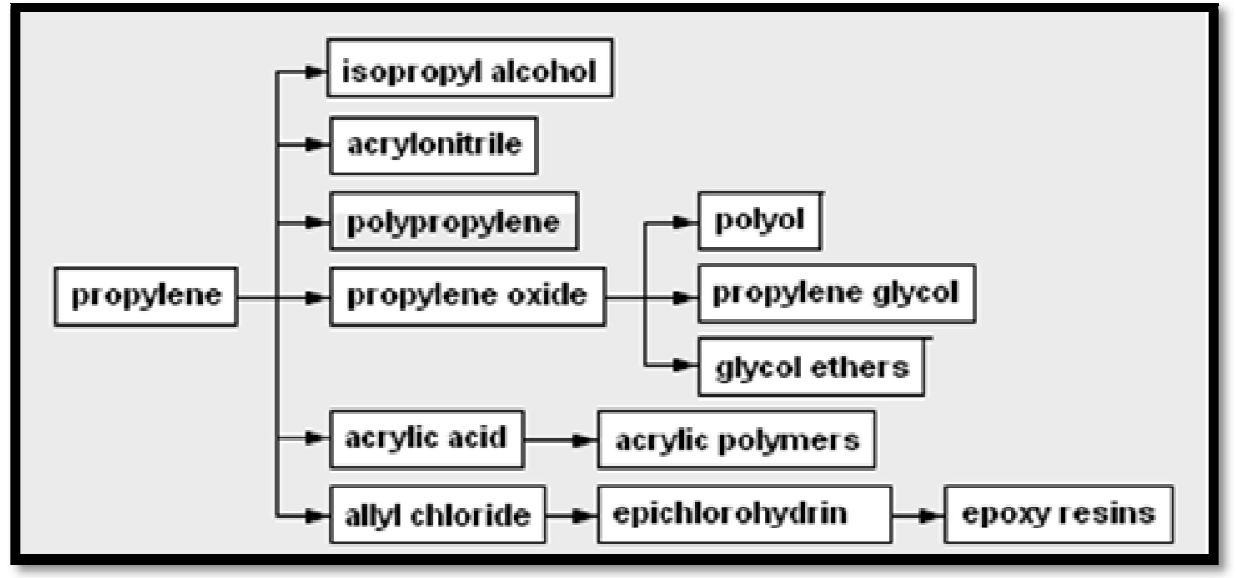

Figure 14: Some of the Basic Chemical Products from Propylene Source: Adapted from Images Propylene

- Processing butenes, lead to the production of butadiene figure 15, a raw material for the manufacture of a type of synthetic rubber and also for the manufacture of butyl alcohols, butanone and substituted butadienes like chlorobutadiene and methylbutadiene.

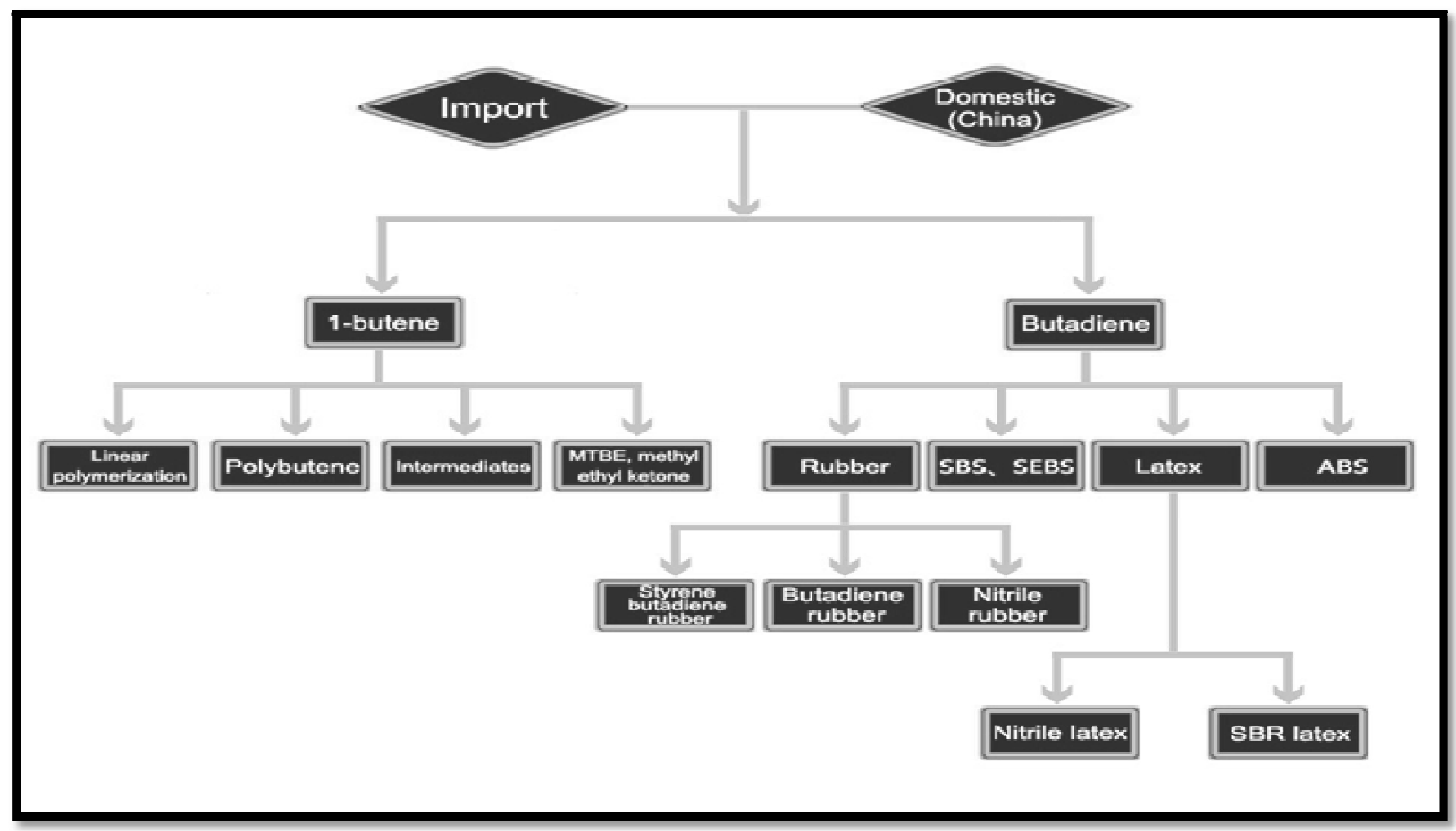

Figure 15: Some of the Chemical and Basic End Use Products from Propylene Source: Adapted from Images Butene Chain

- Ozonolysis of alkenes (olefins): Ozone, $\mathrm{O}_{3}$ is an allotropic form of oxygen, which means that it is the same substance in different molecular form and possessing different properties (Hess, 1980). The equation for the conversion of oxygen to ozone is $\left(3 \mathrm{O}_{2}=2 \mathrm{O}_{3}\right)$.

Alkenes add ozone to give compounds called ozonides (Bamkole and Ogunkoya, 1978; Brown et al., 2005), which are highly explosive in the free state.

$$
\mathrm{RCH}=\mathrm{CHR}+\mathrm{O}_{3} \longrightarrow \mathrm{RCHO}_{3} \mathrm{CHR}
$$

(R represent, either another hydrogen atom or an alkyl group or a phenyl group)

This reaction is noteworthy because it is one of the very few organic reactions that break C-C bonds. 
- Acetylene is very useful because it can undergo several chemical reactions, needed for manufacturing products in different industries such as production of polyethene (plastics). Acetylene is widely used in the oxy-acetylene welding torch because it burns in oxygen with a very hot flare. It is also used as fuel.

> Propyne also known as methylacetylene is commonly used as a substitute for acetylene both as fuel and for welding torches. It is being investigated as a possible fuel for rockets in spacecraft.

\subsection{Aromatics (Benzene) Process Techniques and Products / Uses}

Benzene $\left(\mathrm{C}_{6} \mathrm{H}_{6}\right)$ liquid is the simplest aromatic hydrocarbon and by far the most widely used, it is an important solvent as well as the raw material for the manufacture of many chemicals figure 16.

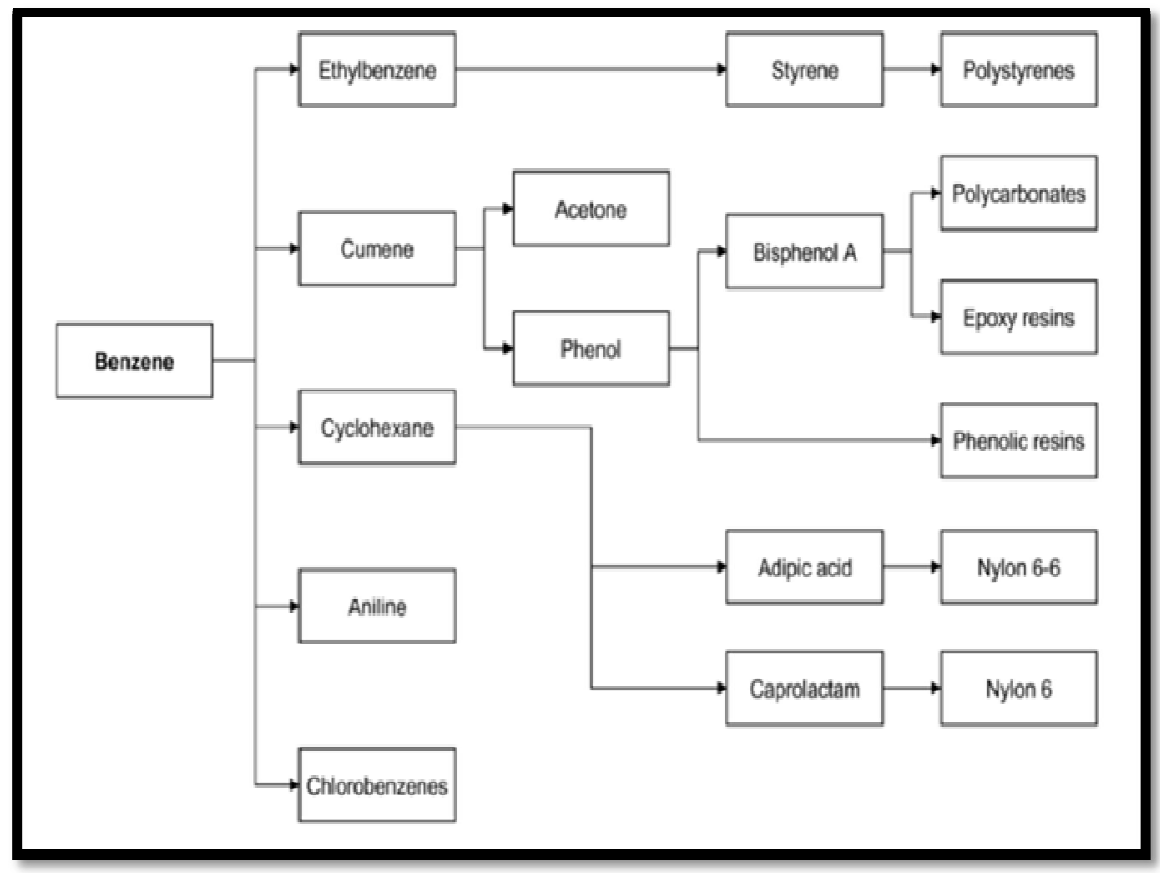

Figure 16: Some of the Basic Chemical Products from Benzene

Source: Adapted from Images of Products from Aromatic Hydrocarbon

\subsection{Process Techniques for Making Chemical Products via Functional Groups Reactions}

This includes, all the products made from:

- Primary functional groups (alkyl group, alkene group, alkyne group, cyclo-hydrocarbons and phenyl group), and

- Hydrocarbon derivative functional group reactions, such as (i) halogenation, alkyl halides, acyl halides; (ii) oxidation derivatives, alcohol (-OH), ethers (-O-) aldehydes $(\mathrm{C}=0)$, ketones $(\mathrm{C}=0)$, amides $\left(\mathrm{CONH}_{2}\right)$, carboxylic acids $(\mathrm{COOH})$, esters $(\mathrm{COO})$;

$>$ nitrogen derivatives, amines(- $\left.\mathrm{NH}_{2}\right)$, amino acids, nitriles, and nitro;

$>$ ( sulfur derivatives, thiols and disulfides; (v) organometallics compounds, eg organomagnesium, organolithium, organomercury, oganocopper, organopalladium, carbenes and carbenoids, alkene metathesis etc.; (vi) heterocyclic compounds and (vii) interconversion of functional groups.

\subsubsection{Process Techniques for the Primary Functional Groups Reactions: Alkyl Group, Alkene Group, Alkyne Group and} Phenyl Group

- Alkyl group petrochemicals process techniques : The alkyl functional groups petrochemicals are obtained by the chemical reaction that are designed to remove a hydrogen atom from an alkane components of the flared associated natural gas, to yield methyl $\left(-\mathrm{CH}_{3}\right)$, ethyl $\left(-\mathrm{C}_{2} \mathrm{H}_{5}\right)$, propyl $\left(-\mathrm{C}_{3} \mathrm{H}_{7}\right)$, butyl $\left(-\mathrm{C}_{4} \mathrm{H}_{9}\right)$, pentyl $\left(-\mathrm{C}_{5} \mathrm{H}_{11}\right)$, hexyl $(-$ $\left.\mathrm{C}_{6} \mathrm{H}_{13}\right)$, heptyl $\left(-\mathrm{C}_{7} \mathrm{H}_{15}\right)$, octyl $\left(-\mathrm{C}_{8} \mathrm{H}_{17}\right)$, nonyl $\left(-\mathrm{C}_{9} \mathrm{H}_{19}\right)$, decyl $\left(-\mathrm{C}_{10} \mathrm{H}_{21}\right)$ etc., which is attached to another carbon chain. The dashes in the formulae indicate the location of the bonds available for attachment to basic organic molecules or to other groups (Ebbing et al., 1995; Hess, 1980).

- Alkene group petrochemicals process techniques: The alkenes petrochemicals are obtained by the chemical reaction that contain a functional group (Timberlake, 2006) that is a double bond between two adjacent carbon atoms $(C=C)$, which makes it very reactive with other organic molecules.

- Alkyne group petrochemicals process techniques: alkynes petrochemicals are obtained by the chemical reaction that contain a triple bond $(\mathrm{C} \equiv \mathrm{C})$, making it very useful for reactions with other organic molecules.

- Cyclo-hydrocarbons petrochemicals process techniques: This includes all the petrochemicals obtained by the chemical reactions involving cycloalkanes, cycloalkenes, cycloalkynes and their derivatives. They undergo all the basic reactions of hydrocarbons to produce different useful petrochemicals. 
D Cycloalkanes (cycloparaffins or naphthenes) and their derivatives: Cycloalkanes petrochemicals are obtained from alkanes with single bonded carbon atoms linked in a ring (cyclic or loop). Cycloalkanes have two fewer hydrogen atoms than the corresponding alkanes (Timberlake, 2006). Because of their cyclical nature, cycloalkanes have their own unique properties. Table 7 shows some examples of cycloalkanes, while figure 17 shows some of their derivatives.

\begin{tabular}{|c|c|c|c|c|c|c|}
\hline \multicolumn{7}{|c|}{ Examples of Simple Cycloalkanes } \\
\hline Name & Cyclopropane & Cyclobutane & Cyclopentane & Cyclohexane & Cycloheptane & Cycloalkane \\
\hline $\begin{array}{c}\text { Molecular } \\
\text { Formula }\end{array}$ & $\mathrm{C}_{3} \mathrm{H}_{6}$ & $\mathrm{C}_{4} \mathrm{H}_{8}$ & $\mathrm{C}_{5} \mathrm{H}_{10}$ & $\mathrm{C}_{6} \mathrm{H}_{12}$ & $\mathrm{C}_{7} \mathrm{H}_{14}$ & $\mathrm{C}_{\mathrm{n}} \mathrm{H}_{2 \mathrm{n}}$ \\
\hline Structural & $\mathrm{H}_{\mathrm{C}}$ & $\mathrm{H}_{2} \mathrm{C}-\mathrm{CH}_{2}$ & & & & $\left(\mathrm{CH}_{2}\right)_{\mathrm{n}}$ \\
\hline $\begin{array}{c}\text { Line } \\
\text { Formula }\end{array}$ & $\triangle$ & & & & & \\
\hline
\end{tabular}

Table 7: Some Examples of Cycloalkanes

Source: Adapted Images of Cycloalkanes

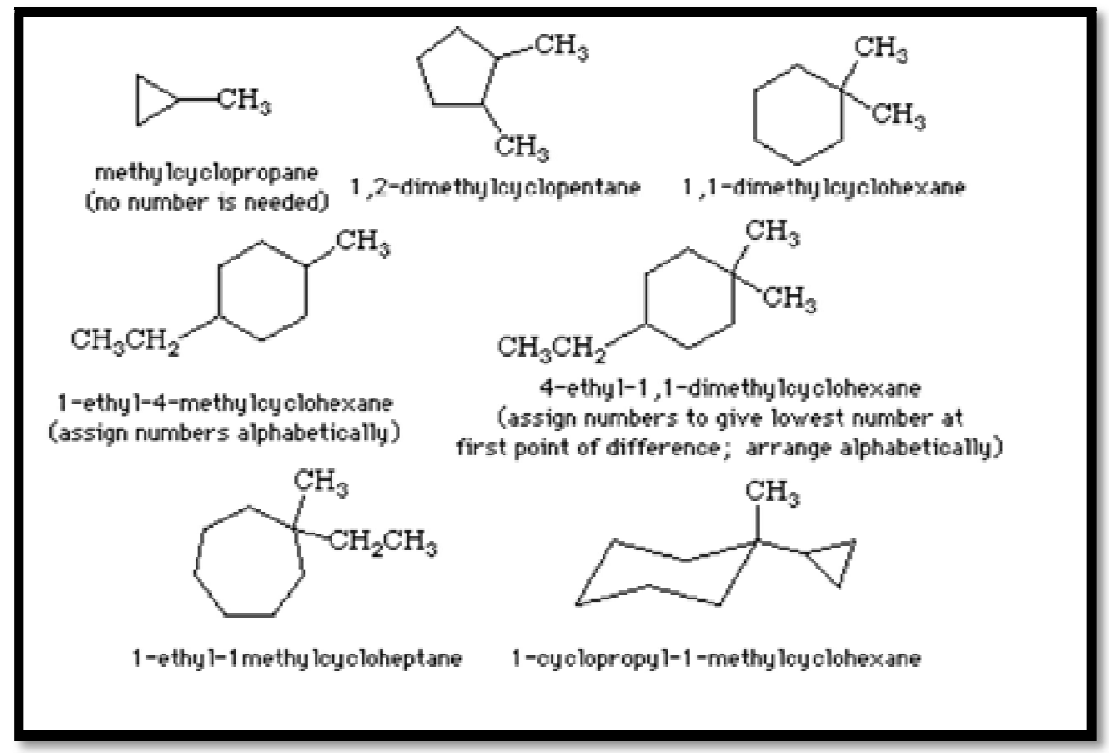

Figure 17: Some Examples of the Derivatives of Cycloalkanes Source: Adapted from Images of Cycloalkanes

- Cycloalkenes and their derivatives: Cycloalkenes petrochemicals are obtained from alkenes that consist of three or more carbon atoms linked together with at least one double bond to form a structural ring. Due to their double carbon-carbon bond cycloalkenes are more reactive than cycloalkanes. Figure 18 show some common cycloalkenes. 


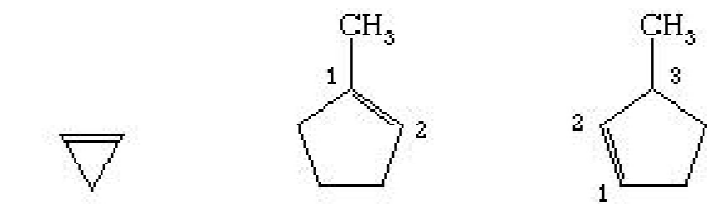

oyolopropene 1-methyloyolopentene 3-methyloyolopentene

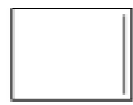

Cyclobutene<smiles>C1C2CC3CC1C3C2</smiles>

Cyclopentene

cyclohexene

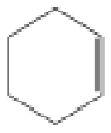<smiles>C1=CCCC=C1</smiles>

1.4 Cyclohexadiene

Figure 18: Show Some Common Cycloalkenes

Source: Adapted from Images of Cycloalkenes

> Cycloalkynes and their derivatives: Cycloalkynes petrochemicals are obtained from alkynes with closed ring of carbon atoms containing one or more triple bonds. Figure 19 shows some common cycloalkynes.

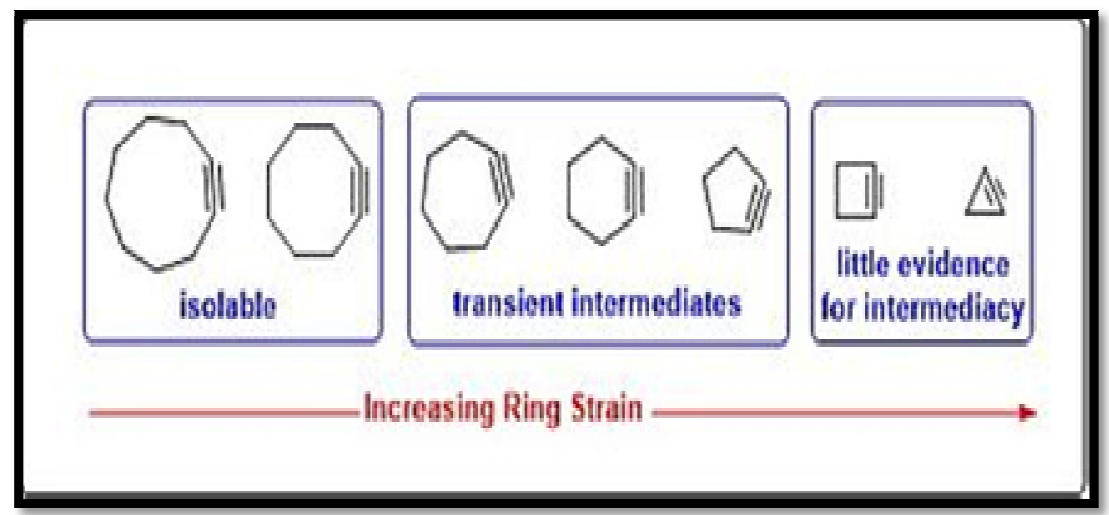

Figure 19: Some Simple Cycloalkynes

Source: Adapted from Images of Cycloalkynes

- Phenyl group petrochemicals process techniques: Removing one hydrogen atom from benzene ring result to the phenyl group $\left(-\mathrm{C}_{6} \mathrm{H}_{5}\right)$. The different types of phenyl group petrochemicals are mono-substituted benzenes (alkyl benzene), di-substituted benzenes (when 2 substituents occur on a benzene ring), poly-substituted benzenes (when 3 or more substituent are present on a benzene ring), figure 20.

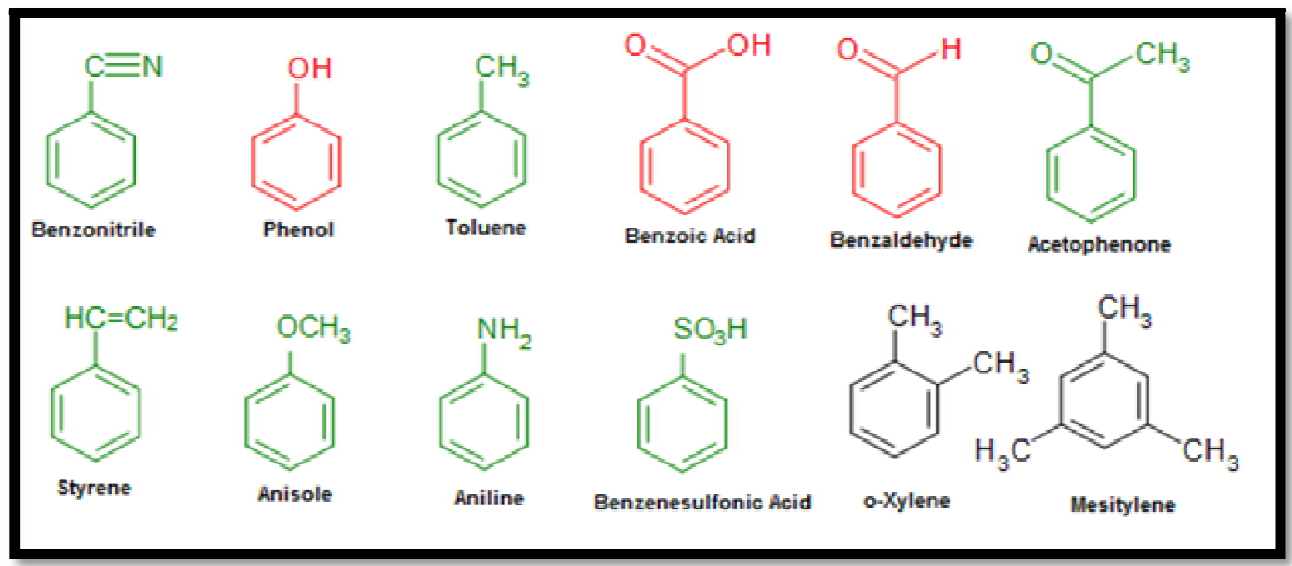

Figure 20: Some Examples of Benzene Derivatives Source: Adapted From Images of Phenyl Group 
- Methylbenzenes (toluenes, xylenes): The methylbenzene $\left(\mathrm{C}_{6} \mathrm{H}_{5} \mathrm{CH}_{3}\right)$ is a solvent and is also used to make drugs, dyes and explosives like trinitrotoluene, TNT $\left(\mathrm{C}_{6} \mathrm{H}_{2} \mathrm{CH}_{3}\left(\mathrm{NO}_{2}\right)_{3}\right.$. Two alkyl substituents on the benzene ring yields three isomers called the xylene (o-xylene, p-xylene, and m-xylene), (Ebbing et al., 1995).

- Styrene, also known as ethenylbenzene, vinylbenzene, phenylethene, Phenylethylene, Cinnamene, Styrol, Diarex $\mathrm{HF}$ 77, Styrolene, and Styropol is an organic compound with the chemical formula $\mathrm{C}_{6} \mathrm{H}_{5} \mathrm{CH}=\mathrm{CH}_{2}$. It is the precursor to polystyrene and several copolymers (wikipedia- styrene, n.d.).

- Linear alkyl benzene (LAB) is produced via the alkylation of benzene with normal olefins derived from a variety of sources. Linear alkylbenzene sulfonic acid figure 21, is mainly used to produce household detergents including laundry powders, laundry liquids, dishwashing liquids and other household cleaners as well as in numerous industrial applications like as a coupling agent and as an emulsifier for agricultural herbicides and in emulsion polymerization.

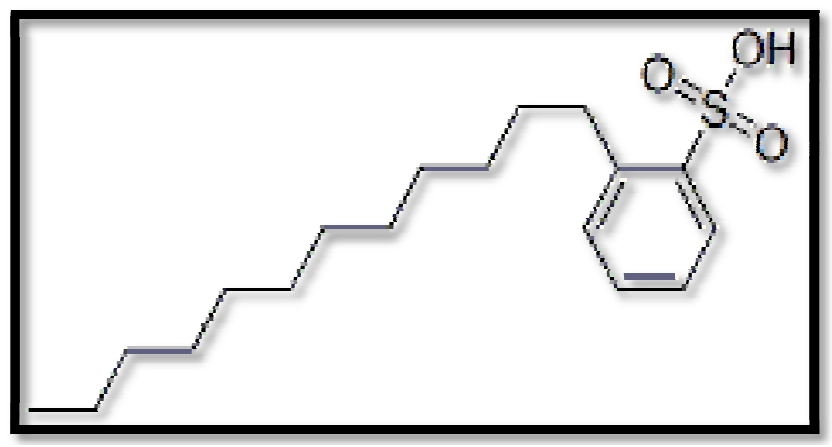

Figure 21: Linear Alkylbenzene Sulfonic Acid

Molecule Structure Image

Source: Adapted From Images of Linear

Alkylbenzene Sulfonic Acid

- The benzene ring petrochemicals are found in some amino acids (the building blocks of proteins), in pain relievers such as aspirin, acetaminophen, and ibuprofen and in flavorings such as vanillin (Timberlake, 2006), figure 22.

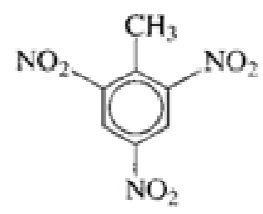

INT $(2,4,6$-trinitutoluthe<smiles>CC(=O)Oc1ccccc1C(=O)O</smiles>

Axpiin<smiles>COc1ccc(O)c(C=O)c1</smiles>

vanillin<smiles>CC(C)Cc1ccc(C(C)C(=O)O)cc1</smiles>

Thuproten

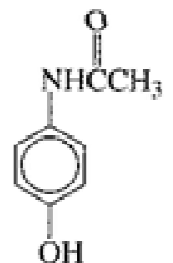

Acetaminophen

Figure 22: Some Common Aromatic Compounds

Source: Adapted from Timberlake, 2006

7.3.2. Process Techniques for Making the Halides Family of Petrochemicals from (Alkanes, Alkenes, Alkynes and Benzenes)

Alkanes compounds containing halogen atom (s) are called haloalkanes or alkyl halides with the symbol R-X. If the halogen is bonded to a doubly bonded carbon of an alkene, it is called haloalkenes (also known as alkenyl halide or vinylic halide, while if it is bonded to a benzene ring it is called haloarenes (also called aryl halide with the symbol (Ar-X) (Brown et al., 2005). Below are some halogenation products and their major uses.

- With alkanes, the petrochemicals are obtained by substitution reactions in which the replacement is achieved by just exposing the mixture to light or heating (Hess, 1980):

$\mathrm{CH}_{4}+\mathrm{Cl}_{2} \longrightarrow \mathrm{HCl}+\mathrm{CH}_{3} \mathrm{Cl}$ (methyl chlorine or chloromethane) - anaesthetic

$\mathrm{CH}_{3} \mathrm{Cl}+\mathrm{Cl}_{2} \longrightarrow \mathrm{HCl}+\mathrm{CH}_{2} \mathrm{Cl}_{2}$ (methylene chlorine or dichloromethane)-solvent

$\mathrm{CH}_{2} \mathrm{Cl}_{2}+\mathrm{Cl}_{2} \longrightarrow \mathrm{HCl}+\mathrm{CHCl}_{3}$ (chloroform or trichloromethane) -solvent and anaesthetic

$\mathrm{CHCl}_{3}+\mathrm{Cl}_{2} \longrightarrow \mathrm{HCl}+\mathrm{CCl}_{4}$ ( carbon tetrachloride or tetrachloromethane) -solvent

The most widely used solvent by dry cleaner are dichloromethane, 1,1,1- trichloroethane, and 1,1,2- trichloro-1,2,2trifluoroethane, while the widely used anaesthetic are halothane (also known as fluothane $\left(\mathrm{F}_{3} \mathrm{C}-\mathrm{CHClBr}\right)$, chloromethane is used for minor surgeries (Timberlake, 2006).

- With alkenes, it is an addition reaction in which the petrochemical products contain fewer double bonds than the reactant.

$\mathrm{C} \cdot \mathrm{H}_{2}=\mathrm{CH}_{2}+\mathrm{HC} \longrightarrow \mathrm{C} \cdot \mathrm{H}_{2} \mathrm{C} . \mathrm{H}_{2} \mathrm{Cl}$ ( chlornethane) 


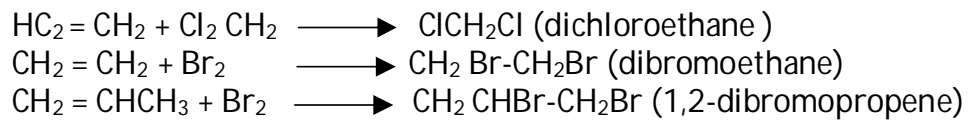

(iii) With alkynes in which $(\mathrm{R}=\mathrm{H}$ or $\mathrm{R}=$ alkyl and $\mathrm{X}=$ halogen), it is an addition reaction in which the petrochemical products contain fewer triple bonds than the reactant.

$$
\begin{aligned}
& \mathrm{RC} \equiv \mathrm{CH}+\mathrm{X}_{2} \longrightarrow \mathrm{RCX}=\mathrm{CHX} \\
& \mathrm{RCX}=\mathrm{CHX}+\mathrm{X}_{2} \longrightarrow \mathrm{RCX}_{2} \mathrm{CHX}_{2}
\end{aligned}
$$

For instance, addition of hydro-bromic acid to acetylene :

$$
\begin{aligned}
& \mathrm{CH} \equiv \mathrm{CH}+\mathrm{HBr} \longrightarrow \mathrm{CH}_{2}=\mathrm{CHBr} \text { (1 bromoethene) } \\
& \mathrm{CH}_{2}=\mathrm{CHBr}+\mathrm{HBr} \longrightarrow \mathrm{CH}_{3} \mathrm{CHBr}_{2}
\end{aligned}
$$

(iv) For aromatics, the petrochemicals are obtained by substitution reactions in which the hydrogen atoms on the benzene ring are replaced by the halogen atoms in the presence of catalyst.

7.3.3. Process Techniques for Making Oxidation Derivative Petrochemicals: Alcohols, Ethers, Aldehydes, Ketones, Carboxylic Acids and Its Subsequent Derivatives (Esters, Acyl Halides, Anhydrides, Amides, and the Salts of Carboxylic Acids)

- Review of Alkanes Oxidation: Alkanes undergoes combustion when they react with oxygen to produce carbon dioxide, water and energy and that is the basis of their use as fuels (Bamkole and Ogunkoya, 1978; Timberlake, 2006). If the supply of oxygen is limited, incomplete combustion of alkanes yields Carbon Monoxide or carbon black. For example,

Methane: $\mathrm{CH}_{4}(\mathrm{~g})+2 \mathrm{O}_{2}(\mathrm{~g}) \quad \longrightarrow \mathrm{CO}_{2}(\mathrm{~g})+2 \mathrm{H}_{2} \mathrm{O}(\mathrm{l})$ + heat energy and limited supply of oxygen in the combustion of methane yields Carbon Monoxide

$$
2 \mathrm{CH}_{4}(\mathrm{~g})+3 \mathrm{O}_{2}(\mathrm{~g}) \underset{\text { limited oxygen supply }}{\longrightarrow} \quad \begin{aligned}
& 2 \mathrm{CO}(\mathrm{g})+\underset{\mathrm{H}_{2} \mathrm{O}(\mathrm{g})}{\longrightarrow}+\text { heat energy } \\
&
\end{aligned}
$$

However, if the oxidation of alkane hydrocarbons is carried out gently, a number of important intermediate compounds such as alcohols, aldehydes, ketones, carboxylic acids etc., can be formed. The gentle or mild oxidation of hydrocarbons involves either the insertion of an oxygen atom into the molecule or the removal of two hydrogen atoms from the molecule (Hess, 1980). For instance,
(a) $\mathrm{CH}_{4}(+\mathrm{O}) \longrightarrow \mathrm{CH}_{3} \mathrm{OH}$ (methyl alcohol)
(b) $\mathrm{CH}_{4}\left(-\mathrm{H}_{2},+\mathrm{O}\right) \longrightarrow \mathrm{HCHO}($ formaldehyde)
(c) $\mathrm{CH}_{4}\left(-\mathrm{H}_{2},+2 \mathrm{O}\right) \rightarrow \mathrm{HCOOH}$ (formic acid)

and, the oxidative coupling of methane $(\mathrm{OCM})$ is used to produce other hydrocarbons

(d) $2 \mathrm{CH}_{4}+\mathrm{O}_{2} \longrightarrow \mathrm{C}_{2} \mathrm{H}_{4}+2 \mathrm{H}_{2} \mathrm{O}$

(e) $2 \mathrm{CH}_{4}+1 /{ }_{2} \mathrm{O}_{2} \longrightarrow \mathrm{C}_{2} \mathrm{H}_{6}+\mathrm{H}_{2} \mathrm{O}$

(ii)Alcohols are petrochemicals derived from alkanes in reaction which replaced one or more of the hydrogen atoms with the hydroxyl $(-\mathrm{OH})$ group to yield the $(\mathrm{ROH})$ family figure 23, phenols are petrochemical compounds in which one or more $(-\mathrm{OH})$ group are attached to a benzene ring. Their properties are different from those of the alcohols (Ebbing et al., 1995). Some common examples of alcohols and phenols are:

Methyl Alcohol (methanol), $\mathrm{CH}_{3} \mathrm{OH}$, used as solvent, paint remover, anti-freeze, fuel, and production of many synthetic chemicals and to make plastics, medicines, acetic acid $\mathrm{CH}_{3} \mathrm{COOH}$,(Timberlake, 2006).

Ethyl Alcohol (ethanol), $\mathrm{C}_{2} \mathrm{H}_{5} \mathrm{OH}$, it ranks next to water as an important solvent, used for chemical products and in preparing pharmaceutical drugs, cosmetics perfumes, varnishes, gasohol-mixture of ethanol (10\%) and gasoline used as fuel.

Phenol (carbolic acid), $\mathrm{C}_{6} \mathrm{H}_{5} \mathrm{OH}$, it is used as an antiseptic (disinfectant), in the preparation of plastics and other aromatic chemicals.

Glycerine, $\mathrm{C}_{3} \mathrm{H}_{5}(\mathrm{OH})_{3}$ or 1,2,3-propanetriod $\mathrm{CH}_{2}(\mathrm{OH}) \mathrm{CH}(\mathrm{OH}) \mathrm{CH}_{2}(\mathrm{OH})$, is used as a skin softener in products such as skin lotions, cosmetics, shaving creams and liquid soaps.

Ethylene glycol or 1,2-ethanediol is used as anti-freeze in heating and cooling systems, solvents for paints and inks, production of plastics and synthetic fibers such as Dacron. 
Primary, secondary, tertiary alcohol - what does it mean?

(3)<smiles>CCCCCC</smiles>

Methanol<smiles>CCO</smiles>

Primary alcohol<smiles>CC(C)O</smiles>

Secondary Alcohol<smiles>CC(C)(C)O</smiles>

Tertiary Alcohol<smiles>Oc1ccccc1</smiles>

Phenol

\section{"f of Carbons attached to the carbon bonded to $\mathrm{OH}$ (also known as the "carbinol" carbon):}

0 (unique)
2

$2^{\circ}$ alcohol
3

$3^{\circ}$ alcohol aint no such thing as a "quaternary alcohol"

Figure 23: Types of Alcohols

Source: Adapted from Images of Alcohols Group

- Ethers are the various petrochemicals, obtained in reactions, when an oxygen atom is attached by single bonds ($\mathrm{O}-$ ) to two carbon groups, either alkyls or aromatic rings (ROR'). The best-known ether is diethyl ether $\left(\mathrm{CH}_{3} \mathrm{CH}_{2} \mathrm{OCH}_{2} \mathrm{CH}_{3}\right)$, used as an anesthetic. Ethers are important solvents in chemistry and medical laboratories. Structurally alcohols and ether can be related to water (Ebbing et al., 1995; Timberlake, 2006). Comparatively, replacing one hydrogen atom in a water model* with either an alkyl or a benzene ring will yield an alcohol or a phenol respectively**. Subsequent replacement of the second hydrogen atom by another alkyl or benzene ring yields an ether*** figure 24 . Ethers are important solvents in chemistry and medical laboratories (Timberlake, 2006).
$(\mathrm{H}-\mathrm{O}-\mathrm{H})^{*}$
$(\mathrm{R}-\mathrm{O}-\mathrm{H}) * *$
Water
An alcohol/ phenol
$\left(\mathrm{R}-\mathrm{O}-\mathrm{R}^{\prime}\right) * * *$
An ether

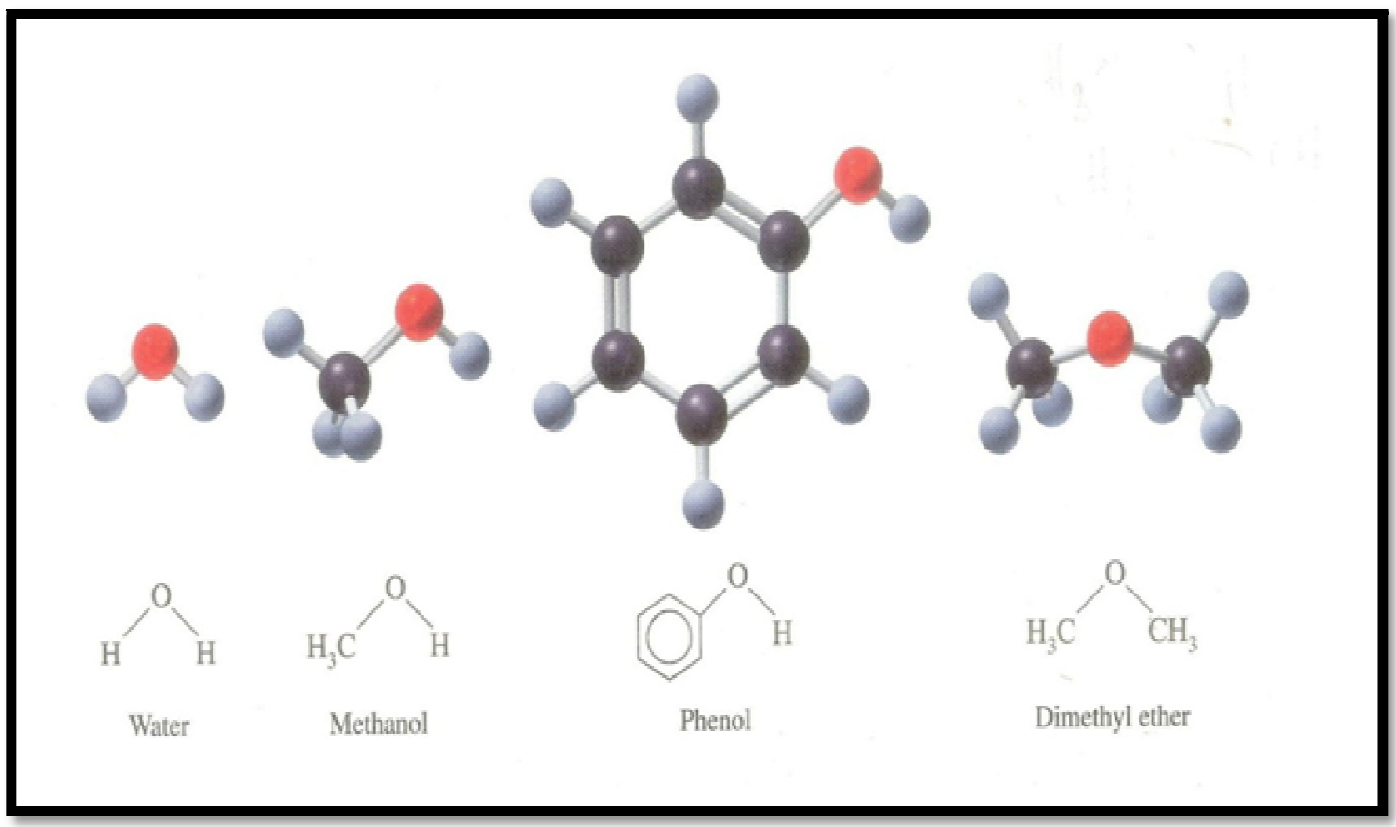

Figure 24: Structural Resemblance of Water, Alcohol and Ether Source: Adapted from Timberlake, 2006

Epoxides is a class of ethers with exceptional chemical reactivity compared with the other ethers. An example is ethylene oxide (also known as Oxirane) which is often synthesized on an industrial scale. Epoxides undergo a variety of ring-opening reactions, to produce different types organic compounds including alcohols, pharmaceutical drugs e.g. anesthetic procaine and novocaine, drugs for treating hypertension (high blood pressure), migrane headaches, glaucoma,

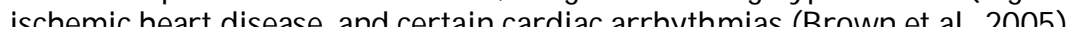


(vi) Aldehydes petrochemicals are obtained from reactions in which the carbonyl functional group $(\mathrm{C}=0)$ is bonded to at least one hydrogen atom and possibly to either another hydrogen or an alkyl group or an aromatic ring (Timberlake, 2006) represented as $\mathrm{R}$ in the condensed formula (RCHO). They are useful starting materials and intermediates in the syntheses of organic compounds. The simplest aldehydes and ketones are liquids at room temperature while many of the higher molecular weight compounds exist as crystalline solids (Bamkole and Ogunkoya,1978).

Methanal (formaldehyde), HCHO, it is used as disinfectant/ antiseptic, a preservative for biological specimens and in the manufacture of polymers for plastics, dyes, explosives etc. Condensation reaction of urea and formaldehyde yields the plastic sheet called formica. The polymerization of methanal yields the product called formalin, which is $37 \%$ aqueous solution of methanal. Evaporating formalin to dryness yields a polymeric white solid compound product called paraformaldehye $\left(\mathrm{CH}_{2} \mathrm{O}\right)_{3}$ or trioxan.

Ethanal(acetaldehyde), $\mathrm{CH}_{3} \mathrm{CHO}$, it is used in the pharmaceutical industry for the manufacture of synthetic drugs and it responsible for the flavor/ scent of alcoholic beverages. Ethanal is polymerized to produce paraldehyde $\left(\mathrm{CH}_{3} \mathrm{CHO}_{3}\right.$ and metaldehyde $\left(\mathrm{CH}_{3} \mathrm{CHO}\right)_{4}$. Paraldehyde is used in medicine as a hypnotic, while metaldehyde is used as a garden bait to attract and poison slug and snails (Bamkole and Ogunkoya, 1978).

(v) Ketones are petrochemical compounds with carbonyl functional group $(\mathrm{C}=0)$ bonded to two alkyl groups or aromatic rings represented as $\mathrm{R}$ and $\mathrm{R}^{\prime}$ in the condensed formula (RCOR'). They are used as the starting materials and intermediates for the syntheses of many organic compounds. The simplest ketone is propanone (acetone), $\mathrm{CH}_{3} \mathrm{COCH}_{3}$, which is a good solvent for the manufacture of explosives, photographic film, artificial fibres like acetate rayon, nail polish/remover and methacrylate used to make polymethacrylate (lucite or plexiglas).

Carbohydrates may be defined as polyhydroxy aldehydes and ketones or as compounds which yield these on hydrolysis (Bamkole and Ogunkoya, 1978). Common examples of carbohydrates (simple sugars) are glucose (also called dextrose), with a polyhydroxy aldehyde structure and fructose (also called laevulose) with a polyhydroxy ketone structure, figure 25. Carbohydrates constitute one of the main classes of foodstuffs. The carbohydrate cellulose is used for the manufacture of paper, certain artificial fibres, plastics and explosives.

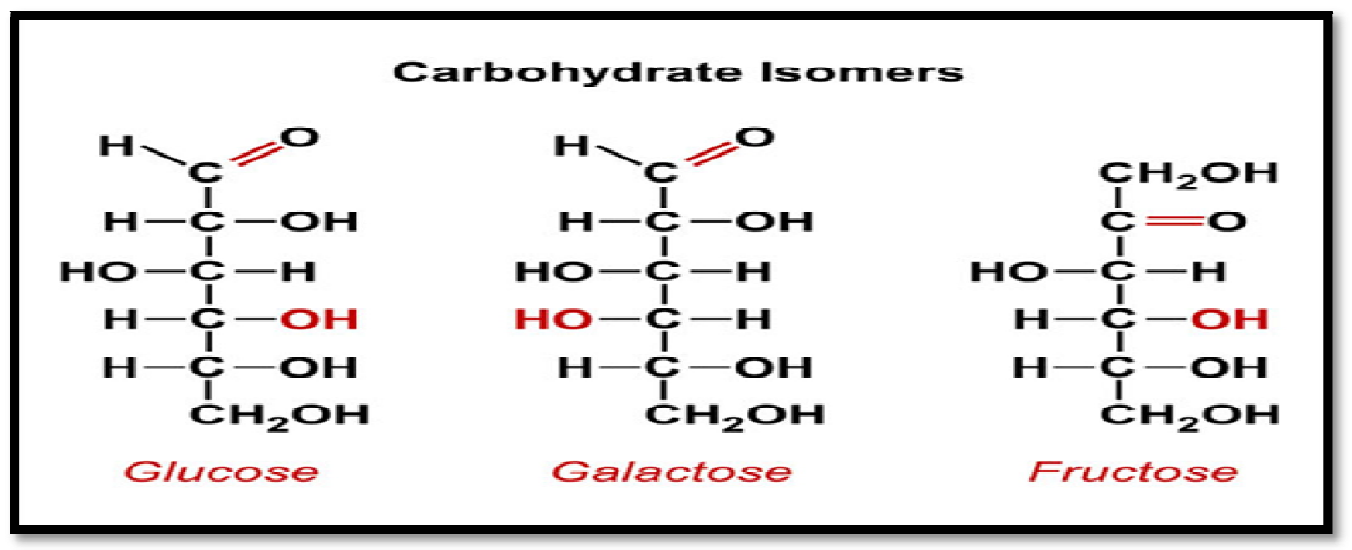

Figure 25: Common Examples of Carbohydrates

Source: Adapted From Images of Carbohydrates

(vi) Carboxylic Acids are petrochemicals obtained when both the hydroxyl $(\mathrm{OH})$ group and the carbonyl $(\mathrm{C}=0)$ group combined as $(\mathrm{COOH})$, is attached to either an alkyl group or an aromatic group(RCOOH), (Bamkole and Ogunkoya,1978) The aromatic carboxylic acid is called benzoic acid (Timberlake, 2006). The simple carboxylic acids are:

(a) Formic acid ( $\mathrm{HCOOH}$ or $\mathrm{CH}_{2} \mathrm{O}_{2}$ ), also known as Methanoic acid. The principal use of formic acid is as a preservative and antibacterial agent in livestock feed. When sprayed on fresh hay or other silage, it arrests certain decay processes and causes the feed to retain its nutritive value longer (formic acid, n.d.).

(b) Acetic acid (ethanoic acid or mono-carboxylic acid), $\mathrm{CH}_{3} \mathrm{COOH}$, are excellent solvent used in the preparation of photographic film and synthetic fibres.

(c) Oxalic acid (di-carboxylic acid), $\mathrm{H}_{2} \mathrm{C}_{2} \mathrm{O}_{4}$, are important reducing agents used to bleach wood and rust stains in clothing (Hess, 1980).

(d) Citric acid (tri-carboxylic acid), $\mathrm{H}_{3} \mathrm{C}_{6} \mathrm{H}_{5} \mathrm{O}_{7}$, are used as ingredient in many drugs and soft drinks.

(e) Food industry uses many organic acids for the production of soft drinks, food products etc. For example, acetic acid is used in making vinegar

Other derivatives from the Carboxylic Acids are (Esters, acyl halides, anhydrides, amides, and the salts of carboxylic acids): Other important classes of petrochemicals are obtained when the hydroxyl group $(\mathrm{OH})$ of a carboxylic acid is replaced by certain other groups:

(vii) Esters are petrochemicals formed when the hydroxyl group of a carboxylic acid is replaced by an alkoxy group (RCOOR'). Esters are used extensively in many industries such as the beverages, confections, medicines, cosmetics, because they have pleasant scents (Bamkole and Ogunkoya, 1978; Hess, 1980). They are used to reproduce the aromas and flavors of natural fruits such as banana, pear, orange, apple, pineapple wintergreen, strawberries in artificial and synthetic products such as perfumes, drugs, fruit drinks, soft drinks, ice creams etc. Fats and oils contain esters of glycerol

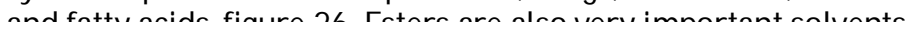


Saponification of fats and oils is used for the manufacture of hard soaps, synthetic detergents, candles, explosives like nitroglycerine, cosmetic and pharmaceutical preparations while hydrogenation of oils is used for making margarine (Bamkole and Ogunkoya, 1978). Also, fats and oils are essential foodstuff.

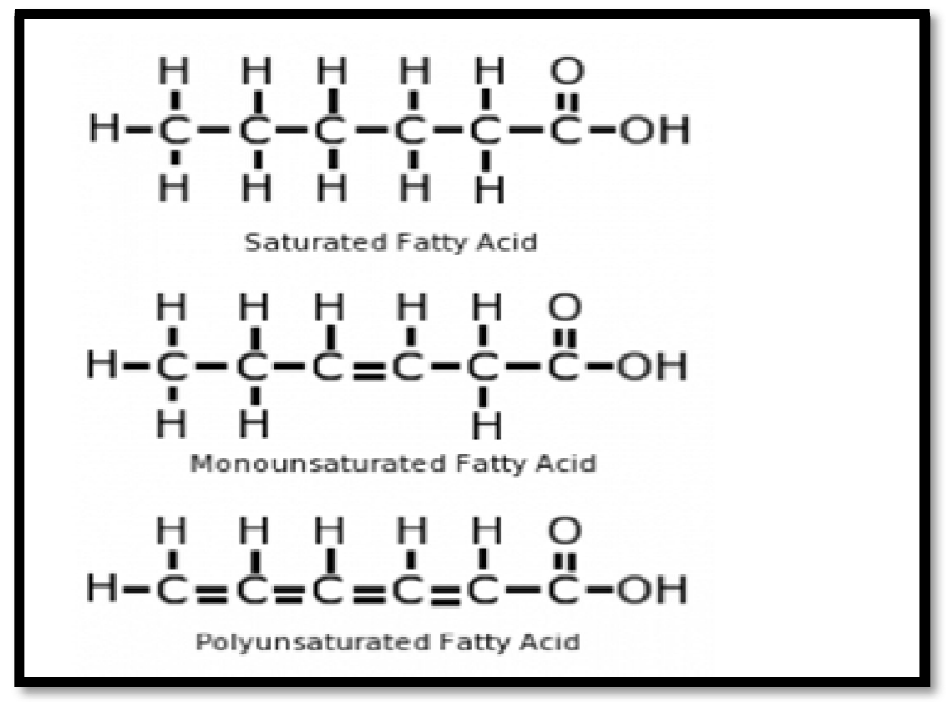

Figure 26: Some Examples of Fatty Acids

Source: Adapted from Images of Fats and Oils

(viii) Acyl Halides are petrochemicals formed when the hydroxyl group of a carboxylic acid is replaced by a halogen atom ( $\mathrm{Cl}, \mathrm{F}, \mathrm{Br}$, I) resulting to the molecular formula (RCOOX). Acyl halides are generally more reactive than alkyl halides. The most useful acyl halide is ethanoyl chloride ( $\mathrm{CH}_{3} \mathrm{COCl}$.), also known as Acetyl chloride, and is used for acetylation reactions, i.e., the introduction of an acetyl group. Two major classes of acetylations include esterification $\left(\mathrm{CH}_{3} \mathrm{COCl}+\mathrm{HO}-\mathrm{CH}_{2}-\mathrm{CH}_{3} \rightarrow \mathrm{CH}_{3}-\mathrm{COO}-\mathrm{CH}_{2}-\mathrm{CH}_{3}+\mathrm{H}-\mathrm{Cl}\right)$ and the Friedel-Crafts reaction.

(ix) Anhydrides are petrochemicals formed when the hydroxyl group of a carboxylic acid is replaced by a carboxylate (RCOORCO). Precisely, two molecules of monocarboxylic acids condensed, and one molecule of water is eliminated. The most commonly used anhydride is ethanonic anhydride or acetic anhydride, is the chemical compound with the formula $\left(\mathrm{CH}_{3} \mathrm{CO}\right)_{2} \mathrm{O}$, is widely used as a reagent in organic synthesis. It is mainly used for preparing heroin.

(x) Salts of Carboxylic Acids are crystalline solids petrochemicals with the characteristic properties of ionic compounds and are readily soluble in water. Soaps are generally sodium or potassium salts of higher fatty acids such as stearic acid. Sodium salts are salts composed of sodium cations and the conjugate base anions of some inorganic or organic acid. They can be formed by the neutralization of the acid with sodium hydroxide. Examples of sodium salts of carboxylic acids are sodium formate(HCOONa), the sodium salt of formic acid or sodium acetate( $\left.\mathrm{CH}_{3} \mathrm{COONa}\right)$. Sodium salts of organic acids find application in preservatives.

\subsubsection{Process Techniques for Making Nitrogen Derivative Petrochemicals: Amines, Amides, Amino Acids and Nitriles}

- Amines: An amine is a petrochemical compound that is structurally derived by replacing one or more hydrogen atoms of ammonia $\left(\mathrm{NH}_{3}\right)$ with hydrocarbons (alkyl or aromatic) groups. Amines are used for the manufacturing of drugs, such as antihistamines (diphenhydamine); norepinephrine, benzedrine and phenylephrine, used in remedies for colds, hayfever, and asthma (Timberlake, 2006). The aromatic amines use the name aniline and they are also used in the manufacture of various polymers, such as polyurethane, and in the preparation of dyes. Other drugs include nicotine, quinine for malaria treatment, atropine used as an anesthetic for eye examination.

- Amides are derived from either ammonia or amines or carboxylic acids.

- An amide of every day significance is urea $\mathrm{CO}\left(\mathrm{NH}_{2}\right)_{2}$ i.e. ammonium cyanate $\left(\mathrm{NH}_{4} \mathrm{CNO}\right)$. It is used to manufacture formaldehyde-urea plastics, barbiturates, fertilizers and hydrazines(Bamkole and Ogunkoya,1978)

- Nylon is a polyamide referred to as nylon 66. It is prepared commercially by heating adipic acid HOOC $\left(\mathrm{CH}_{2}\right)_{4} \mathrm{COOH}$ with hexamethylene diamine, $\mathrm{NH}_{2}\left(\mathrm{CH}_{2}\right)_{6} \mathrm{NH}_{2}$, under pressure to eliminate water.

- Amino Acids are petrochemical compounds that have both the amino $\left(-\mathrm{NH}_{2}\right)$ group and the carboxylic acid ($\mathrm{COOH}$ ) group(Myers et al.,2007). An amino acid may be visualized as a carboxlic acid in which one of the hydrogen atoms of the carbon chain has been replaced by an amino functional group e.g.

- $\mathrm{CH}_{3} \mathrm{CHCOOHNH}_{2}$ (2-aminopropanoic acid) and $\mathrm{NH}_{2} \mathrm{CH}_{3} \mathrm{CH}_{2} \mathrm{COOH}$ (3-aminopropanoic acid), (Bamkole and Ogunkoya,1978)

- Nitriles(alkyl cyanides), are petrochemicals obtained when functional group $(C \equiv N)$ is attached to either a single hydrogen atom ( $\mathrm{HCN}$-hydrogen cyanide) or to an alkyl group $\left(\mathrm{CH}_{3} \mathrm{CN}\right.$-ethanonitrile or acetonitrile or methyl cyanide) or to a benzene ring (Bamkole and Ogunkoya,1978; Brown et al., 2005).

- Nitro are petrochemicals that have the functional group $\left(-\mathrm{NO}_{2}\right)$ attached to either the alkyl group or the benzene ring, singly or in combination with other functional group. 


\subsubsection{Process Techniques for Making Sulfur Derivative Petrochemicals: Thiols, Disulfides}

- Thiols are family of sulfur-containing petrochemicals that have a sulfhydryl (-SH) group. They have structures similar to alcohols except that a (-SH) group takes the place of an (-OH) group (Timberlake, 2006). Thiols have strong disagreeable odors like onions, garlic, oysters, rotten eggs and cheddar cheese, hence they used as dorants. For instance, to help detect natural gas (methane) leaks, a small amount of ethanethiol is added to the gas supply. Some other examples are (a) Methanethiol(oyster and cheese) $\mathrm{CH}_{3}-\mathrm{SH}$, (b) 1-propanethiol(onion) $\mathrm{CH}_{3}-\mathrm{CH}_{2}-\mathrm{CH}_{2}$ $\mathrm{SH}$, (c) 2-propene-1-thiol (garlic) $\mathrm{CH}_{2}=\mathrm{CH}-\mathrm{CH}_{2}-\mathrm{SH}$.

- Thioethers: symmetrical sulfides, RSR (also called symmetrical thioethers) are compounds with the (-S) group attached to two alkyl group forming an alkylsufanyl group (Brown et al.,2005). If it is attached to the phenyl it forms phenyl sulfanyl group. Oxidation of dimethyl sulfide yields dimethyl sulfoxide (DMSO) on industrial scale and further oxidation gives the dimethyl sulfone.

- Disulfides: Thiols undergo oxidation by loss of hydrogen atoms from the (-SH) groups to yield products called disulfides i.e. form alkyldisulfanyl group (Timberlake, 2006). The functional group of disulfide is (-S-S-) group and examples are dimethyl disulfide, diethyl disulfide, and figure 27.
$\mathrm{CH}_{3}-\mathrm{S}-\mathrm{H}+\mathrm{H}-\mathrm{S}-\mathrm{CH}_{3}$
(0)
$\mathrm{CH}_{3}$-S S- $\mathrm{CH}_{3}$
$+\quad \mathrm{H}_{2} \mathrm{O}$
methanethiol
dimethyl disulfide

They are mostly used as reagents (i.e.) reductants to drive a reaction to specific products

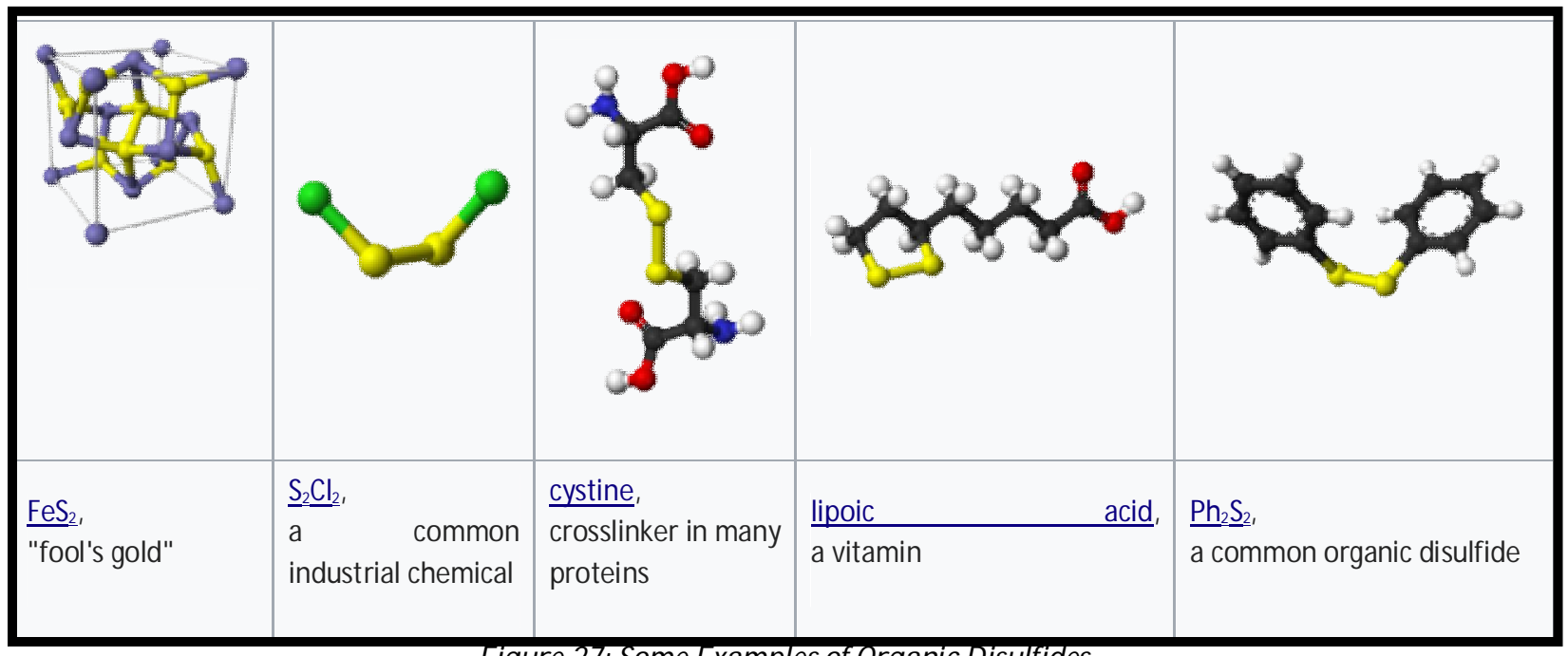

Figure 27: Some Examples of Organic Disulfides

Source: Adapted from Wikipedia-Disulfides

\subsubsection{Process Techniques for Making Organometallic Petrochemical Compounds}

Organomagnesium, Organolithium, Organocopper, Organopalladium, Carbenes and Carbenoids, Alkene Metathesis

(i) Organomagnesium compound ( $\mathrm{RMgX}$ ) reagents (commonly called Grignard reagents) are produced when magnesium metal is mixed with an ether solvent, such as diethyl ether or tetrahydrofuran (THF) and the mixture is slowly added to an alkyl, aryl, or alkenyl (vinylic) halide. The reactions are referred to as "Oxidative Additions" (Brown et al 568)

(ii) Organolithium compound (RLi) reagents are produced when two equivalents of lithium metal are reacted with alkyl, aryl, or alkenyl (vinylic) halide

(iii) Alkene Metathesis using Carbenes $\left(\mathrm{R}_{2} \mathrm{C}\right)$

The simplest carbene is methylene $\left(\mathrm{CH}_{2}\right)$ while one the common carbene is dichlorocarbene $\left(\mathrm{Cl}_{2} \mathrm{C}\right)$. In an alkene metathesis, two alkenes interchange the carbons attached to their double bonds (Brown et al., 2005).

$$
\mathrm{R}_{2} \mathrm{C}=\mathrm{CH}_{2}+\mathrm{CH}_{2}=\mathrm{CCl}_{2} \underset{\text { catalyst }}{\longrightarrow} \mathrm{H}_{2} \mathrm{C}=\mathrm{CH}_{2}+\mathrm{R}_{2} \mathrm{C}=\mathrm{CCl}_{2}
$$

This is the mechanism of the remarkable polymerization reaction called ring-opening alkene metathesis polymerization (ROMP), used to form highly unsaturated polymers or fully conjugated materials (plastics). It is a chain - growth polymerization in which monomers are joined together without loss of atoms e.g., ethylene $\left(\mathrm{CH}_{2}=\mathrm{CH}_{2}\right)$ and substituted ethylene such as propylene $\left(\mathrm{CH}_{2}=\mathrm{CHCH}_{3}\right)$, vinyl chloride $\left(\mathrm{CH}_{2}=\mathrm{CHCl}\right)$, 1,1-dichloroethylene $\left(\mathrm{CH}_{2}=\mathrm{CCl}_{2}\right)$, acrylonitrile $\left(\mathrm{CH}_{2}=\right.$ $\mathrm{CHCN})$, tetrafluoroethylene $\left(\mathrm{CF}_{2}=\mathrm{CF}_{2}\right)$, styrene $\left(\mathrm{CH}_{2}=\mathrm{CHC}_{6} \mathrm{H}_{5}\right)$, ethyl acrylate $\left(\mathrm{CH}_{2}=\mathrm{CHCOOCH} \mathrm{CH}_{3}\right)$, methyl methacrylate" $\mathrm{CH}_{2}=\mathrm{CCOO}\left(\mathrm{CH}_{3}\right)_{2}$ "- (Brown et al., 2005):

$$
\begin{gathered}
\mathrm{n} \mathrm{CH} \mathrm{CH}_{2}=\mathrm{CH}_{2} \\
\text { Ethylene }
\end{gathered} \stackrel{\begin{array}{l}
\left(-\mathrm{CH}_{2}=\mathrm{CH}_{2}-\right)_{\mathrm{n}} \\
\text { Polyethylene }
\end{array}}{\longrightarrow}
$$

Monomers that undergo chain - growth polymerizations include such compounds as alkenes, alkynes, allenes, isocyanates, and cyclic compounds, such as lactones, lactams, ethers, and epoxides. 


\subsubsection{Process Techniques for Making Heterocyclic Petrochemical Compounds}

Heterocyclic petrochemical compounds are cyclic compounds that contain atoms other than carbon in their ring. They react differently from carbon only rings and also differently from each other. Figure 28 show some common heterocyclic compounds in organic chemistry while figure 29 show some derivatives of heterocyclics.

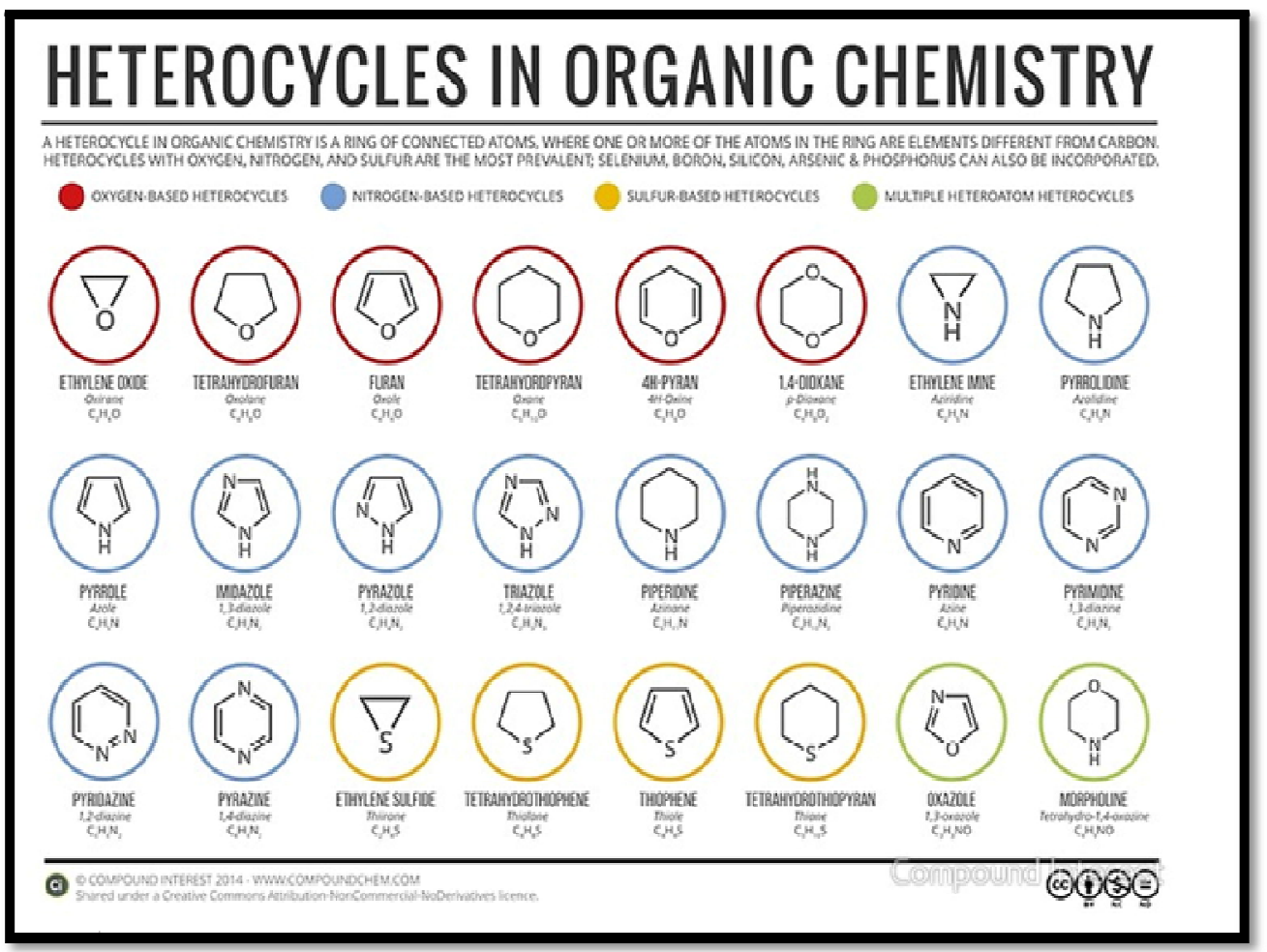

Figure 28: Some Common Heterocyclic Compounds in Organic Chemistry Source: Adapted from Images of Heterocycles

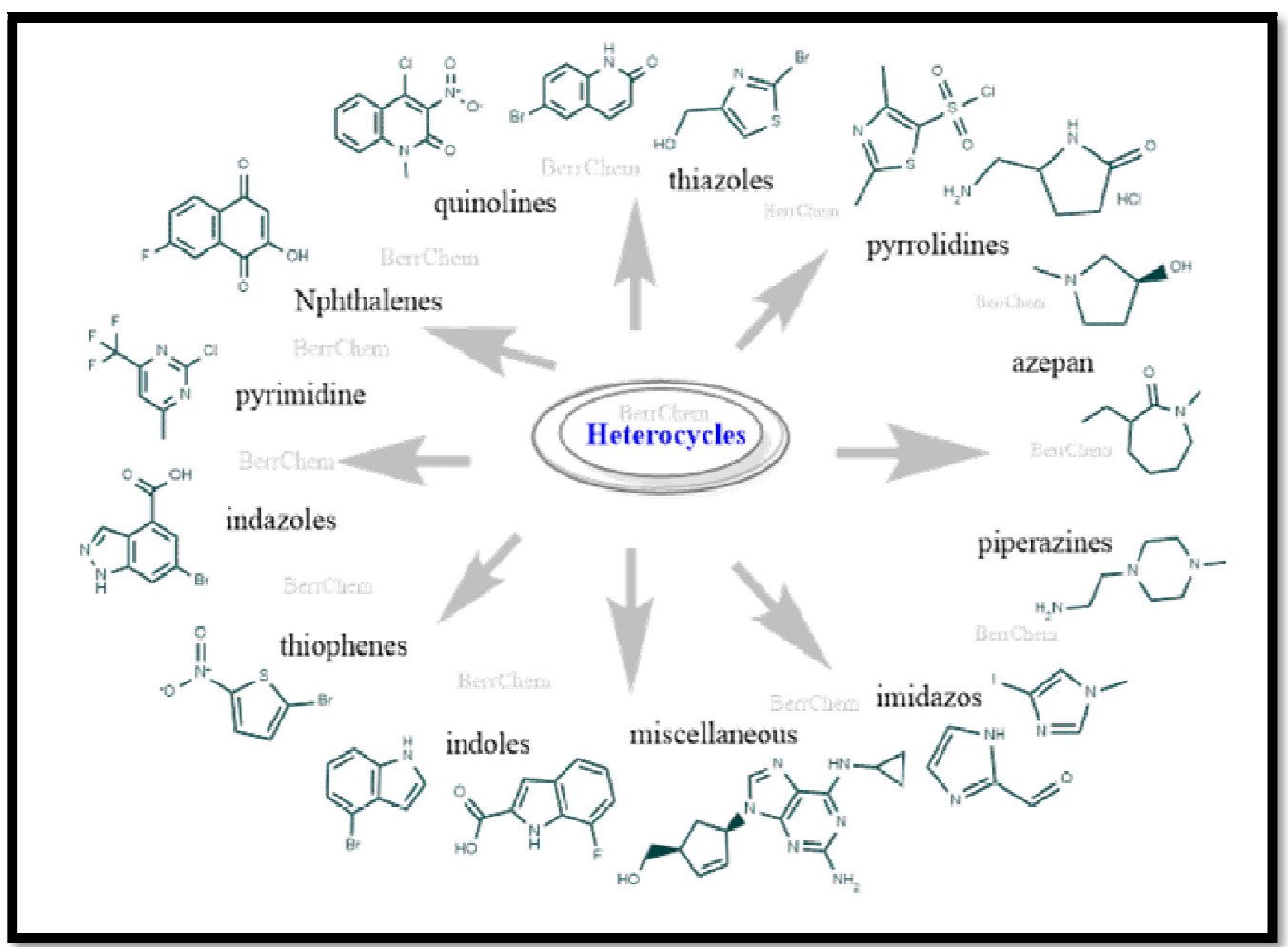

Figure 29: Some Derivatives of Heterocyclic Compounds.

Source: Adapted from Images of Heterocycles 
7.3.8. Process Techniques for Making Petrochemicals from the Interconversion of Functional Groups

Notably, the chemistry of the organic molecule is the chemistry of the functional group or groups. Starting with any compound of a particular functional group, it is possible to synthesize a whole range of new compounds with different functional groups, by using simple reactions i.e. careful choice of reaction conditions, directed at the production of any desired compound with specified functional group, figure 30.

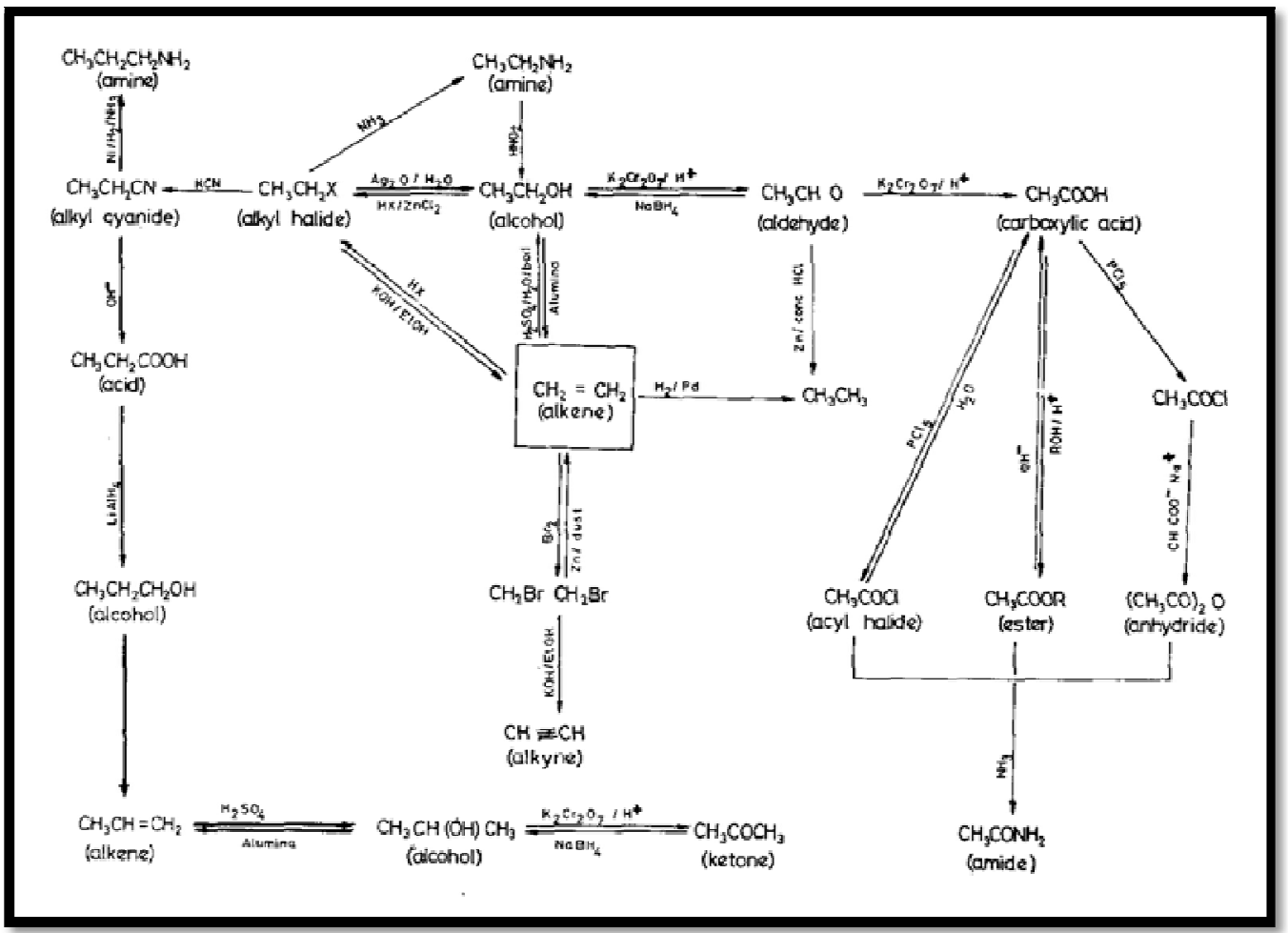

Figure 30: Interconversion of Functional Groups Source: Adapted from Bamkole and Ogunkoya, 1978

7.4. Process Technique for Obtaining Petrochemicals and Other Useful Products from Synthesis Gas (Syngas): Carbon Monoxide/ Hydrogen $\left\{\mathrm{CO} / \mathrm{H}_{2}\right\}$

The syngas is, converted to hydrocarbons building blocks $\left(-\mathrm{CH}_{2}-\right)$ or hydrocarbons chain extension in presence of a catalyst, equation 42 , which can produce different compounds of hydrocarbons (liquids) via polymerization of the hydrocarbon building block, equation 43 and equation 44 .

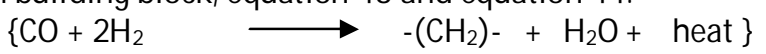

(i) Formation of alkenes (Olefins)

$$
\underset{\text { syngas }}{\mathrm{nCO}+2 \mathrm{nH}_{2}} \underset{\text { Olefins hydrocarbons }}{\longrightarrow} \mathrm{C}_{\mathrm{n}} \mathrm{H}_{2 \mathrm{n}}+\underset{\text { water of synthesis }}{\mathrm{nH}_{2} \mathrm{O}}+\text { heat (electricity) }
$$

(ii) Formation of oxygenates: alcohols or other oxygen containing compounds

$$
\underset{\text { syngas }}{\mathrm{nCO}+2 \mathrm{nH}_{2}} \underset{\text { Oxygenates(alcohol) }}{\longrightarrow} \mathrm{C}_{\mathrm{n}} \mathrm{H}_{2 \mathrm{n}+1} \mathrm{OH}+\underset{\text { water of Synthesis }}{(\mathrm{n}-1)\left(\mathrm{H}_{2} \mathrm{O}\right)}+\text { heat (electricity) }
$$

Figures 31: shows the different Petrochemicals, Chemicals, and useful end products obtainable from various combinations of gaseous hydrogen and carbon monoxide. 


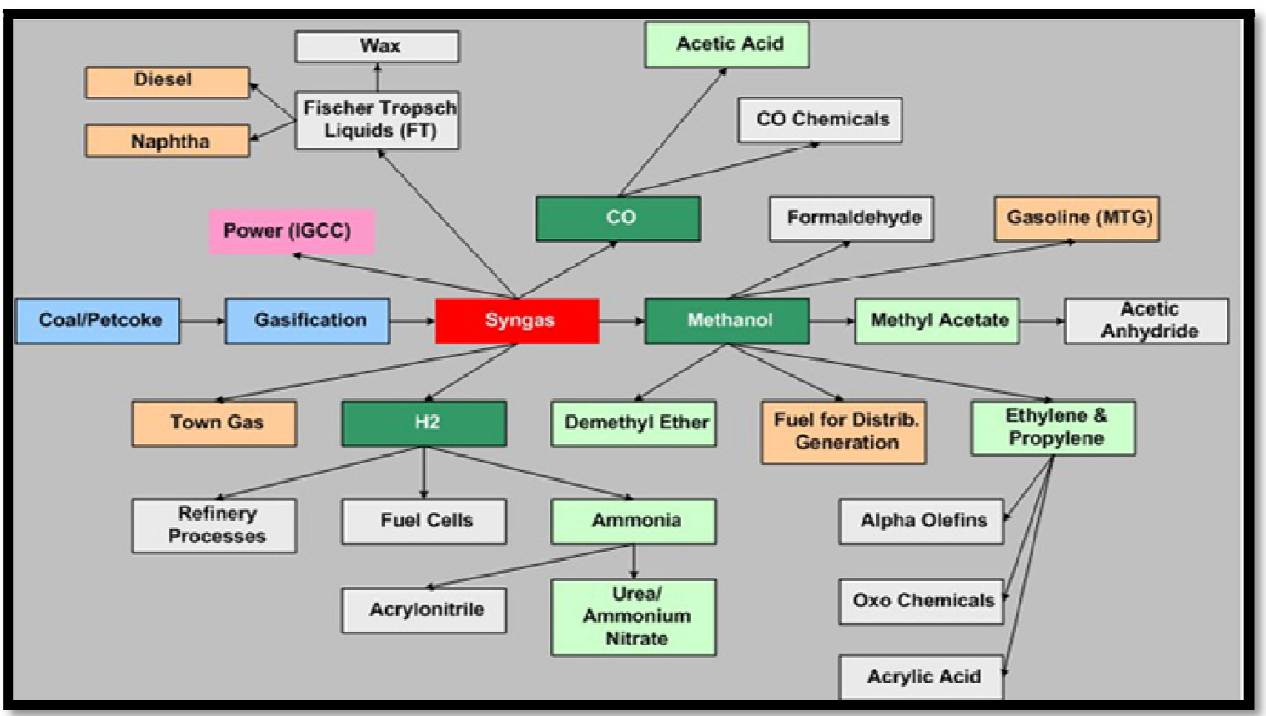

Figure 31: Schematic of Major Products from Syngas

Source: Adapted from Images of Chemical from Methanol

The key oxo alcohols that are usually produced include the following: 2-methyl-2-butanol (2M2B), n-butanol, 2ethylhexanol, isononyl alcohol, and isodecyl alcohol.

OXO alcohols are mainly used for production of plasticisers and acrylates as well as in paints and varnishes, refining and organic industry (Wikipedia-Oxo alcohol n.d.).

\subsection{Process Techniques for the Conversion Natural Gas Stream to Carbon Black and Its Uses}

The flare associated stranded natural gas is used to produce Carbon black (figures 32), through various high temperature processes (Wikipedea Carbon black, n.d.). Carbon black is a form of paracrystalline carbon, also known as acetylene black, channel black, and furnace black, lamp black and thermal black. It is produced by the incomplete combustion of heavy petroleum products such as FCC tar, coal tar, ethylene cracking tar, with natural gas.

- Furnace Black Process: Carbon black is produced by blowing petroleum oil or coal oil into high-temperature gases to combust them partially.

- Channel Process: Carbon black is produced by bringing partially combusted natural gas into contact with channel steel (H-shaped steel).

- Acetylene Black Process: Carbon black is produced by thermally decomposing acetylene gas.

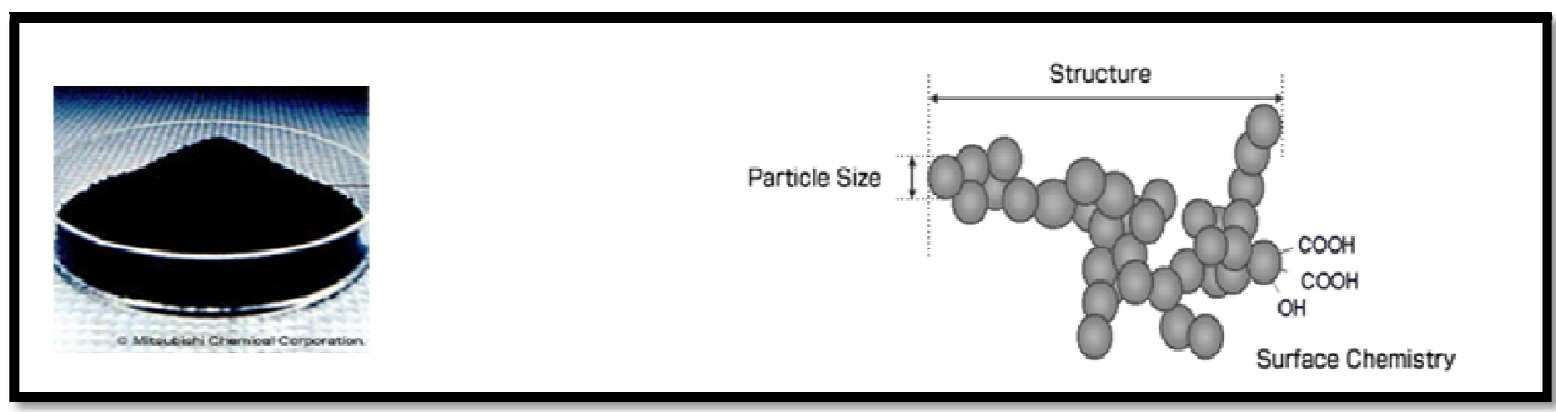

Figure 32: Carbon Black, Surface Chemistry

Source: Adapted from Images of Carbon Black

Carbon black is mainly used as reinforcing filler in tires and other rubber products. In plastics, paints, and inks, it is used as a color such as newspaper inks, printing inks, India inks, as black pigment for inkjet ink or toners, resin coloring. Resins with carbon black are used in automobile bumpers, wire coverings and steel pipe linings which require weather resistance in particular.

Furthermore, carbon black is used in various other applications as an electric conductive agent, including antistatic films (fuel caps and fuel-introducing pipes of automobiles), fibers, and floppy disks. Because it provides stable resistance, it is also used in electronic equipment related material in various display components, magnetic recording materials, and OA rolls. Also, carbon black with various combined functions for special applications can be developed (Mitsubishi Chemical Corporation) under very rigorous laboratory analytical procedures using organic solvents and high temperatures organic contaminants such as polycyclic aromatic hydrocarbons (PAHs). 


\section{Real-Time Valuable Products from the Non-Hydrocarbon Components of the Flare Stream}

\subsection{Real-Time Direct Valuable Chemicals and Products from Pure Nitrogen Produced from Flared Gas Processing}

Nitrogen is used in either liquid or gaseous by various industries, such as the chemical industry, the medical and pharmaceutical industry, the food industry, etc. liquid nitrogen (at temperatures below $-196.5{ }^{\circ} \mathrm{C}$ ) is stored in properly insulated containers figure 33, (Wikipedia-Nitrogen, n.d.; Uses of Nitrogen).

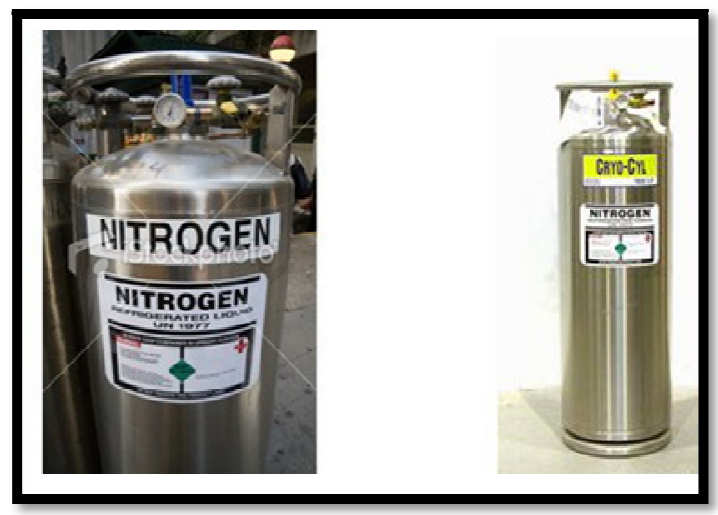

Figure 33: Insulated Liquid Nitrogen Container Source: Adapted From Images of Liquid Nitrogen Cylinders

\subsubsection{Chemical Industry}

It is used for production of ammonia $\left(\mathrm{NH}_{3}\right)$ by the reaction of nitrogen with hydrogen using the Haber process figure 34 .

Ammonia Synthesis

$\mathrm{N}_{2}(\mathrm{~g})+3 \mathrm{H}_{2}(\mathrm{~g})$

$2 \mathrm{NH}_{3}(\mathrm{~g})+$ Heat $(-92 \mathrm{Khmol}-1)$

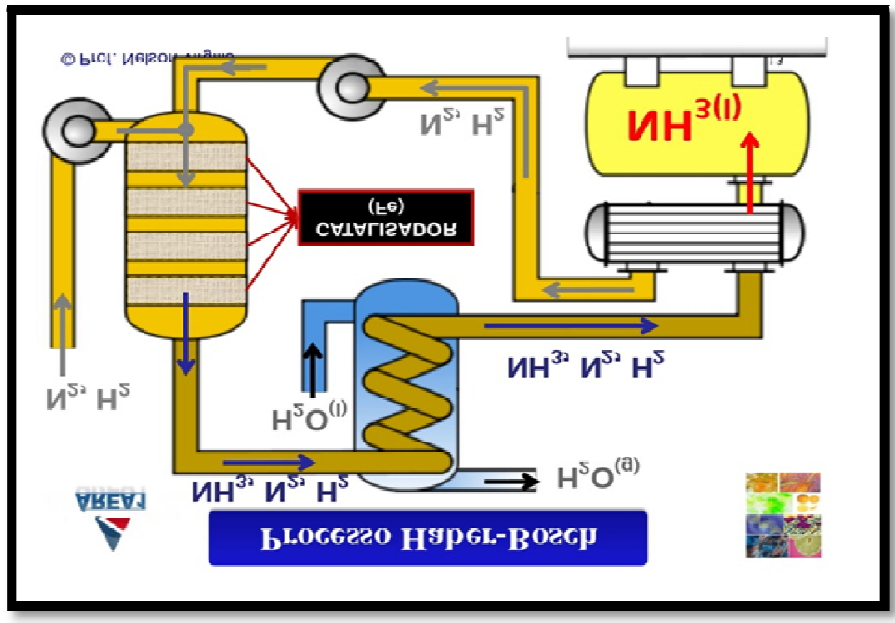

Figure 34: Cyclic Production of Liquid Ammonia.

Source: Adapted From Images of Ammonia Process Units

- The ammonia is used directly as fertilizer by adding it to irrigation water for plants that needing much nitrogen and it is also used to produce either urea $\left(\mathrm{NH}_{2} \mathrm{CONH}_{2}\right)$, which is used as a fertilizer or nitric acid $\left(\mathrm{HNO}_{3}\right)$, which is subsequently used to make fertilizer.

- Ammonia is used as a disinfectant in many households, and as a feed supplement for livestock.

- Ammonia is also used in the plastic industry while the Nitric acid made form ammonia is used in explosives.

$>$ (Ammonia is used for the production of many other industrially important compounds, organic nitratesammonium nitrate (propellants and explosives), trinitrotoluene (TNT)- for the plastic industry, nitrogen dioxide, nitrogen triiodide, nitroglycerin and cyanides.

$>$ It is used an oxidizing agent, as a flour bleaching agent and rocket fuel

\subsubsection{Medical and pharmaceutical}

- Liquid nitrogen is used as a refrigerant, much like solid carbon dioxide (dry ice), for cryopreservation of reproductive cells (sperm and egg), nerves, blood, stem cells, and various other biological specimens. Also it used in cooling various clinical devices that produce heat when they are overclocked such as the cryotherapy setting, infrared detectors or X-rav detectors. and the central processina units in computers. 
- It is used for the production of many pharmacological drugs such as anesthetic agent (a form of nitrous oxide), antibiotics, amphetamines, as well as the organic nitrates (nitroglycerin and nitroprusside) that control blood pressure by metabolizing into nitric oxide.

\subsubsection{Food Industry}

- Pure nitrogen is classified as a food additive by the European Union with the E number of E941

- A combination of nitrogen and carbon dioxide is used for the preservation (such as refrigeration) of packaged or bulk foods. Also nitrogen can be used as a replacement, or in combination with, carbon dioxide to pressurize beers, enabling the nitrogen-charged beers to be packaged in cans and bottles.

- Nitrogen tanks can be used to replace carbon dioxide tanks as the main power source for painball guns.

\subsubsection{Other Industrial Sectors}

- Oil companies use high pressure liquid nitrogen for enhanced oil recovery

- Electrical companies used Nitrogen in incandescent light bulbs to prevent the tungsten filament from burning up and in the production of electronic parts such as transistors, diodes and integrated circuits. Also, dried and pressurized nitrogen gas is used as a dielectric gas for high voltage equipment. For the information technology (IT) equipment it used in the fire suppression systems.

- Used for certain types of welding and soldering operations

- In the steel industry it used in the manufacturing of stainless steel

- It is used for both air and liquid pollution control by its ability to eliminate organic compound content.

- In the manufacturing industry, it is used for shrinking fittings, and in liquid form it is used for tunnel creation and excavation during manufacturing and construction work.

\subsection{Real-Time Direct Valuable Chemicals and Products from the Pure Carbon Dioxide Produced from Flared Gas Processing} Gas processing plants produce Carbon dioxide in mainly two forms - Liquid and Solid.

Liquid Carbon dioxide is used by many industries, such as, the oil industry, the food industry, the agricultural industry, biological industry, the medical industry, the pharmacological industry, and the chemical industry etc. for the production of many consumer and utility products that require pressurized gas.

\subsubsection{Oil Industry}

It is used for enhanced oil recovery and enhanced coal bed methane recovery (i.e. rapid vaporization of liquid carbon dioxide is used for blasting in the coal mines).

\subsubsection{Food Industry}

- (Both the Liquid and solid carbon dioxide are important refrigerants in food industry for storage and shipping of ice cream and other frozen foods. It is used in packaging of foodstuffs, supercritical drying of some food products and technological materials.

- ( It is used as beverage to make carbonated soft drinks and soda water, the mineral water or beer.

\subsubsection{Agricultural and Biological}

- High concentrations of carbon dioxide is used to kill pests such as whiteflies and spider mites in a greenhouse.

It has been proposed that $\mathrm{CO}_{2}$ from power generation be bubbled into ponds to stimulate growth of algae that could then be converted into biodiesel fuel (wikipedia- Carbon dioxide, n.d.). Also using photosynthesis, A strain of the 'cyanobacterium synechococcus elongatus' has been genetically engineered to produce the fuels is obutraldehyde and isobutanol from $\mathrm{CO}_{2}$.

\subsubsection{Medical and Pharmacological}

A $95 \%$ by $5 \%$ ratio of oxygen and carbon dioxide is used to balance blood for breathing while a $50 \%$ by $50 \%$ ratio forms an inhalable gas known as Carbogen, which has variety of medical and research uses.

\subsubsection{Chemical Industry}

- It is used as a raw material for production of urea figure 35 and methanol figure 36 , as well as in the production of, carbonates, bicarbonates, and sodium salicylate, in recycling of waters from Acid Mine Drainage (AMD). 


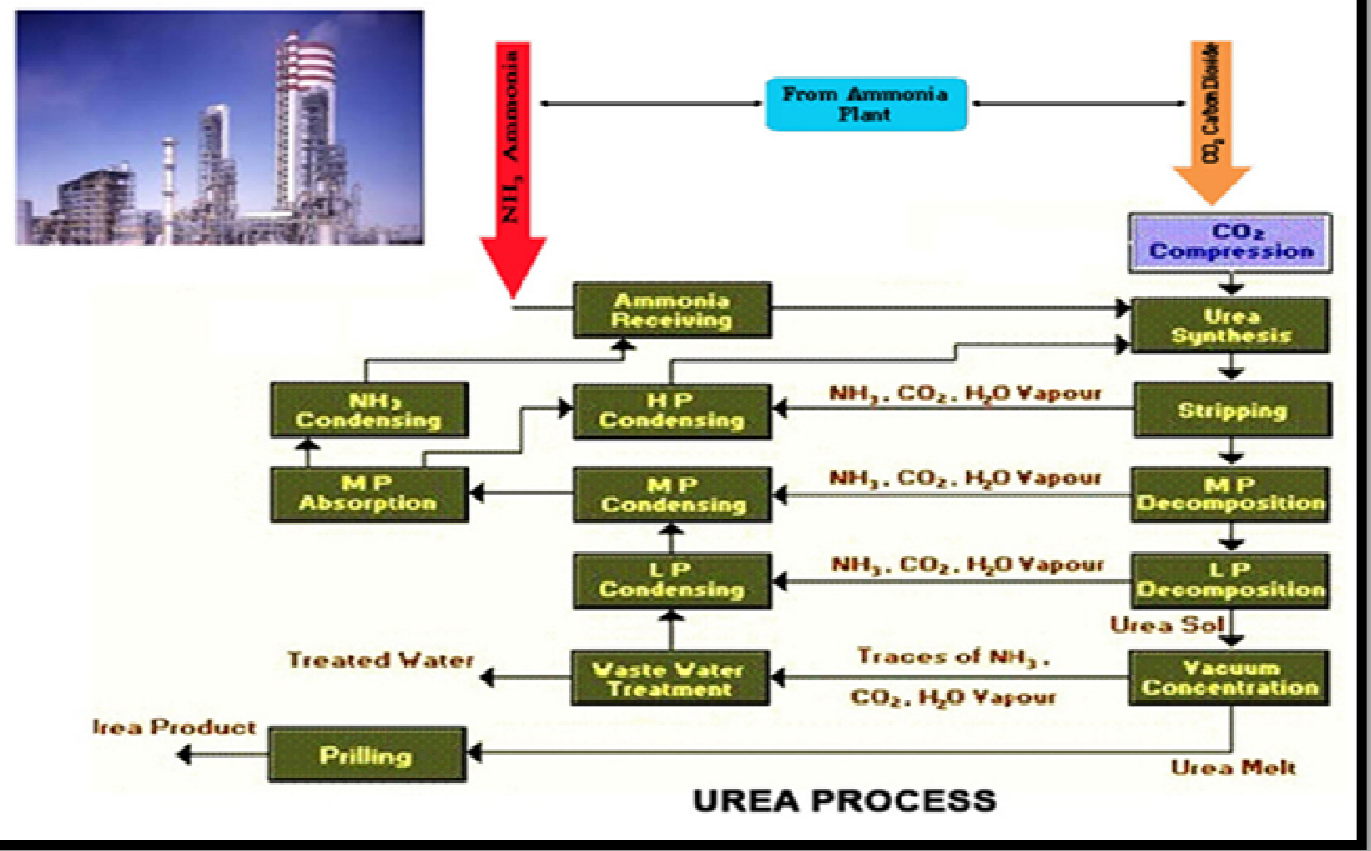

Figure 35: Urea Production from the Synthesis of Ammonia and Carbon Dioxide Source: Adapted from Images of Ammonia Process Units

Urea Synthesis: $2 \mathrm{NH}_{3}(\mathrm{~g})+\mathrm{CO}_{2}(\mathrm{~g}) \longleftrightarrow\left(\mathrm{NH}_{2}\right)_{2} \mathrm{CO}(\mathrm{s})+\mathrm{H}_{2} \mathrm{O}(\mathrm{l})$

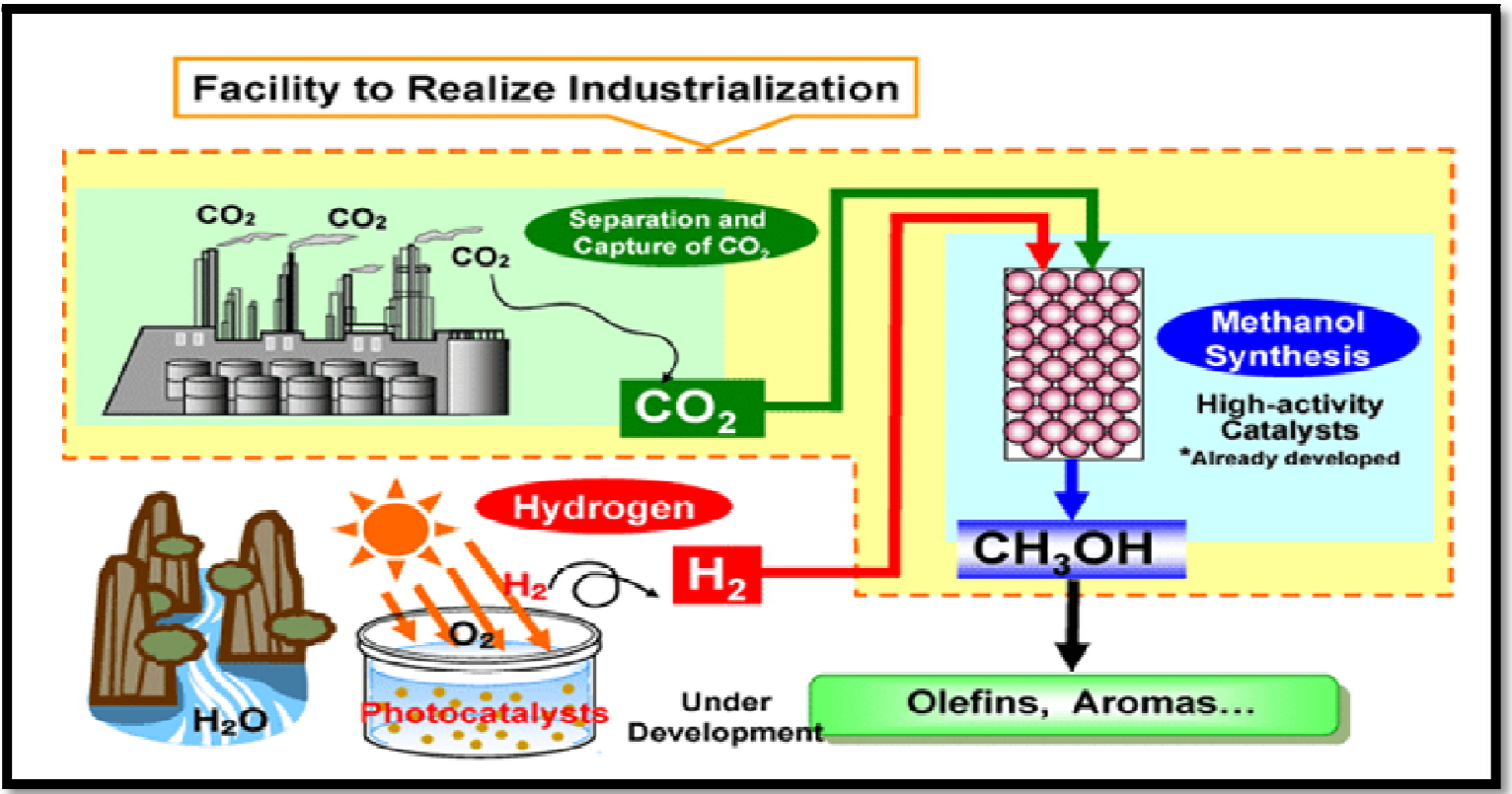

Figure 36: Methanol Production from the Synthesis of Hydrogen and Carbon Dioxide Source: Adapted from Images of Production of Methanol from Carbon Dioxide

\subsubsection{Other Uses Includes}

(i) Liquid Carbon dioxide is used as Solvent for many organic compounds.(ii) The common type of industrial gas laser uses carbon dioxide as a medium.(iii) It is also used as an atmosphere for welding.(iv) It is used to enhance hardness in the manufacture of casting influences in metals industry (v) Carbon dioxide is the cheapest noncombustible pressurized gas and it is inside tins in life jackets while Compressed carbon dioxide gas is used in paintball markers, airguns, for ballooning bicycle tires.(vi) It is used in extinguishing the fires because it does not burn and does not help in burning rather it starves the flame of oxygen when it is flooded around the environment(figure 37). 


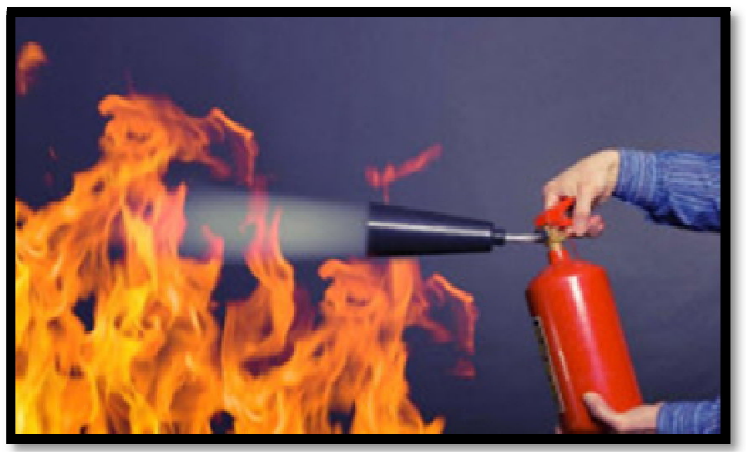

Figure 37: Carbon Dioxide Gas in Extinguishing Fires Source: Adapted From Images of Uses of Carbon Dioxide

\subsection{Real-Time Value of the Pure Water Obtained from Flared Gas Processing}

The water produced from the associated natural gas flare stream processing operation could be used on the Site for cooling plants that needs water to cool their equipment (power steam turbine plants) or for chemical reaction processes, such as steam reformation, and as either a reactant (an important weak electrolyte that reacts with many elements and compounds) or as a medium in which reactions take place. Also, it could be bottled at the site for commercial sales to motels, hotels, restaurants, office buildings, other commercial facilities, and production beverages such as beer, soft drinks and various other goods. Alternatively, it could be channeled to residential homes for drinking, cooking, bathing, washing clothes and dishes, flushing toilets, recreational swimming pools, fish farming, raising algae or aquatic plants.

uses include irrigation, livestock, mining which includes quarrying, milling (such as crushing, screening, washing, and flotation), and other operations as part of mining activity. Major water-using industries include steel, chemical, paper, and petroleum refining. Industries often reuse the same water over and over for more than one purpose. For instance, electricity is generated by turning a turbine using steam power. After the steam is used to turn the turbines, it is condensed back to water by cooling it. The condensed water is then routed back to the boiler, where the cycle begins again.

\section{Overall Process Layout for Petrochemicals Production from Natural Gas}

The process plants for converting the entire flare stream to petrochemicals, chemicals and other useful products are organized into 5 main categories as follows, figure 38:

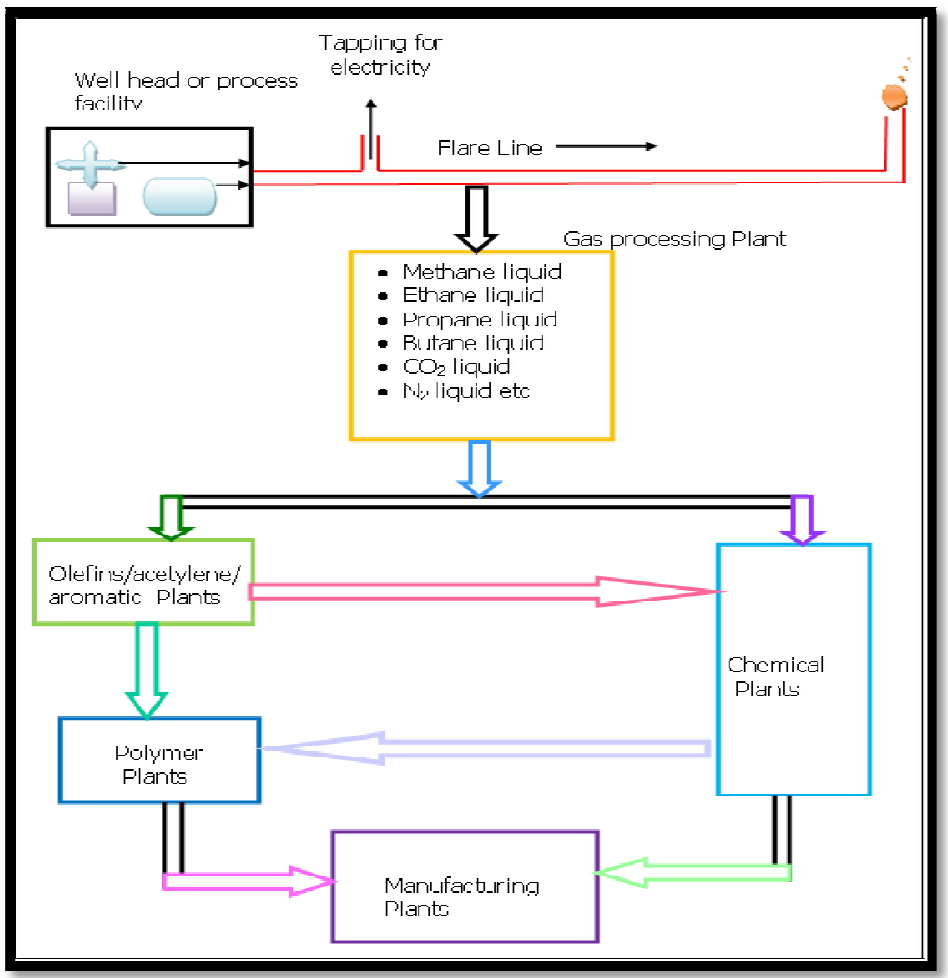

Figure 38: Overall Petrochemicals Production Layout 
- Skid mounted gas processing plant: Extraction and Fractionation of the natural gas liquids (NGLs) and the Liquefaction of methane, carbon dioxide, nitrogen and water vapor. The various products (hydrocarbons and nonhydrocarbons) are used directly as liquid methane, ethane, commercial propane, commercial butane, propanebutane mixture ( $\mathrm{LPG})$, gasoline $\left(\mathrm{C}_{5}+\right)$, liquefied nitrogen, liquefied carbon dioxide and water by various industries.

- Olefins/Acetylenes/aromatics production plants: This includes all the various specification plants that can catalytically crack each of the produced saturated hydrocarbon liquids to any specified unsaturated hydrocarbon form, ethylene, propylene, butylene, butadiene, pentylene plus, ethyne, aromatics and hydrogen, such as, ethylene plant, propylene plant, butene-1 plant, linear alkyl benzene (LAB) plant, benzene plant, toluene plant, xylene plant etc. Each of the products are used by either the polymer industries or the chemical industries as raw material, while the produced hydrogen are used for the production of other organic compounds such as ammonia fertilizer, ammonium nitrate (liquid fertilizer) and nitric acid or in fuel cells for electricity generation.

- Polymer plants: The Olefins/Acetylenes/aromatics are polymerized into larger molecules in any of the following plants, low density polyethylene (LDPE) plant, linear low density polyethylene (LLDPE) plant, high density polyethylene (HDPE) plant, polypropylene (PP-resin) plant, polyethylene terephthalate (fibre) plant, polystyrene/ ethylbenzene plant, polyurethane plant, polyisoprene plant, polyacrylic plant, polyester plant, coking (carbon black) Plant, substituted butadienes (i.e. Polymers of dienes) such as chlorobutadiene, methylbutadiene, which still contain double bonds(called elastomers), polyvinyl chloride (PVC), polyvinyl acetate, polychloroprene and polyacrylonitrile etc. Each of the products are used by many manufacturing industries, such as, plastics (pail, bowls, soap cases, food packaging, toys, bottles etc.); poly vinyl chloride (electrical insulator cables, pipes, flexes, sheeting and flooring materials); textiles (nylon terylene, suit cases, kit wear etc.); synthetic rubber (crepe soles of shoes, car tires, hoses at petrol service stations, rubber-based paints, gaskets etc.).

- Chemicals plants: Each of the various components of the produced saturated hydrocarbons or the unsaturated olefins/ acetylenes products can react with either oxygen, water, nitrogen, sulfur or any of the different functional groups in organic chemistry, in various plants, named after their products, such as, methanol (methanol/ MTBE) plant, ethylene oxide plant, ethylene glycol plant, propylene oxide plant, ethanol amines (Mono, Di, and Tri) plants, halogenations (chlorination e.g. methyl chlorides) plant, sulphonation (carbon disulphides) plant, propan-2-ol plant, ethyl and butyl ethanoates plants, isopropanol plant, methyl tetra butyl ether (MTBE). Also, some of the chemicals are subsequently used for the production of other chemical e.g. methanol and ammonia, Figure 39.

- Manufacturing industries/ plants : This includes all the plants that uses the products from both the polymer plants and the chemical plants for manufacturing various end use products for household (detergents, food and drink flavors, cosmetics, styrofoam, furniture, etc.), agricultural chemicals (composed of both pesticides/insecticidesorganochlorine/ weed killer and fertilizer); medical, pharmaceutical (synthetic drugs); anti-oxidants, surfactants, solvents(for industrial and laboratory uses), refrigerant/coolants, carpeting aerosols, antifreeze, adhesives, thinner mixes, lubricants, gels, elastomers, industrial greases/ wax, dynes, alcohols, bullet proof vests explosives, parts (consumer electronics, automobile, solar panels, wind turbines).

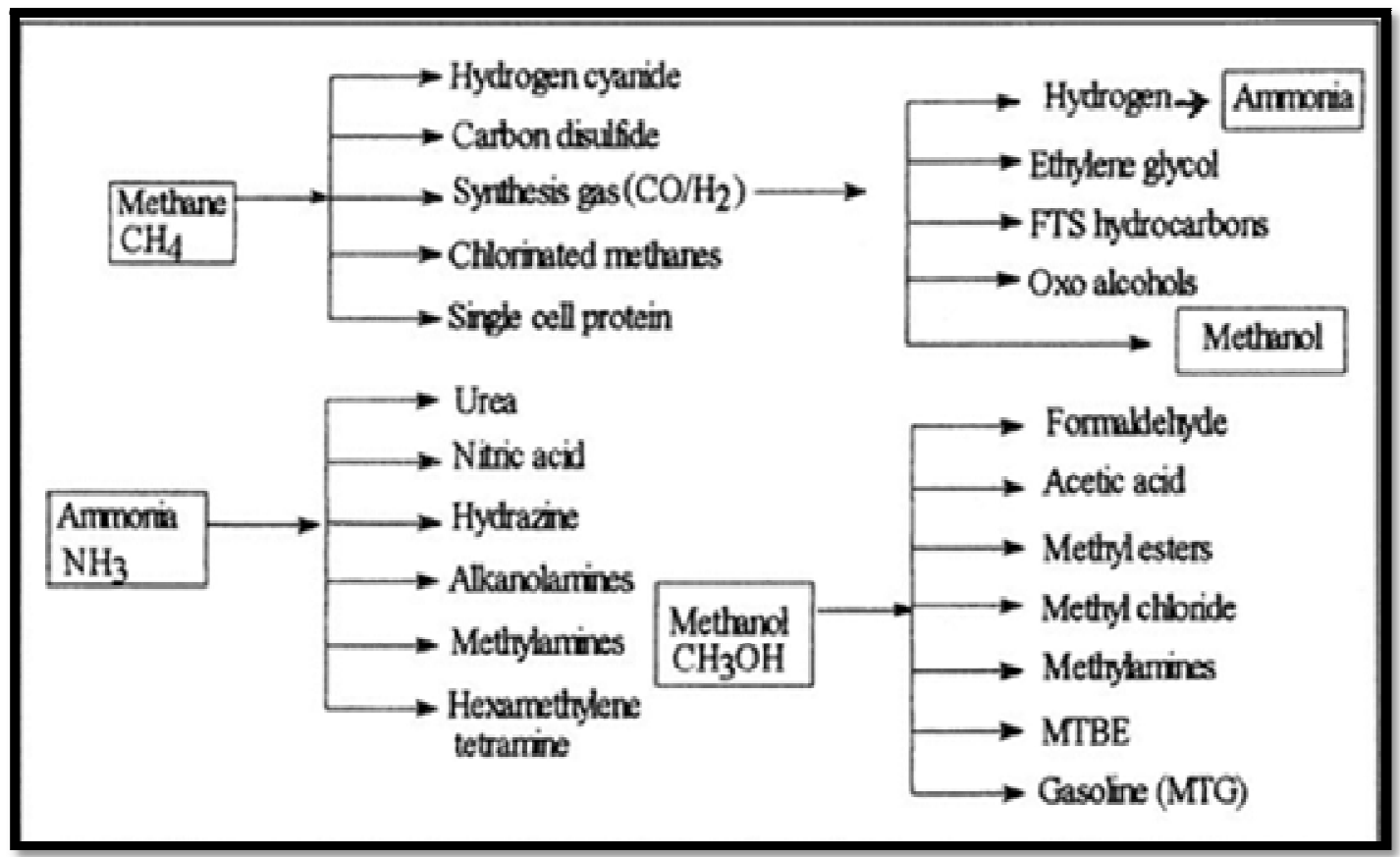

Figure 39: The Basic Chemicals Obtained from Ammonia and Methanol Source: Adapted Images of Chemical from Methanol 


\section{Conclusions}

The history of the chemicals industry can be traced back to ancient times (as early as 7,000 BC), when alkali and limestone were combined to make glass. During the industrial revolution (1736-1918) the chemical industry relied on coal, molasses, fats, oils, salts, ores, water and the atmosphere as sources of raw materials for its manufacturing processes. The petroleum chemicals industry started in the United States in 1918 with the manufacture of alcohol (isopropyl alcohol) from surplus refinery gas. Presently, about $95 \%$ of the total world production of organic chemicals (endless variety) comes from petroleum. The $40 \%$ to $50 \%$, associated natural gas flared in Nigeria, if converted, could satisfy all the domestic requirement for petrochemicals and chemicals at reduced retail prices, as well as create numerous jobs, earn foreign revenue, stimulate infrastructural development, and bring gas flaring to extinction in Nigeria. For the Nigerian typical representative flare stream composition (table 3 ) and conditions (table 4 ), at 20MM scfd rate, the daily liquid production is 503.726 tons of hydrocarbons, 21.196 tons of carbon dioxide, 1.141 tons of nitrogen and 0.906 tons of water.

This study identified 5 stages/categories of chemical products/utilization, each having different varieties of specialty plants in operation, to yield specific desired products. From this study, it is possible, using different customized skid mounted mini gas processing units in real-time to convert the entire components (hydrocarbons and non-hydrocarbons such as nitrogen, carbon dioxide and water) of the flared associated stranded natural gas stream, to the various petrochemicals required by different industries, such as food, toiletries, soaps and detergents, cosmetic(shampoos, perfumes), luggage, fertilizer (ammonia), films, recording discs and tapes, synthetic (artificial) fibers and rubbers, polyester clothes, agriculture, pesticides, explosives, resins,, epoxy resins, solvents, flooring and insulating materials, varnishes, glues, adhesives, lubricants, paints, printing, plastics of all descriptions, medical, pharmaceutical drugs (aspirin), agricultural, chemical, manufacturing diverse parts for boats, automobiles, aircraft, etc. Presently Chemists have discovered or made well over ten million compounds composed of carbon with hydrogen, oxygen and nitrogen (Brown et $\mathrm{al}$, 2005). Most of the reactions, utilize the abundant free nitrogen (78\%) and oxygen (21\%) in the air; hydrogen and steam from water. For example, for the production of synthetic fibers like nylon by co-polymerization, hydrogen from water and nitrogen from air are united to form ammonia, which is converted to hexamethylenediamine in a series of steps. Next, phenol is extracted from petroleum (natural gas, crude oil or coal tar) and converted to adipic acid in a separate series of steps. The two synthetic compounds are condensed to form giant fibrous nylon molecules after eliminating water. Thus, air and water are the source of raw material for most organic compounds production from hydrocarbons.

Despite the fact that these petrochemical products have already penetrated virtually all the material markets such as the agricultural, pharmaceutical, chemical, medical, building, automotive, electrical, synthetic fibers, synthetic rubber, cleaning agents, the food markets, plastics and resins, etc. The limit in the number of producible petrochemicals from petroleum and natural gas, the diversity of products and the extension of their application has by no means been reached. Through advanced technology and practical research, new products (constantly growing number of commercially manufactured products from petrochemical/ chemical plants) will continue to be added to the long list of those recovered or made from natural gas. Generally, the traditional materials produced from metal, glass, leather etc. used in the home and in the building, engineering, automobile, aviation, electric and electronic industries etc. are increasingly replaced by molded, extruded, machined and reticulated articles and materials from petrochemicals.

Nigerian investors can embark on the production of the following highly and locally demanded end products:

- Plastics and resins (from Polypropylene, polyethylene etc.) e.g. house wares, pails/buckets, cups, saucers and plates, television cabinets, chairs, clothes pegs, parts of refrigerators and washing machines, basins, container lids, toys, caps and closures; crates, hypodermic syringes; bottles for detergents and cosmetics; oil drums, jerry cans, plates, chair back covers, chemical tanks, agricultural tanks, septic shipping tanks, pipes, wire insulations and cable jacketing, shipping sacks, woven sacks far packages (e.g. sacks for packaging grains etc.), food and drug packaging containers, carpet underlay and floor carpets (tufts and backing), prayer mats, ropes, yarns, textiles and fishing nets, geotextiles (used for road stabilization and erosion control; films and packaging materials e.g. luggage/ carrier bags, liner bags, produce bags, deep freezer films, film wrappers, stretch wrap, mulch film (cropping), lamination film, display packaging, cloth/garment wraps, recording discs and tapes planting bags, netting and heavy-duty film for fertilizer sacks manufacture, paints and surface coatings generally; automobile components(motorcar, boats, aircraft, train and ship industry) :battery casing, fascia panel/ dashboards, steering wheels, car seats and interior fittings, hoses and some engine parts; building industry :wall and floor coverings electricity cables and light fittings, pipes, plumbing, and insulation against the cold.

- Synthetic fibers (Polyethylene, Terephthalats etc.) - clothing, floor coverings (carpets), decorative textiles, tire cords, ropes, thread, drapery, per press fabric, reel tape, film, netting, pillow stuffing, file jackets, beer and soft drink crates etc.

- Synthetic rubber (from carbon black and polymers of substituted butadienes)) - e.g. manufacture of tires, rubber products (e.g. tubes), pigments printing, printers' ink, polish (e.g. shoe polish); special purpose types of synthetic rubber such as oil-resistant synthetic rubber used for hoses, hoses fan belts and conveyor belts, caskets, foot wear and PVC tiles, engine mountings, etc.

- Manufacturing chemicals (from organic solvents and industrial chemicals): Such as alcohols, ketones, esters chlorinated hydrocarbons and glycerin.

- They are mainly used as chemical intermediates for the manufacture more complex organic chemicals- alcohols are used in paints, extracting oil from seeds or perfumes from flowers; ketones and esters are the solvent base of many paints and lacquers; chlorinated hydrocarbons are used for dry cleaning, glycerin used in the manufacture of resins, pharmaceuticals(drugs), foodstuffs, cosmetics explosives and in carbon black to reinforce rubber for motor tires, making sulphuric acid, vulcanizing rubber( Shell International Petroleum Company Limited, 1975). 
- Materials for agriculture (from linear alkyl benzene, Solvent etc.) fertilizer, cattle feed improvers, LAB is an active material for bio-degradable Synthetic detergents (i.e. powdered and liquid detergents) and shampoos, keroSolvent used for insecticides, paints and varnishes, degreasers, polishes for shoes, floors and furniture, and metal cleaners*

- Cleaning agents (from linear alkyl benzene, sulphuric acid, ethanolamines, lsopropanol etc.)

$>$ Detergents, Chlorinated hydrocarbons are used for dry cleaning and degreasing, mainly in the engineering industry*

$>$ Isopropanol is widely used in Perfumery and cosmetics, Paints, textiles (dyes and pigments), detergents and toiletries, brewing, printing, pharmaceuticals, and for synthesizing acetone, diacetone alcohol, methyl oxide and methyl isobutyl ketone

$>$ Ethanolamine is used as solvent to absorb and regenerate $\mathrm{H}_{2} \mathrm{~S}$ and $\mathrm{CO}_{2}$ from gas stream, as surface active agents in laundry detergents, dishwashing detergents and soluble oils, and for floor and furniture's polishes.

$>$ Ethylene oxide and Ethylene glycol is used for non-comic detergents, household detergents, and cleaners, anti-freeze, fumigation and coolants, preservatives e.t. c.

And a host of others in the foam industries, Pharmaceuticals and some initiative products that can be designed and mass produced specifically for Nigerian's household everyday needs.

\section{References}

i. About IEPL - Indorama Eleme Petrochemicals Limited https://www.indoramaeleme.com/about-iepl.php (accessed 17:07:18)

ii. Bamkole, T.O., Ogunkoya, L., 1978. Introductory Organic Chemistry. Second Edition. Daystar Press, Ibadan. pp. 46, 61- 63, 125-126,139, 151-153, 168-169, 180, 190, 204.

iii. Brown, W.H, Foote, C. S., Iverson, B.L., 2005. Organic Chemistry, Fourth Edition, Thomson Books/ Coll Belmont, United State. pp. 1, 236, 293, 457-459, 567-569, 689, 963, 1143.

iv. Ebbing, D.D., Wentworth, R.A.D, Birk, J. P., 1995. Introductory Chemistry. Houghton Mifflin Company. p. 4, 611, 627,630-631.

v. Ekejiuba, A. I. B., 2017. Real-Time Monetization of the Flare Associated Stranded Natural Gas in Nigeria: Quantitative Analysis and Qualitative Values. The International Journal of Science \& Technology, Vol. 5 Issue 8, p. 96.

vi. Formic acid https:/ / pubchem.ncbi.nlm.nih.gov/ compound/ formic acid (accessed 23/ 06/ 2018)

vii. Hess, F.C., 1980. Chemistry Made Simple. W.H. Allen and Company Ltd London. pp. 160, 239, 241, 243, 246, 249.

viii. Ikoku, C. U., 1980. Natural Gas Engineering: A Systems Approach. Pennwell Books Tulsa, Oklahoma USA. pp. 103104.

ix. International Energy Agency, 2010. Natural Gas Liquids: Supply Outlook 2008-2015, Oil Industry and Markets Division https:/ / www.iea.org>NGL2010-free (accessed 19: 05: 17).

x. Katz, D.L. et al., 1959. Handbook of Natural Gas Engineering McGraw-Hill Book Company, New York. p. 25.

xi. Levorsen, A. I., 1967. Geology of Petroleum, W.H. Freeman and Company San Francisco. pp. 190, 177, 218.

xii. Myers, R.T., Oldham, K.B., Tocci, S., 2007. Chemistry. Harcourt Education Company, Austin. pp. 683, 699-700, 718.

xiii. Natgas, 2013. Processing Natural Gas natural gas, org.>naturalgas>processing-ng (accessed 19: 5:17)

xiv. Nigerian plastics, printing and packaging sector enjoys staggering...

xv. https:// www.ppp-nigeria.com/ nigeria-plastic-print-package.html (accessed 17:07:18)

xvi. Ogunade Kunle, 2016. Manufacturers import $80 \%$ of raw materials due to lack of... energymixreport.com >il\&Gas〉DownstreamTheGuardian reports (accessed 18: 07:18)

xvii. Timberlake, K.C., 2006. An Introduction to General, Organic and Biological Chemistry. Ninth Edition Person Benjamin Cummings, San Francisco USA.pp. 337, 340, 344, 347, 350, 376, 385, 388-389, 397, 400, 428, 444.

xviii. OilGasNg.Com. Dangote Refinery and Petrochemical Plant - www.oilgasng.com/dangote-refinery-andpetrochemical-plant-update/ (accessed 18:07:18)

xix. S \& P Global Platt Petrochemical Index (PGPI)-March 2018, https:// www.platts.ru/new-features/2014/ petrochemical/pgpi/ldpe(accessed 6:07:18).

xx. S \& P Global Platt Petrochemical Index (PGPI)-March 2018, https://www.platts.ru/new-features/2014/ petrochemical/pgpi/ldpe(accessed 6:07:18).

xxi. Shell International Petroleum Company Limited, 1975. Chemicals From Petroleum. The Oil Venture, Brian Denyer, England, p.42-49.

xxii. TechnoFunc. 2012- History of Chemicals Industry. www.technofunc.com/index.php/.../chemicalsindustry/ .../ history-of-chemicals-industry (accessed 05:07:18).

xxiii. Wikipedia-Chemical Industry (accessed 05:07:18).

xxiv. Wikipedia-Chemical substances (accessed 22:06:18).

xxv. Wikipedia-Disulfides (accessed 4:07:18)

xxvi. Wikipedia, n.d. Steam Reforming https:// en.wikipedia.org>wiki>steam.reforming (accessed 22:05:17).

xxvii. Images of alcohols group (accessed 15:07:18)

xxviii. Images of ammonia process units(accessed 16:05:17)

xxix. Images of butene chain (accessed 19:07:18)

xxx. Images of carbohydrates (accessed 26:06:18) 
xxxi. Images of Carbon black accessed (accessed 15:07:18)

xxxii. Images of chemical from methanol (accessed 11:7:18)

xxxiii. Images of cycloalkanes (accessed 23:06:18)

xxxiv. Images of cycloalkenes (accessed (23:06:18)

xxxv. Images of cycloalkynes (accessed 23:06:18)

xxxvi. Images of ethylene accessed (18:07:18)

xxxvii. Images of fats and oils (accessed 26:06:18)

xxxviii. Images of heterocycles (accessed 24:06:18)

xxxix. Images of Linear alkylbenzene sulfonic acid (accessed 15:07:18)

xl. Images of liquid nitrogen cylinders (accessed 15:06:18)

xli. Images of Olefin flow diagram for the production of petrochemicals (accessed 7:09:17)

xlii. Images of phenyl group (accessed 23:06:18)

xliii. Images of products from aromatic hydrocarbon (accessed 19:07:18)

xliv. Images of Production of methanol from carbon dioxide(accessed 15:07:18)

xlv. Images of propylene accessed (18:07:18)

xlvi. Images of types of hydrocarbons (accessed 15:07:18)

xlvii. Images of the complete flare line from the wellhead to the flare stack (accessed 7:09:17)

xlviii. Images of the list of all the functional groups in organic chemistry (accessed 22:06:18).

xlix. Images of uses of carbon dioxide (accessed 30:11:17) 